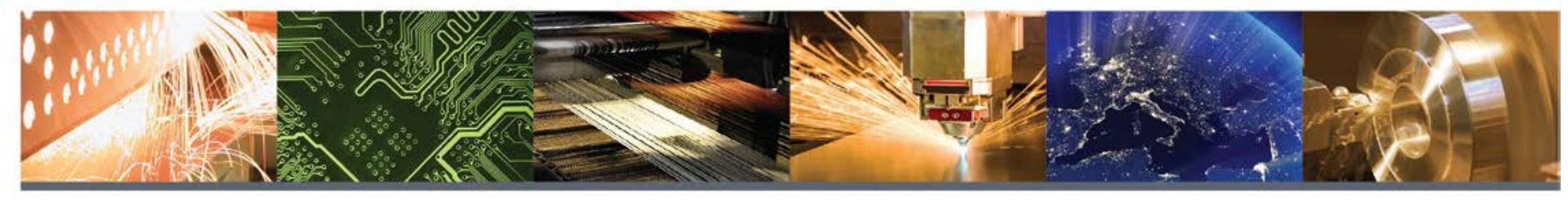

\title{
Evaluation of Agricultural Equipment Manufacturing for a Bio-Based Economy
}

Margaret Mann, Mary Biddy, and Chad Augustine

National Renewable Energy Laboratory

Quang Nguyen and Hong $\mathrm{Hu}$

Idaho National Laboratory

Mahmood Ebadian and Erin Webb

Oak Ridge National Laboratory

CEMAC is operated by the Joint Institute for Strategic Energy Analysis for the U.S. Department of Energy's Office of Energy Efficiency and Renewable Energy.

Technical Report

NREL/TP-6A20-71570

June 2019

Contract No. DE-AC36-08GO28308 


\section{Evaluation of Agricultural Equipment Manufacturing for a Bio-Based Economy}

Margaret Mann, Mary Biddy, and Chad Augustine

National Renewable Energy Laboratory

Quang Nguyen and Hong $\mathrm{Hu}$

Idaho National Laboratory

Mahmood Ebadian and Erin Webb

Oak Ridge National Laboratory

Clean Energy Manufacturing Analysis Center

15013 Denver West Parkway

Golden, CO 80401

303-275-3000
CEMAC is operated by the Joint Institute for Strategic Energy Analysis for the U.S. Department of Energy's Office of Energy Efficiency and Renewable Energy.

\section{Technical Report}

NREL/TP-6A20-71570

June 2019

Contract No. DE-AC36-08GO28308 


\section{NOTICE}

This work was authored in part by the National Renewable Energy Laboratory, operated by Alliance for Sustainable Energy, LLC, for the U.S. Department of Energy (DOE) under Contract No. DE-AC36-08G028308. Funding provided by the U.S. Department of Energy Office of Energy Efficiency and Renewable Energy Advanced Manufacturing Office. The views expressed herein do not necessarily represent the views of the DOE or the U.S. Government.

This report is available at no cost from the National Renewable Energy Laboratory (NREL) at www.nrel.gov/publications.

U.S. Department of Energy (DOE) reports produced after 1991 and a growing number of pre-1991 documents are available free via www.OSTI.gov.

Cover Photos: (left to right) iStock 2225189; iStock 16687273; Oak Ridge National Laboratory; iStock 24304597; iStock 26005993; iStock 2069560

NREL prints on paper that contains recycled content. 


\section{Acknowledgments}

The authors thank the U.S. Department of Energy's Bioenergy Technologies Office (BTO) for primary funding support of this analysis. In particular, we thank Jay Fitzgerald (BTO), Steve Thomas (BTO) and Mark Elless for their guidance and overall management of this analysis. We also thank Ashwin Ramdas (NREL) for his contributions to the analysis, and Debra Sandor (NREL) and Jill Engel-Cox (NREL) for their help in reviewing this report. 


\section{Nomenclature or List of Acronyms}

AFSS

ATC

CFSS

DOE

FTE

GCFI

GDP

IBSAL

IMPLAN

INL

MITR

MST

NAICS

NREL

OECD

ORNL

$R \& D$

RPM

SAF

SCC

SCM

USDA

WSM advanced feedstock supply system

Autonomous Tractor Corp.

conventional feedstock supply system

U.S. Department of Energy

full-time equivalent

gross cash farm income

gross domestic product

Integrated Biomass Supply Analysis and Logistics

Economic Impact Analysis for Planning

Idaho National Laboratory

Manufacturing and International Trade Report

Material Science Technology

North American Industry Classification System

National Renewable Energy Laboratory

Organisation for Economic Co-operation and Development

Oak Ridge National Laboratory

research and development

Refiner Products Manufacturing

Single-Pass, Autonomous, Follow-Me

Screw Conveyor Corp.

Supply Characterization Model

U.S. Department of Agriculture

West Salem Manufacturing 


\section{Executive Summary}

This report provides the analysis results of agricultural and preprocessing equipment and manufacturing requirements to support the mobilization of the projections in the U.S. Department of Energy 2016 Billion-Ton Report (U.S. Department of Energy 2016) utilizing the conventional supply chain logistics. The report discusses the required number of agricultural machinery and their market values and the potential economic impacts to the United States associated with this transition, the drivers and barriers of the transition in agricultural equipment, and the factors that impact the transition in agricultural machinery to support the growth of a large-scale biofuel and bioproducts industry in short and long terms. Short and long terms refer to the early development and mature development phases of the cellulosic biofuels industry in the United States. With respect to the 2016 Billion-Ton report, short term refers to projections for 2022, and long term refers to projections for 2040.

\section{Agricultural Equipment Requirements and Economic Impacts}

Five major biomass resources are selected for the analysis of feedstock equipment and manufacturing requirements to support the mobilization of commercial quantities of biomass resources utilizing the conventional supply chains. These biomass resources are corn stover; the perennial grasses switchgrass and miscanthus; coppice woody crops (such as willow); and noncoppice woody crops (such as poplar). Based on the 2016 Billion-Ton Report, 304 million-652 million tons/year of these biomass resources are projected to be available from agricultural lands in the United States. Using the Oak Ridge National Laboratory Supply Characterization Model, the selected biomass resources could support an estimated 240-358 potential biorefineries that convert 230 million - 340 million tons of selected biomass resources to biofuels annually. In the short term, it is estimated that about 280,000 pieces of equipment with a market value of $\$ 36$ billion would be required to harvest and deliver the biomass to the biorefineries. In the long term, this number is estimated to be about 380,000 pieces with a market value of more than $\$ 47$ billion.

Analysis of the current U.S. agricultural equipment manufacturing industry suggests that approximately $70 \%-80 \%$ of total U.S. agricultural equipment demand is supplied from domestic manufacturers. Without large changes in existing international trade policy and global manufacturing infrastructure status, it is reasonable to assume that U.S. agricultural equipment manufacturing under the 2016 Billion-Ton Report scenarios will be similar to the status quo, with U.S. production supplying $70 \%-80 \%$ of U.S. demand. Economic impacts from the required agricultural equipment are estimated using the Economic Impact Analysis for Planning (IMPLAN) model. The sum of direct long-term employment impacts is more than 56,000 fulltime equivalent job years, and the sum of the total long-term impacts is over 340,000 full-time equivalent job years. The domestic manufacture of the required equipment would result in almost $\$ 11$ billion in direct value added (contribution to the gross domestic product) and nearly $\$ 40$ billion in total value added (contribution to the gross domestic product) over the long term. These estimates assume that $75 \%$ of all agricultural equipment is manufactured domestically and that all required agricultural equipment is newly manufactured. The estimates also do not 
account for the potential use of the existing agricultural equipment fleet to harvest and deliver biomass.

\section{Transition Drivers and Barriers}

The project team identified and studied several recent technology transitions that took place in the agricultural farm machinery and the preprocessing equipment industry, such as the development of mobile pellet harvesters, self-propelled balers, and autonomous agricultural equipment. These transitions were evaluated to outline the drivers and barriers of these new pieces of equipment. These transitions also provided insights into the transition needed from existing biomass supply chain systems to advanced supply chains. The project team completed this task by contacting and interviewing the companies behind the development of these pieces of equipment.

A review of five recent transitions in agricultural equipment revealed that the main drivers behind the introduction of new and improved machineries include:

- Improving the field efficiency of harvest and collection operations.

- Increasing biomass transport efficiency and stability of biomass in storage.

- Increasing demand for renewable energy sources.

- Eliminating the need for skilled operators or any operators at all.

- Reducing wheel traffic and the damage that excessive wheel traffic causes to the growth of the next crop.

- Reducing operator fatigue.

- Reducing equipment costs (e.g., fuel consumption, maintenance, and repair) and increase the service life of the existing agricultural fleet.

- Reducing emissions.

- Improving implement control.

- Recognizing the potential of autonomous technology used in other industries.

- Downsizing field equipment.

- Improving the quality of collected biomass (e.g., lower ash content).

However, the adoption of these new technologies comes with challenges and barriers, including:

- Resistance from the existing farm machinery industry and its dealers

- Lack of availability of parts suppliers in some regions of the country

- Lack of strong service/support capabilities in the existing distribution and dealer network 
- High costs of new technologies

- Organizational conflicts within companies between departments promoting existing vs. new technologies, or between manufacturers promoting new technology and dealers that depend on servicing existing technology for revenue

Farm machinery supply chains need strong signals from biomass producers, biomass logistics companies, and biomass end users to tackle the barriers for the adoption of new technologies.

The results also indicate the existing fleet of agricultural and preprocessing equipment can meet a portion of the equipment demand created by future biorefineries and their suppliers. The use of the existing equipment fleet depends on their age, efficiency, and availability in the supply region; the introduction of new technology or major changes in the equipment design; the biomass supply strategy of the biorefineries and their suppliers (e.g., ownership, leased, or rental); and feedstock specifications of biorefineries. With the growth of the biorefinery industry in the United States, the original equipment manufacturers should be able to meet the increased demand for logistical and preprocessing equipment. The primary drivers for the current advancement in farm equipment are improving field efficiency and lowering operating costs. However, as indicated by the struggle of pioneer integrated biorefineries to achieve design production rate, the conventional feedstock supply system, equipment, and methods may not meet the quality feedstock requirements for biofuel technologies. Specifically, the use of corn stover bales resulted in significant variability in biomass properties, which led to low operational reliability and product yields. The delivery of feedstock with consistent quality to the gate of biorefineries at a competitive price requires a transition strategy to advanced and dedicated biomass supply chains and development of new technologies in logistical and preprocessing equipment.

Recognizing several deficiencies in the conventional feedstock supply system, Idaho National Laboratory has developed an advanced feedstock supply system to provide stable, consistent feedstock quality to biorefineries. The advanced feedstock supply system features distributed depots either near the biomass sources or near the biorefineries and includes two scenarios of agricultural biomass supply chains: baling and chopping. A major barrier to the transition from the conventional feedstock supply system to the advanced feedstock supply system is the lack of clear understanding (from the supply side as well as conversion side) of required specifications of feedstock for integrated biorefineries. The current approach of using low-cost agriculture residues with variable properties has led to severe operating difficulties of several pioneer biorefineries. Further research and development will be required to develop equipment and methods that supply low-cost and consistently high-quality biomass feedstock to biorefineries. Until this advanced biomass preprocessing technology is commercially proven at large scale, it is difficult to determine the requirements for transition to a commodity-based feedstock supply system. 


\section{Table of Contents}

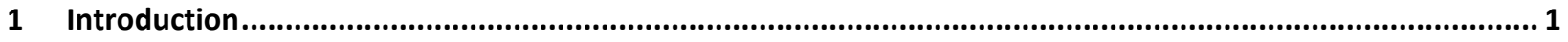

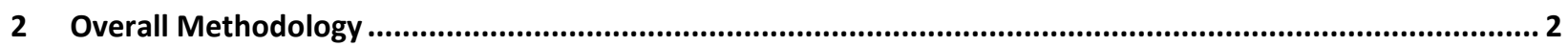

3 Potential Availability of Main Biomass Resources from Agricultural Lands ................................................... 5

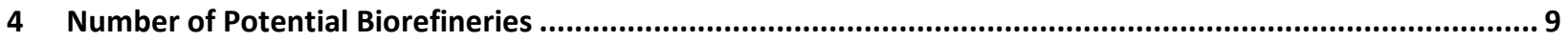

5 Baseline Biomass Supply Chains and the Existing Machinery Fleet Used in Baling and Chopping Logistics

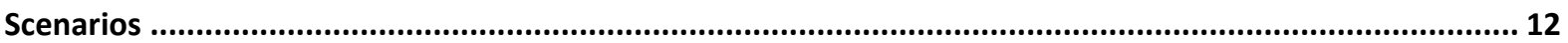

6 Required Number of Agricultural Machinery for Baling and Chopping Logistics......................................... 16

7 Equipment Requirements for a Baled Herbaceous System (Biochemical Conversion Pathway) ..................... 24

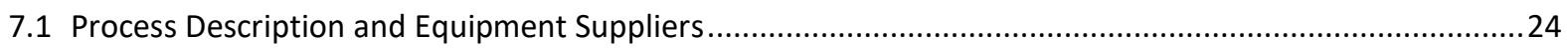

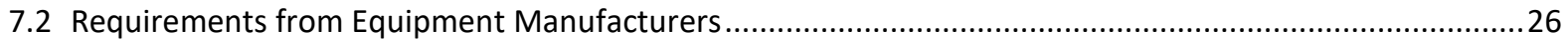

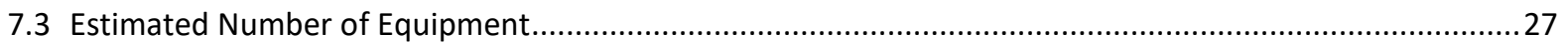

8 Equipment Requirements for Chopped Herbaceous System (Biochemical Conversion Pathway) .................. 29

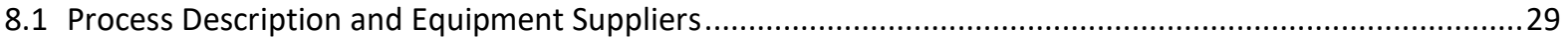

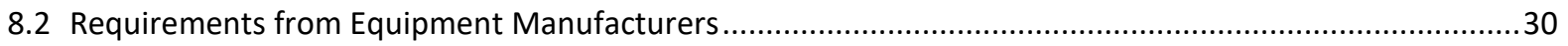

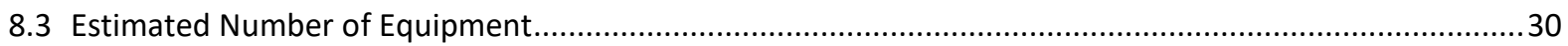

9 Equipment Requirements for Chopped Woody Biomass System (Thermochemical Conversion Pathway) .... 32

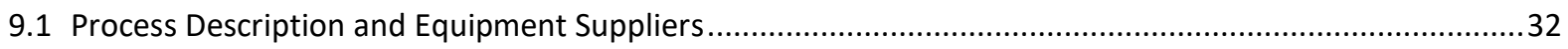

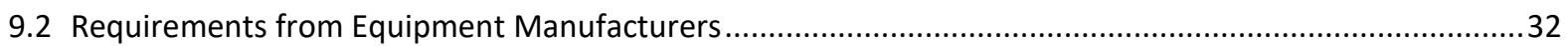

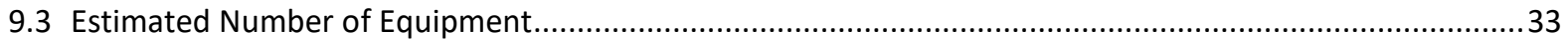

10 Economic Impact of Agricultural Machinery Manufacturing to Support Feedstock Supply for a Large-Scale

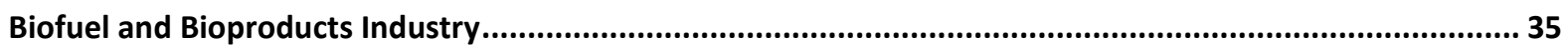

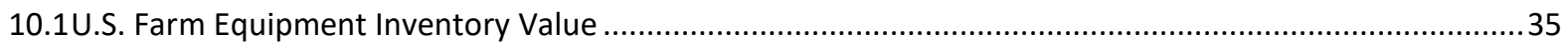

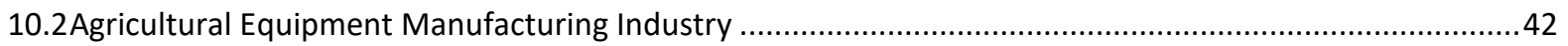

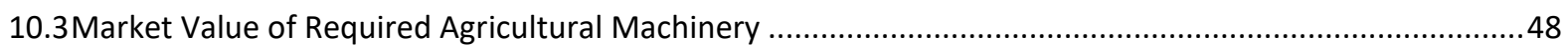

10.4Workforce and Economic Development Impacts of Required Agricultural Machinery ...............................51

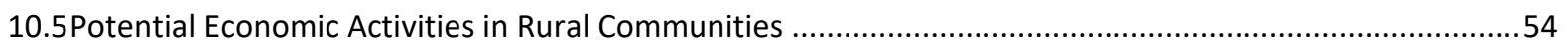

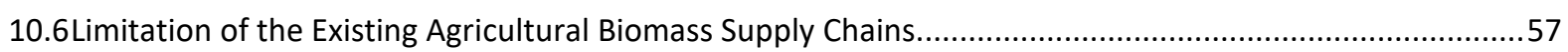

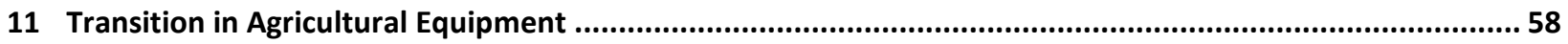

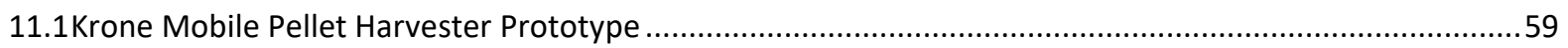

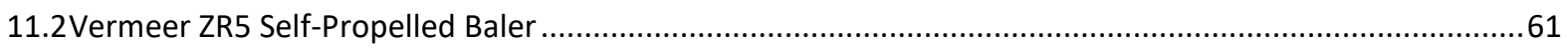

11.3Kinze Manufacturing Autonomous Grain Harvest System ….................................................................62

11.4Autonomous Self-Propelled Baler by Autonomous Tractor Corp. .............................................................65

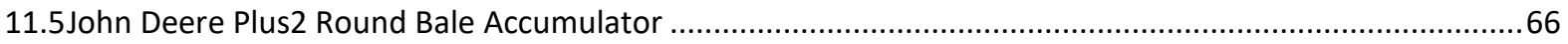

12 Transition from Conventional Feedstock Supply System to Advanced Feedstock Supply System ...................68

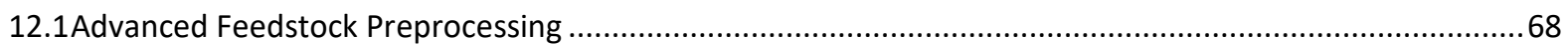

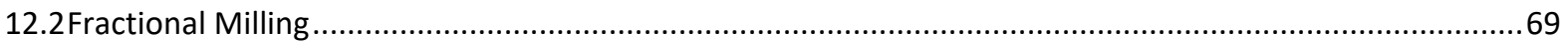

12.3High-Moisture Densification ............................................................................................................ 


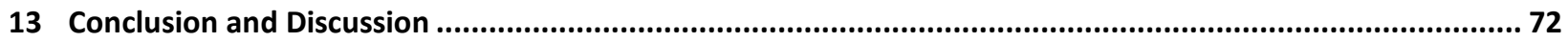

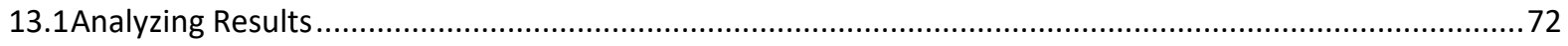

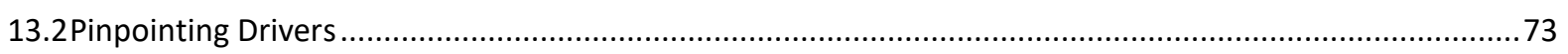

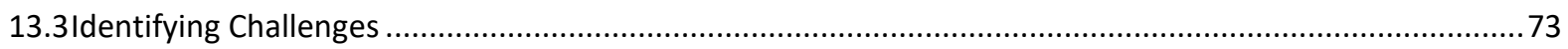

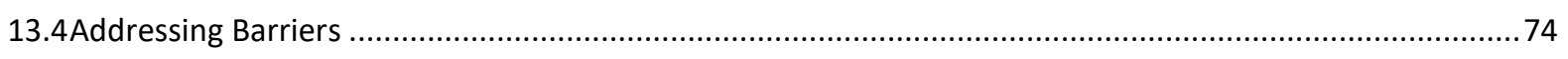

13.5Transitioning to New Feedstock Supply Systems ........................................................................... 76 


\section{List of Figures}

Figure 1. Methodology used to evaluate the existing biomass supply chains and to estimate the required number of agricultural machinery to harvest, collect, store, handle, and transport biomass to the gate of future biorefineries.

Figure 2. Lignocellulosic biomass resources from agricultural lands in the United States................................ 5

Figure 3. Geographic distribution of biorefineries using the five considered biomass resources ....................... 11

Figure 4. Baseline biomass logistics systems for a) baling and b) chopping scenarios ...................................... 13

Figure 5. List of agricultural machines used in a) baling and b) chopping logistics scenarios ........................... 14

Figure 6. Simulated baseline a) baling and b) chopping logistics scenarios in the IBSAL model ........................17

Figure 7. Estimated number of logistical machinery required to deliver 230 million-340 million tons of selected biomass resources to future biorefineries in short term and long term...................................................22

Figure 8. Total number of agricultural machinery in baling and chopping scenarios in short and long terms ...... 23

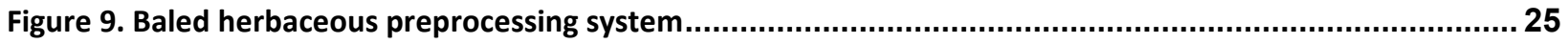

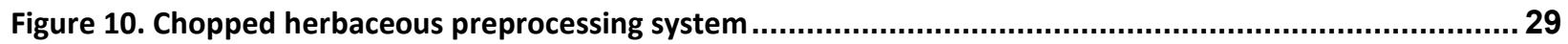

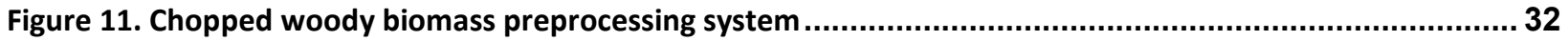

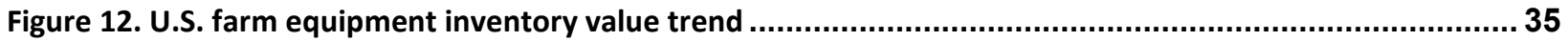

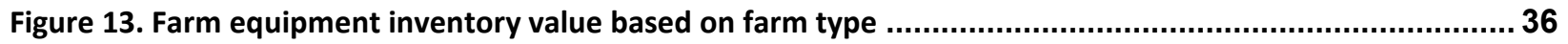

Figure 14. Estimated market value of all farm machinery and equipment on operations in 2012 ...................... 37

Figure 15. Estimated market value of all farm machinery and equipment in operation, average per farm, in U.S. dollars. 39

Figure 16. Farms and their value of production by farm type, 2016 ........................................................... 40

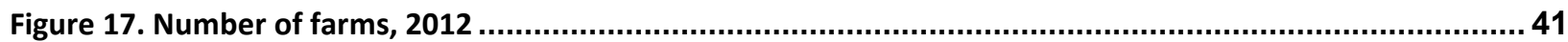

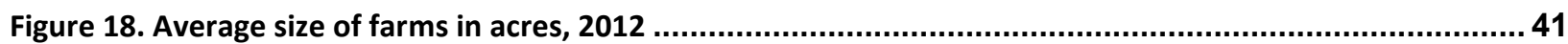

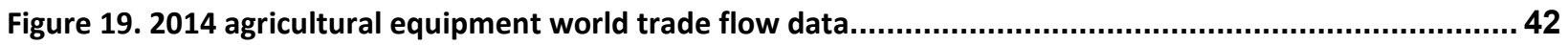

Figure 20. Projected 2019 agricultural equipment world trade flow data ................................................... 43

Figure 21. 2014 world agricultural equipment trade flow data by country................................................. 44

Figure 22. 2019 projected world agricultural equipment trade flow data by country ..................................... 44

Figure 23. 2015 value of farm machinery and equipment production and demand by type (NAICS codes 333111x) in the United States (thousands of dollars) 46

Figure 24. 2016 value of farm machinery and equipment production and demand by type (NAICS codes 333111x) in the United States (thousands of dollars)

Figure 25. Market value of required agricultural machinery to deliver $\mathbf{2 3 0}$ million-340 million tons of selected biomass resources to future biorefineries in short and long terms

Figure 26. Total estimated market value of agricultural machinery in baling and chopping scenarios in short and long runs

Figure 27. Employment impacts (in FTE job years) from market value of baling and chopping scenarios in short 
and long term in Figure 26

Figure 28. Value added (contribution to the GDP) impacts, in billions of U.S. dollars (2017), from market value of baling and chopping scenarios in short and long term in Figure 26

Figure 29. Estimated number of operators required to run the agricultural machinery fleet to meet the daily and annual biomass demands of biorefineries in the short and long terms . 55

Figure 30. Estimated number of participating crop growers................................................................. 55

Figure 31. Estimated net annual income of crop growers by selling their biomass to the future biorefineries .... 56

Figure 32. Stakeholders involved in agricultural equipment supply chains............................................... 58

Figure 33. Krone Premos 5000-the first mobile pellet harvester prototype .............................................60

Figure 34. ZR5 self-propelled baler. Vermeer established an R\&D group called "forage innovation" to develop the

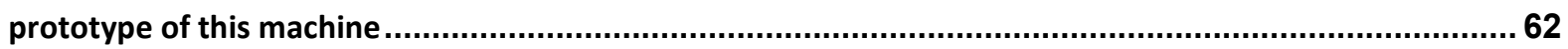

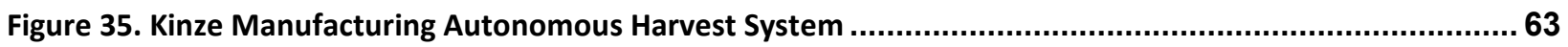

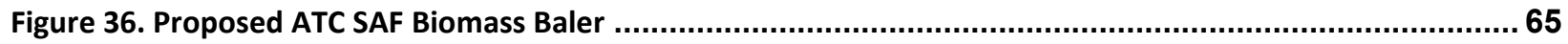

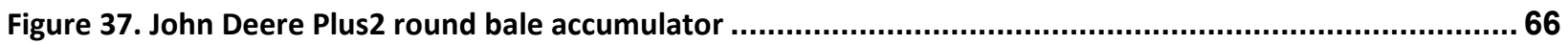

Figure 38. Left: bales collected by John Deere bale accumulators (John Deere 2017); Right: bales collected in a

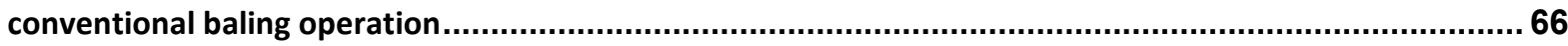

Figure 39. Corn stover bales after 2 years storage near Nevada, lowa .......................................................69

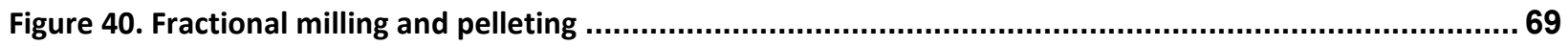

Figure 41. Energy consumptions in conventional and high-moisture pelleting of corn stover ......................... 70 


\section{List of Tables}

Table 1. Potential Availability of Agricultural Residues ( $\leq \$ 80 / D r y ~ T o n)$, Agricultural Wastes ( $\leq \$ 60 / D r y ~ T o n)$, and Energy Crops ( $\leq \$ 80 /$ Dry Ton) from Agricultural Lands in the United States...........................................6

Table 2. Number of Potential Biorefineries in the United States Estimated Using the ORNL SCM ................... 10

Table 3. Major Producers of Agricultural Machines Used in Baling and Chopping Logistics Scenarios................ 15

Table 4. General Profile of a Commercial-Scale Cellulosic Ethanol Plant Modeled in the IBSAL Model ............... 18

Table 5. Required Number of Logistical Machinery to Supply Biomass to a Biorefinery with an Annual Biomass Demand of 800,000 Dry Tons ................................................................................................. 19

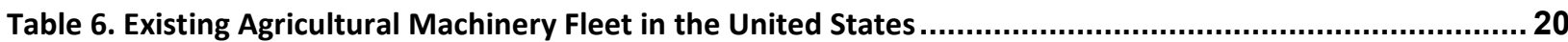

Table 7. Estimated Number of Major Equipment and Turnkey Systems for a Baled Herbaceous Preprocessing

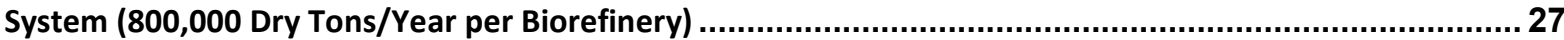

Table 8. Estimated Number of Major Equipment and Turnkey Systems for Chopped Herbaceous Preprocessing Systems (800,000 Dry Tons/Year per Biorefinery)

Table 9. Estimated Number of Major Equipment and Turnkey Systems for Chopped Woody Biomass

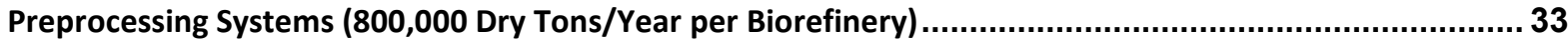

Table 10. Top 10 States by Value of Farm Equipment in 2012 ............................................................... 38

Table 11. Farm Equipment Inventory Value by Farm Size 38

Table 12. Value of Farm Machinery and Equipment (NAICS Code 333111) Production and Demand in the United States (Thousands of Dollars)

Table 13. 2015 and 2016 Value of Total U.S. Demand and Percent Supplied by U.S. Production for Farm Machinery and Equipment Production and Demand by Type (NAICS Codes 333111x) in the United States (Thousands of Dollars)

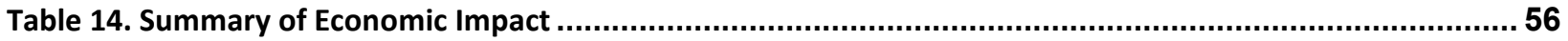

Table 15. Recent Transitions in Agricultural Equipment Manufacturing Studied in This Report........................ 59

Table 16. Drivers and Barriers for the Adoption of Krone Mobile Pellet Harvester, Premos 5000..................... 61

Table 17. Drivers and barriers for the adoption of Vermeer ZR5 self-propelled baler ..................................... 62

Table 18. Drivers and Barriers for the Development of Kinze Manufacturing Autonomous Harvest System ....... 64

Table 19. Drivers and Barriers for the Development of Autonomous Farm Equipment by ATC ........................ 66

Table 20. Drivers for the Development of the John Deere Plus2 Round Bale Accumulator..............................67

Table 21. Reduction in Milling and Pelleting Energy by Fractional Milling..................................................... 70

Table 22. Summary of Potential Drivers and Barriers to Transition from a Conventional Feedstock Supply System to an Advanced Feedstock Supply System ............................................................................ 71 


\section{Introduction}

The mobilization of a billion dry tons of biomass resources from production sources to the gate of biorefineries requires cost-efficient and effective biomass supply chains that are capable of meeting cost, quality, and quantity specifications of these facilities. This calls for the development of biomass logistics systems that provide transparent economic and agronomic values for biomass producers, custom harvest groups, transportation companies, and other stakeholders involved in the logistics systems. These logistics systems need enough equipment and trained workers to harvest, collect, and store large amounts of biomass in a short and uncertain harvest window and handle and transport the biomass to biorefineries according to their feedstock specifications.

This report first outlines the main biomass resources from agricultural lands that have a high potential to be used as feedstocks to produce biofuels and bioproducts. These biomass resources are identified based on their availability and projected future growth in the 2016 Billion-Ton (BT16) Report (U.S. Department of Energy [DOE] 2016). The potential economic availability of these biomass resources is also quantified based on the BT16 Report. Thereafter, the existing agricultural machinery used to harvest, collect, handle, and transport these biomass resources is identified. Finally, the agricultural machinery required to mobilize biomass is quantified based on the potential economic availability of the selected biomass resources.

An important aspect of the analysis is to understand and identify the feedstock properties that are required at a biorefinery gate to support the conversion facility. Although these properties are defined within each conversion strategy design case, ${ }^{1}$ the analysis focuses on utilizing the conventional feedstock supply system (CFSS) and advanced feedstock supply system (AFSS). Because the CFSS (generally associated with bale storage) leads to inconsistent feedstock quality, Idaho National Laboratory (INL) has developed the AFSS that produces consistent quality biomass feedstock delivered to the conversion reactor throat. The CFSS is based on the 2012 state-of-technology INL report effort (INL 2014). The AFSS is based on densification of feedstock. The project focuses on how to build each component of the feedstock supply chain to enable transition from the current state of the industry to a future commodity-based feedstock supply system, using emerging technologies and technology adoption as the pathway. The report comprises three main sections: methods, results, and conclusion and discussion.

\footnotetext{
${ }^{1} \mathrm{~A}$ design case is a techno-economic analysis that outlines a target case and provides preliminary identification of data gaps and research and development needs. More details and design case specifics are available at https://www.energy.gov/eere/bioenergy/strategic-analysis.
} 


\section{Overall Methodology}

The project team reviewed a range of studies that are either under development or have been published to understand feedstock composition requirements at the biorefinery gate as well as equipment required for feedstock harvesting, production, transport, and preprocessing. Composition for the feedstock was outlined for the major hydrocarbon pathways, including catalytic fast pyrolysis, biological upgrading of sugars, and catalytic upgrading of sugars. Equipment information is compiled utilizing modeling tools such as the Biomass Logistics Model and the Integrated Biomass Supply Analysis and Logistics (IBSAL) model.

The project team identified and studied several recent transitions that took place in agricultural farm machinery and feedstock preprocessing equipment. These transitions were evaluated to outline the drivers and barriers of these new pieces of equipment. These transitions also provided insights into the transition needed from existing biomass supply chain systems to advanced supply chains. The project team completed this task by contacting and interviewing the companies behind the development of these pieces of equipment.

A range of metrics was developed for the equipment required for feedstock production, harvesting, transport, and preprocessing. Five major parameters impact the performance of biomass supply chains to mobilize biomass in commercial quantities in a cost-efficient, timely, and effective manner. These parameters include:

1. Biorefinery size: The production capacity of a biorefinery dictates the annual biomass demand of the biorefinery and the biomass delivery schedule. The equipment fleet in the biomass supply chain is planned and scheduled accordingly to avoid the disruption of biomass availability to the bioconversion reactor at the biorefinery.

2. Biomass type and availability and its distribution in the supply area: The density of harvestable biomass in the supply area (i.e., ton/mile) dictates the supply radius within which sufficient amounts of biomass can be harvested and collected to meet the annual biomass demand of a biorefinery. The size of the supply radius impacts the quantity of logistics equipment required. Logistical equipment used in the supply chain must finish harvesting, collecting, and storing biomass during a short and uncertain harvest window. In addition, the biomass type impacts the selection of the machinery type to process biomass at different stages of the supply chain.

3. Harvest window: The length of the harvest window and the number of working days depend on field and weather conditions. The shorter the harvest window, the larger the fleet size to complete field operations.

4. Field capacity of the machinery: Performance of field machinery (e.g., acre/hour or tons/hour) depends on its specifications, such as the width of the machinery, horsepower, and speed, as well as field conditions and the operator's experience. The field capacity of a machine impacts the field fleet size.

5. Daily working hours: Daily working hours vary depending on the timing of the harvest season and the availability of machines and operators. The shorter the working hours, the larger the fleet size to complete field operations. 
All of these five parameters are considered in the evaluation of the existing biomass supply chains and in the estimation of the machinery fleet size to harvest, collect, store, handle, and transport biomass to the gate of future biorefineries. Figure 1 shows the methodology used to estimate the number of agricultural machinery required to mobilize commercial quantities of biomass in the supply chains.

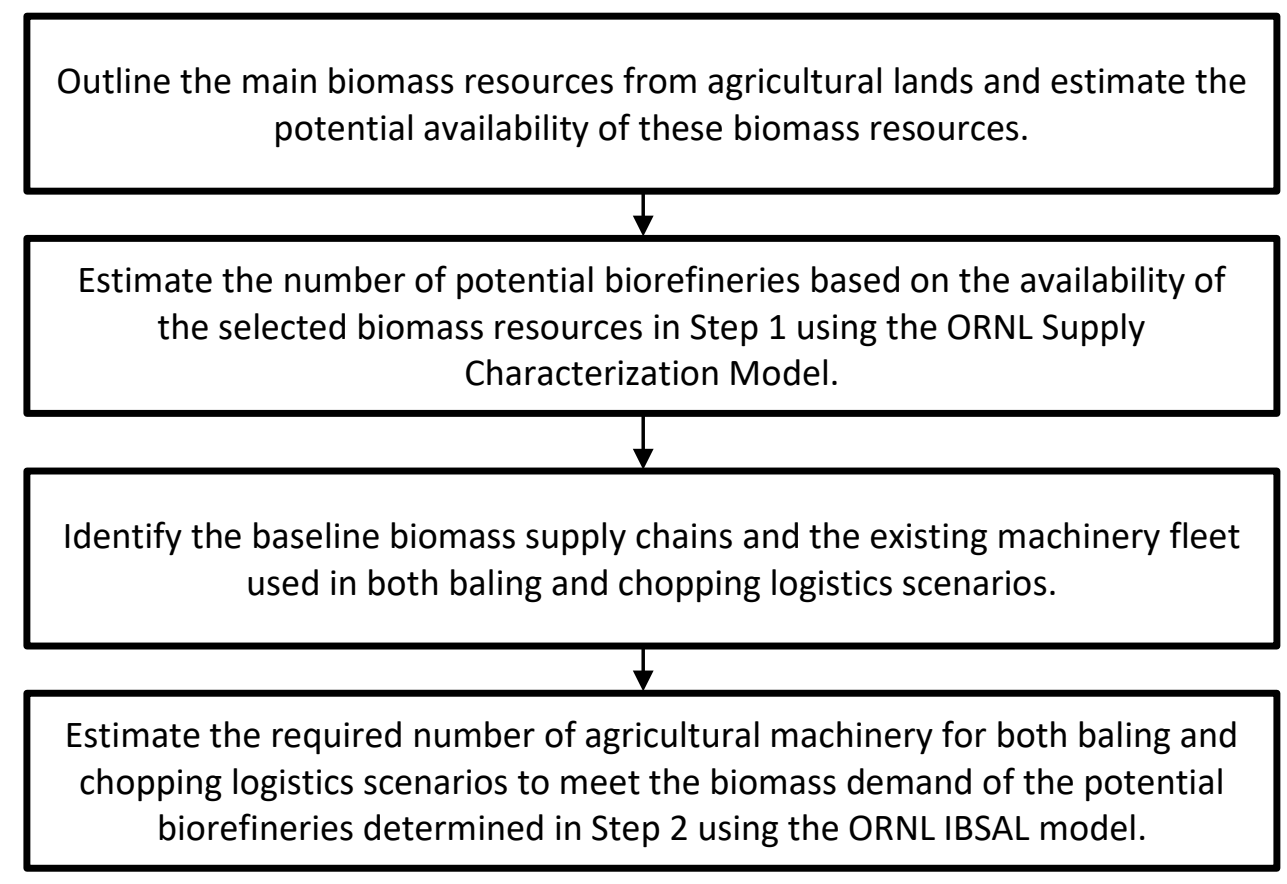

Figure 1. Methodology used to evaluate the existing biomass supply chains and to estimate the required number of agricultural machinery to harvest, collect, store, handle, and transport biomass to the gate of future biorefineries

The 2011 base case for biochemical conversion of lignocellulosic biomass to ethanol (Humbird et al. 2011) and 2013 base case for conversion of biomass to hydrocarbon fuels via the fast pyrolysis and hydrotreating bio-oil pathway (Jones et al. 2013) are used for analyzing equipment and manufacturing requirements for supporting the mobilization of the billion-ton projection utilizing the conventional supply chain logistics. The equipment requirements are grouped into three cases: (1) Baled herbaceous system for agricultural residues such as corn stover, wheat straw, etc., (2) chopped herbaceous system for energy crops such as miscanthus and switchgrass, and (3) chopped/milled woody biomass system for thermochemical conversion pathways. The equipment described in this report reflects actual industrial practices and does not necessarily match with the equipment and process flow shown in the process flow diagrams of National Renewable Energy Laboratory (NREL) reports. For example, the NREL process flow diagram (Humbird et al. 2011) shows that trucks deliver milled corn stover to the biorefinery, which is the case for an $\mathrm{n}^{\text {th }}$ plant where feedstock preprocessing depots produce conversion-ready feedstock. However, currently trucks deliver corn stover bales to pioneer biorefineries. Since the goal of this analysis is to estimate the agricultural and preprocessing equipment and manufacturing requirements to support the mobilization of the projections in the 2016 Billion-Ton Report (U.S. Department of Energy 2016) utilizing the conventional supply chain logistics, existing equipment and industrial practices are used. It is assumed that the 
conversion efficiencies in (Humbird et al. 2011) and (Jones et al. 2013) apply using the conventional supply chain logistics. The feedstock preprocessing equipment requirement reflecting current industrial practice for each 2,200 dry ton/day biorefinery is described below. 


\section{Potential Availability of Main Biomass Resources from Agricultural Lands}

Figure 2 shows the main lignocellulosic biomass resources from agricultural lands in the United States. These biomass resources are divided into two main categories of crop residues (e.g., corn stover and wheat straw) and energy crops (e.g., switchgrass, miscanthus, willow, and hybrid poplar). Crop residues require no additional cultivation or land and represent near-term opportunity feedstocks. Most cellulosic biofuels commercialization strategies to date-such as Abengoa, DuPont, and POET-DSM-have focused on agricultural residues, primarily corn stover. Along with crop residues, dedicated energy crops can complement the process to further commercialize biofuels, biopower, and bioproducts. These crops can improve supply security and help control feedstock quality characteristics. This can be achieved using energy crops alone or in combination with other feedstocks (DOE 2016).

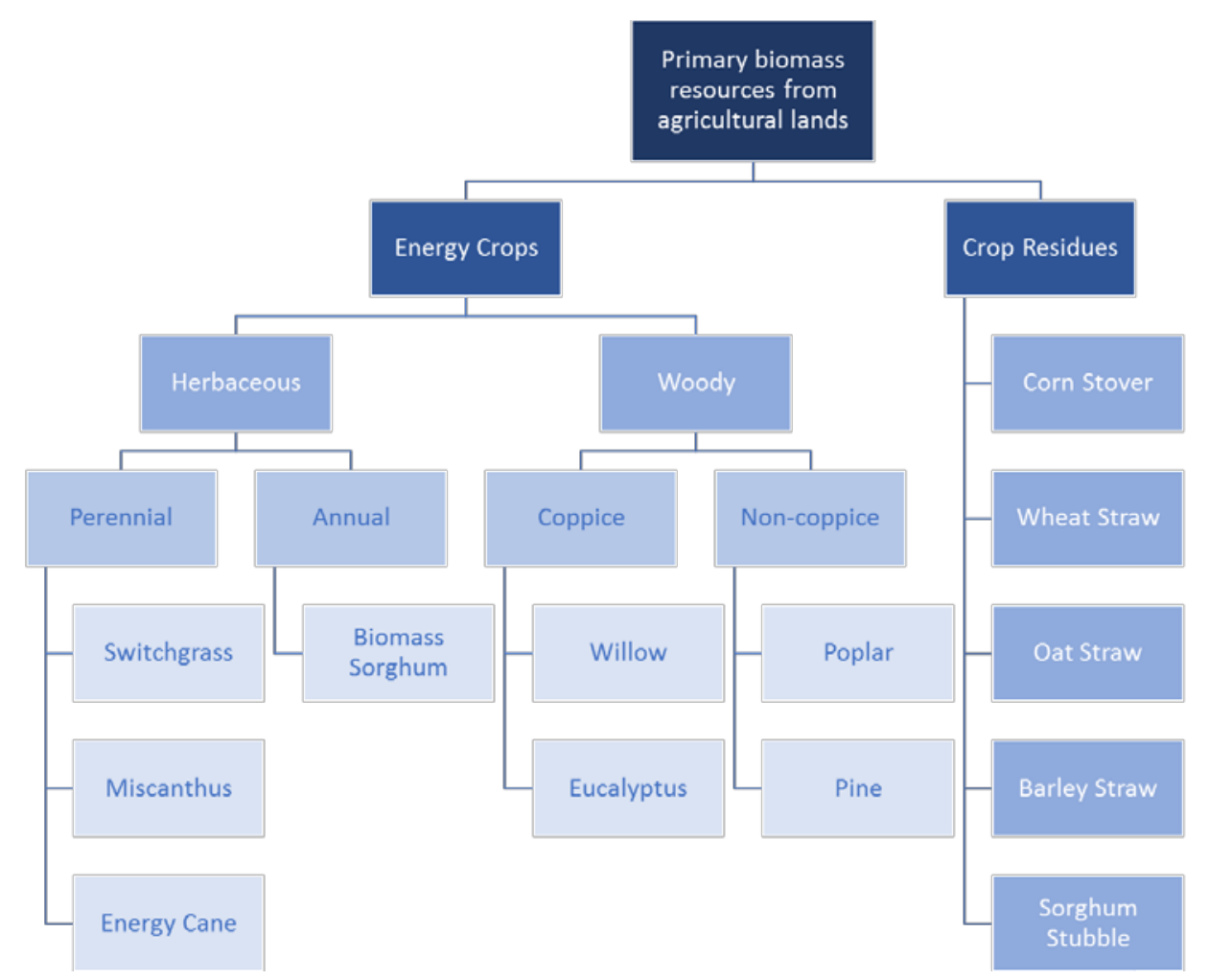

Figure 2. Lignocellulosic biomass resources from agricultural lands in the United States (adapted from DOE 2016)

Table 1 shows the potential availability of lignocellulosic biomass resources in the United States from agricultural lands. The available quantities represent the harvestable biomass for industrial applications such as biofuel and bioproducts. The harvestable biomass is the sustainable amount of biomass that can be removed from fields, leaving sufficient amounts behind to meet the agronomic criteria, including mitigation of soil erosion, maintenance of soil organic matters, and sustained soil fertility. The amount depends on the local conditions and varies from field to field (Jeschke and Heggenstaller 2012). Table 1 also shows the potential 
availability in biomass resources in 2022, 2030, and 2040. In this report, 2022 potential biomass availability is referred to as availability in the short term and represents the early development phase of the cellulosic biofuels industry in the United States. Potential biomass availability in 2040 is referred to as availability in the long term and represents the mature development phase of the biofuels industry.

Table 1. Potential Availability of Agricultural Residues ( $\leq \$ 80 /$ Dry Ton), Agricultural Wastes ( $\leq \$ 60 /$ Dry Ton), and Energy Crops ( $\leq \$ 80 / D r y$ Ton) from Agricultural Lands in the United States, Base Case Scenario (1\% Annual Growth) (DOE 2016, Tables 4.7, Table 5.1, and Table 4.8, Respectively)

\begin{tabular}{|c|c|c|c|c|}
\hline \multirow{2}{*}{ Biomass type } & \multicolumn{4}{|c|}{ Year } \\
\hline & 2017 & 2022 & 2030 & 2040 \\
\hline \multicolumn{5}{|c|}{ Crop Residues (million tons) } \\
\hline Corn stover & 102.0 & 119.0 & 142.0 & 166.0 \\
\hline Wheat straw & 15.0 & 17.0 & 19.0 & 20.0 \\
\hline Sorghum residue & 1.0 & 1.0 & 1.0 & 1.0 \\
\hline Oat residue & 0.0 & 0.0 & 0.0 & 0.0 \\
\hline Barley residue & 0.0 & 1.0 & 1.0 & 1.0 \\
\hline Cotton field residues & 1.5 & 2.0 & 2.2 & 3.2 \\
\hline Cotton gin trash & 1.7 & 1.9 & 2.0 & 2.1 \\
\hline $\begin{array}{l}\text { Orchard and } \\
\text { vineyard prunings }\end{array}$ & 5.5 & 5.6 & 5.8 & 6.0 \\
\hline Rice straw & 4.9 & 5.2 & 5.4 & 5.6 \\
\hline Rice hulls & 1.4 & 1.5 & 1.5 & 1.6 \\
\hline Sugarcane field trash & 1.0 & 1.1 & 1.1 & 1.1 \\
\hline \multicolumn{5}{|c|}{ Energy Crops (million tons) } \\
\hline Switchgrass & 0.0 & 71.0 & 100.0 & 137.0 \\
\hline Miscanthus & 0.0 & 104.0 & 203.0 & 293.0 \\
\hline Biomass sorghum & 0.0 & 1.0 & 18.0 & 58.0 \\
\hline Energy cane & 0.0 & 0.0 & 1.0 & 2.0 \\
\hline Noncoppice & 0.0 & 0.0 & 34.0 & 41.0 \\
\hline Coppice & 0.0 & 10.0 & 19.0 & 15.0 \\
\hline
\end{tabular}

In the United States, the main agricultural biomass is corn stover because of the massive production of corn grain in the country. On average, approximately 102 million dry tons of corn stover can be harvested annually at a price of $\leq \$ 80 /$ ton from 37 states. The Midwestern states produce the majority of corn stover in continuous acres, making them viable locations to secure 
the supply of corn stover to future biorefineries within reasonable supply radii. Corn stover is currently the primary feedstock for cellulosic ethanol production in the United States. The large availability of corn stover in the Midwest has allowed the pioneering cellulosic ethanol plants to exploit the economies of scale and to reduce the unit cost of biofuel production. The Midwestern states of lowa, Nebraska, Illinois, South Dakota, Minnesota, Indiana, and Ohio produce approximately 88 million dry tons, $80 \%$ of the total produced corn stover in the United States. (Ebadian et al. 2017).

Table 1 also shows the potential increase in the production of corn stover in the United States in the short and long terms. This increase is mainly due to the projected increase in the corn yield and improvement in tillage practices. As shown in Table 1, it is projected the amount of harvestable corn stover would increase by $16 \%, 39 \%$, and $63 \%$ compared with the current amounts of harvestable corn stover in the United States (i.e., 102 million dry tons).

The second biomass type that has a high potential growth in the United States is energy crops. The Bioenergy Technologies Office set a long-term price target of \$2/gasoline gallon equivalent for biofuel. This low-price target will require significant cost cutting (from the current state-oftechnology model), not only in feedstock cost but also conversion costs, because low-cost feedstock alone may not be enough to meet the price target. For the bioconversion pathway, increasing the carbohydrate content of feedstock and thus product yield will be another potential option. This latter approach will likely require switching feedstock from agriculture residue, such as corn stover and wheat straw, to energy crops that have high carbohydrate content, such as switchgrass. There are several advantages of using energy crops over agriculture residues:

- Process intensification, such as one-pass harvesting and chopping to size, which could lead to fewer fines

- Lower content of dirt contaminant

- Moisture content preservation in the harvested biomass, which helps the water balance and water footprint of the biorefinery

- Pretreatment and/or coproduct options in high-moisture /ensiled storage

- Lower dry matter loss

- Reduction or elimination of feedstock preprocessing inside the biorefinery battery limit, which greatly improves the operational reliability of biorefineries

- More consistent feedstock properties (compared with baled biomass), which should result in higher conversion yield

- Lower capital expenditure and operational expenditure for the biorefinery.

The increasing demand for renewable energy feedstock has raised interest in growing herbaceous and short rotation woody crops such as switchgrass, miscanthus, willow, hybrid poplar, and eucalyptus for the production of bioenergy, biofuel, and bioproducts (Couto et al. 2011; Guerra et al. 2016; Volk et al. 2016). Modern industrial crop plantations have been 
implementing all the latest advances in genetic improvement and cropping techniques to increase growth rates and yields, shorten rotation length production, and ease propagation from dormant stem cuttings and breeding (Sedjo 1999; Volk et al. 2016). Different companies have been developing and commercializing these crops across the country. DOE and the U.S. Department of Agriculture (USDA) have been supporting the development of these crops by providing financial support for growers, universities, and agricultural equipment manufacturers to improve the production and harvesting of these crops. Among these crops, perennial grasses, including switchgrass and miscanthus, and short rotation woody crops, including willow and hybrid poplar, have the highest potential to be produced in commercial quantities in the United States based on the availability of marginal lands and favorable climate conditions. The United States has the potential to produce about 137 million, 293 million, 41 million, and 15 million dry tons of switchgrass, miscanthus, noncoppice (e.g., hybrid poplar), and coppice crops (e.g., willow), respectively, by 2040 (DOE 2016).

In summary, based on the availability of biomass resources from agricultural lands, five major lignocellulosic biomass resources are selected for the analysis of number of potential biorefineries, feedstock equipment, and manufacturing requirements to support the mobilization of commercial quantities of biomass resources utilizing the conventional supply chains. These biomass resources are corn stover, switchgrass, miscanthus, noncoppice woody crops (e.g., hybrid poplar), and coppice woody crops (e.g., willow). 


\section{Number of Potential Biorefineries}

The number of biorefineries and their production capacity dictate the annual biomass demand and the biomass delivery schedule. The equipment fleet in the biomass supply chain is planned and scheduled accordingly to avoid the disruption of biomass availability to the bioconversion reactors at the biorefineries. Thus, the number and production capacity of future biorefineries impact the required machinery fleet to meet their biomass demand in a timely manner.

The ORNL Supply Characterization Model (SCM), a geographically based modeling system, is used to estimate the number of potential biorefineries. The SCM determines the number and location of biorefineries based on the availability and distribution of biomass in a region, the road network, and the target biomass delivered cost. The quantities of available feedstock for the SCM analyses are the county-level biomass production estimates (dry tons/county for each feedstock). Potential biorefineries are restricted to points in a 50-mile spaced grid superimposed on the 2013 National Highway Planning Network. The corresponding grid points are then linked to the nearest node in the road network.

For this analysis, the annual biorefinery demand is assumed to be 800,000 tons/year, based on analysis by Argo et al. (2013) and Muth et al. (2014), to optimize the cost per gallon of fuel by considering the trade-offs between feedstock transport distance and biorefinery economy of scale. The production estimates for agricultural resources represent materials available at an offered farm gate price of $\$ 60 /$ ton and the DOE delivered cost target of $\$ 84 /$ ton.

Table 2 shows the estimated number of potential biorefineries in the United States. The total number of potential biorefineries is estimated to be between 240 and 358. This range is estimated based on the availability, location and price of biomass in short and long terms and the potential increase in the production of biomass resources in the long term, as shown in Table 1, as well as other factors such as farmer participation rates and dry matter losses. From this available biomass, the estimated number of potential biorefineries would use 230 million340 million tons/year of corn stover, energy crops, and woody crops in the short and long term, respectively. Some biorefineries could be supplied with multiple feedstocks because of the availability of multiple biomass resources in the supply area. It is noted that the estimated number of biorefineries is not a projection or anticipation of the real number of biorefineries in short and long terms. These numbers only represent the potential size of the bioeconomy in the United States based on the availability of the main biomass resources in the United States. 
Table 2. Number of Potential Biorefineries in the United States Estimated Using the ORNL SCM

\begin{tabular}{|l|l|}
\hline Biomass Type & Potential Number of Biorefineries \\
\hline Corn stover & $50-52$ \\
\hline Switchgrass & $14-61$ \\
\hline Miscanthus & $2-23$ \\
\hline Switchgrass + miscanthus & $86-106$ \\
\hline Corn stover + switchgrass & $42-60$ \\
\hline Corn stover + switchgrass + miscanthus & $19-20$ \\
\hline Tree + coppice & $11-23$ \\
\hline Coppice + noncoppice & $4-18$ \\
\hline Tree + noncoppice & $8-24$ \\
\hline Tree + residue + coppice & $3-7$ \\
\hline Total & $240-358$ \\
\hline
\end{tabular}

The potential locations of these biorefineries are shown in Figure 3. These biorefineries are divided into two categories based on their conversion technologies. The first category is biorefineries that use corn stover, switchgrass, and miscanthus as feedstock to produce biofuel using a biochemical conversion pathway. These biorefineries would be mainly located in the Midwest, South, and Southeast regions of the United States where commercial quantities of agricultural biomass resources would be available. The second category is biorefineries that use woody biomass as feedstock to produce biofuel using a thermochemical conversion pathway. The majority of biorefineries would be located in the Northeast, Southeast, and Northwest regions of the United States. 


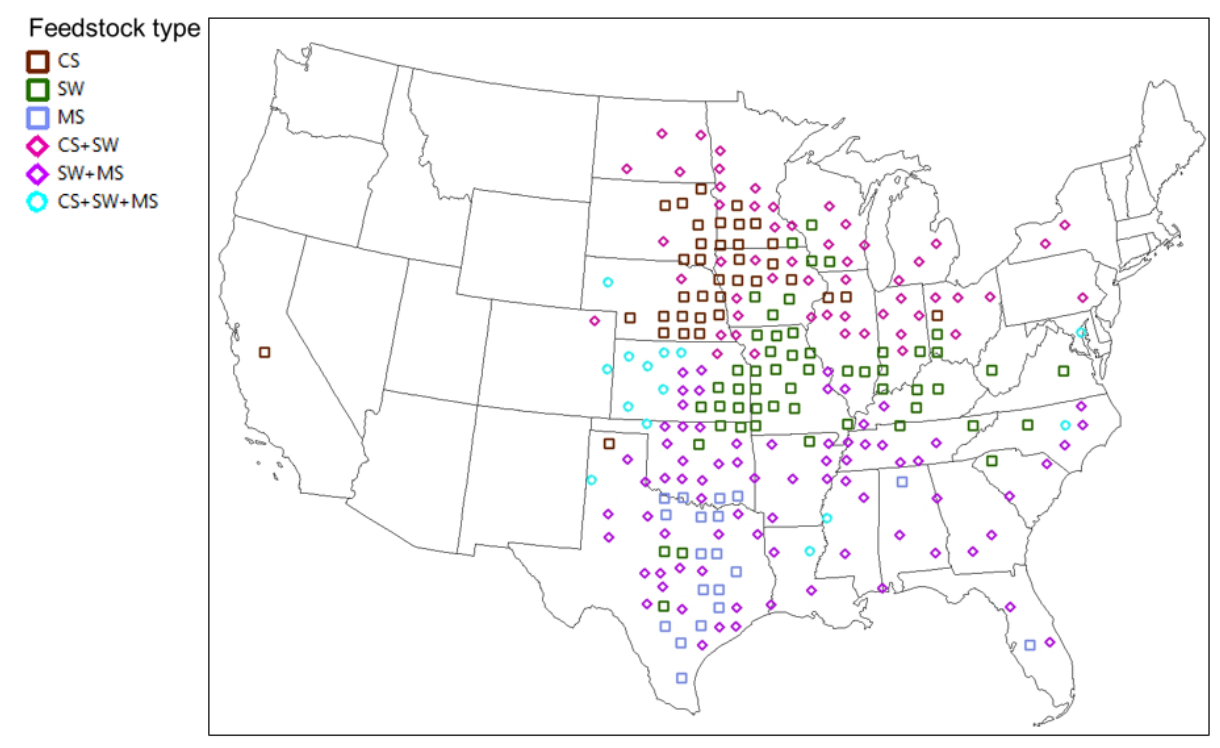

\begin{tabular}{lc}
\hline Feedstock type & Abbreviation \\
\hline Cornstover & CS \\
Switchgrass & SW \\
Miscanthus & MS \\
\hline
\end{tabular}

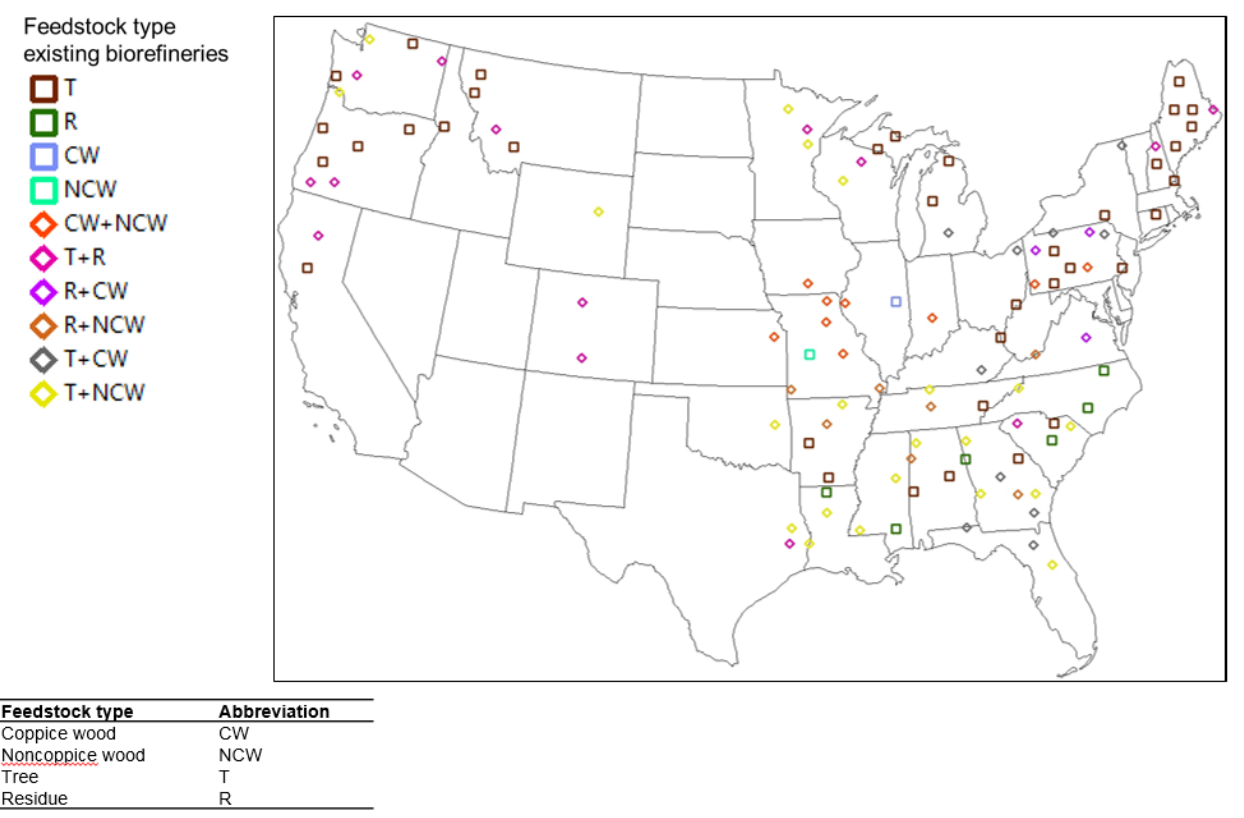

Figure 3. Geographic distribution of biorefineries using the five considered biomass resources.

Top: Biorefineries using corn stover, switchgrass, and miscanthus as feedstock to produce biofuel using a biochemical conversion pathway. Biorefineries are mainly located mainly located in Midwest, South, and Southeast regions of the United States. Bottom: Biorefineries using woody biomass as feedstock to produce biofuel using a thermochemical conversion pathway. Majority of biorefineries are located in Northeast, Southeast, and Northwest regions of the United States (Sharma et al. 2017). 


\section{Baseline Biomass Supply Chains and the Existing Machinery Fleet Used in Baling and Chopping Logistics Scenarios}

Biomass resources considered in this report are currently harvested and collected using the existing agricultural machinery fleet in the United States. Depending on the biomass type and location, different machinery types are used in the logistics system. Two existing logistics systems include baling and chopping scenarios.

Figure 4 shows the baseline biomass logistics system for the baling and chopping scenario. This scenario is developed based on the existing agricultural machinery used in the three pioneering cellulosic ethanol projects in the United States. These plants use corn stover as feedstock for cellulosic ethanol production. This scenario is considered for corn stover, switchgrass, and miscanthus.

The baseline logistics system is the conventional bale system, which takes place after harvesting the main agricultural product such as corn grain. As shown in Figure 4a, during the harvest season, sufficient stover is transported from corn fields to the biorefinery to meet the daily demand (just-in-time delivery). The rest of the harvested stover is stored temporarily at the roadside of fields. Upon the availability of the loading and transportation equipment, the stored bales are either transported to the biorefinery or to the intermediate storage sites. All the collected bales at the roadside of corn fields need to be removed before the commencement of the tillage and fertilizer application for the next cropping season. Stacked bales in the intermediate storage sites may have to be stored for several months before delivery to the biorefinery. Tarps usually cover the stored bales in the intermediate storage sites to minimize their exposure to the elements and the associated dry matter losses. Other storage options, such as open or closed sheds, can be considered depending on the climate conditions and the storage time. Figure 5 a shows the agricultural machines used in the baling logistics scenario.

The second logistics scenario is chopping, in which biomass crops such as switchgrass, miscanthus, willow, and hybrid poplar are chopped using a forage harvester at the field. Figure $4 \mathrm{~b}$ shows the baseline biomass logistics system for the chopping scenario. In the scenario, biomass is chopped right at the field using a forage harvester, and the chopped biomass is blown into collection equipment (e.g., a wagon or silage truck) simultaneously. The collection equipment transports chopped biomass either directly to the biorefinery or to an intermediate storage site. Wheel loaders or agricultural telehandlers are used to handle chopped biomass at a pile storage. The agricultural machines in the chopping scenario are shown in Figure $5 b$.

Table 3 shows the major producers of the existing machines used in both baling and chopping logistics scenarios. In both scenarios, a variety of firms in the United States manufacture the farm machinery. These firms consist of multimillion dollar companies that market a full line of products to short-line manufacturers that focus on a few core competencies as well as small family operations that produce a few custom pieces of equipment per year. In addition to competing among one another, U.S. farm machinery manufacturers, which dominate the industry, face increasing competition from foreign companies in both Europe and Asia. 
Currently, European competitors such as Claas and Krone meet a portion of the demand for farm machinery in the United States.

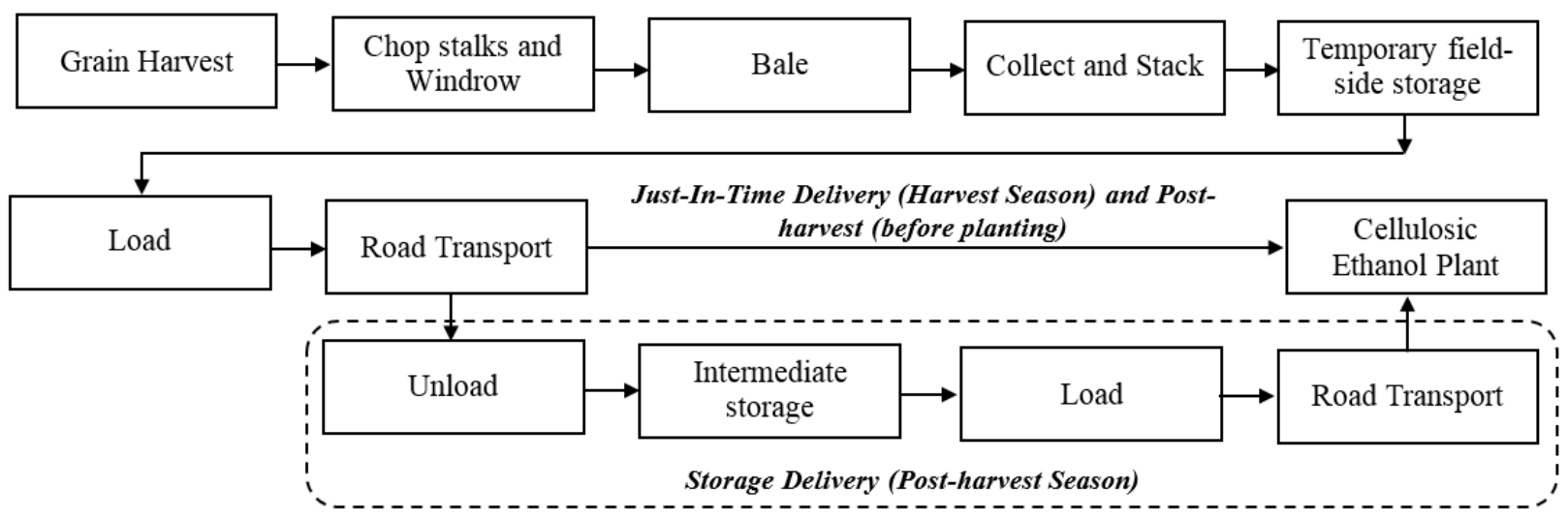

a) Baling scenario
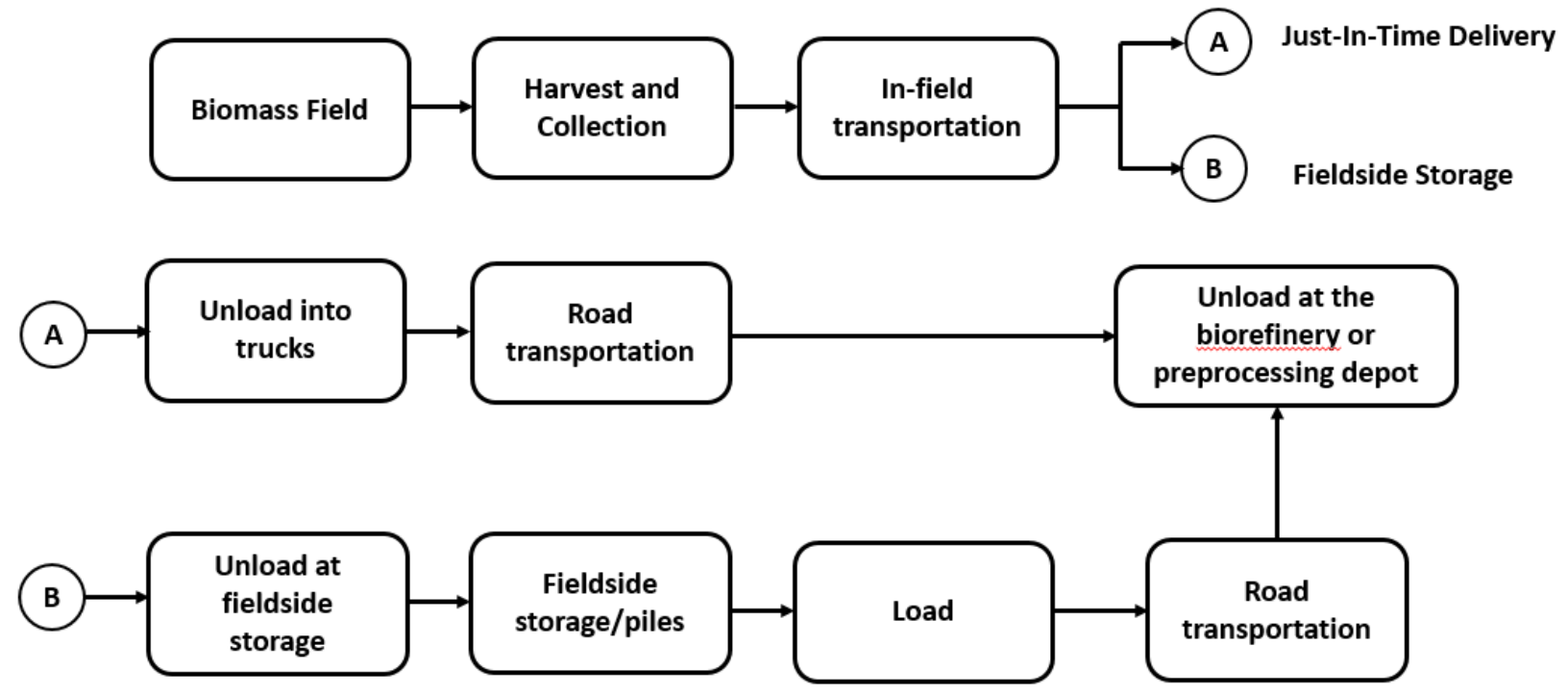

b) Chopping scenario

Figure 4. Baseline biomass logistics systems for a) baling and b) chopping scenarios (Ebadian et al. 2017) 

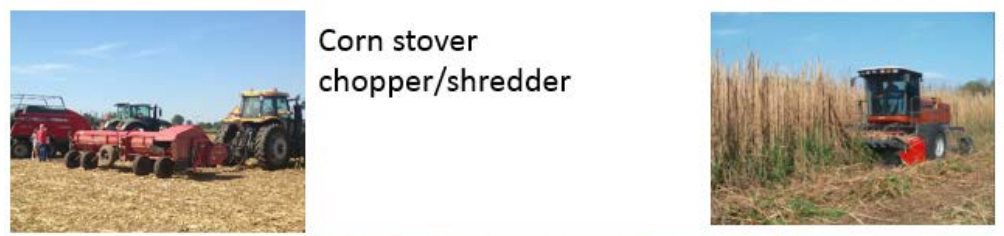

Self-propelled windrower-Miscanthus and switchgrass
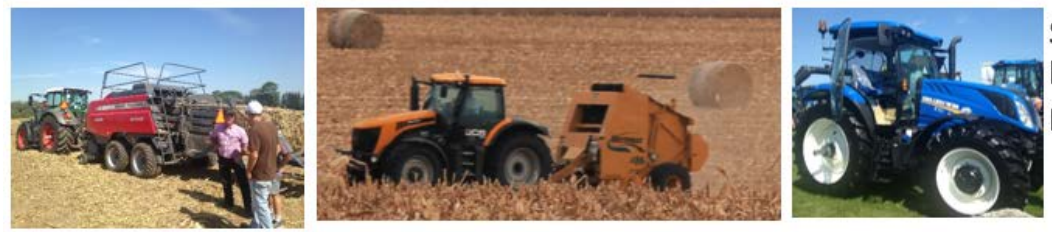

Square and round balers and tractor to pull them
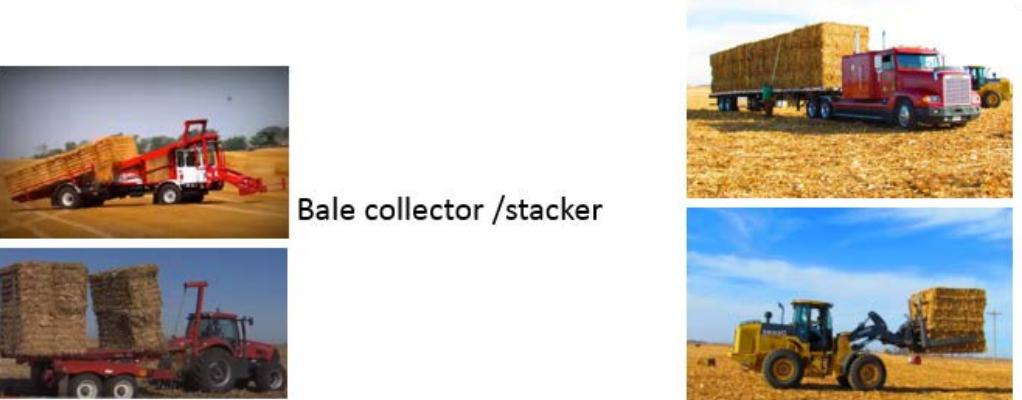

Truck and flatbed trailer

Bale collector /stacker

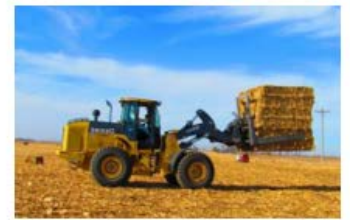

Telescopic loader

a) Baling logistics system

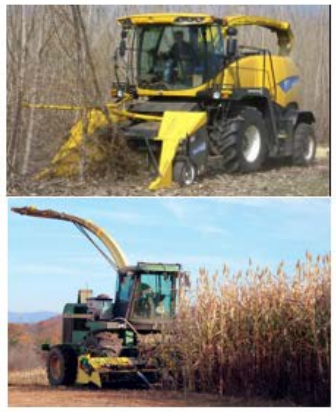

Forage harvester

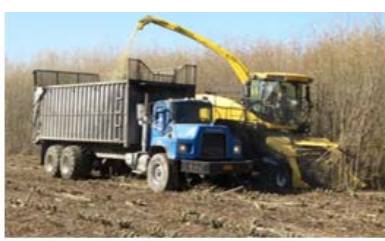

Dump Truck/

Silage truck
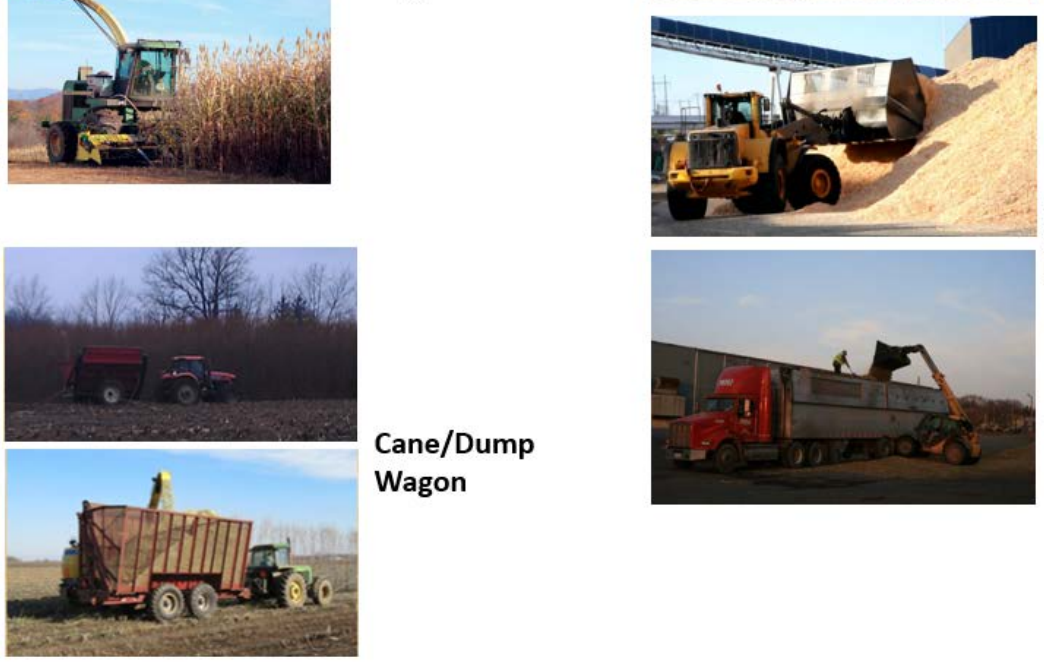

Agricultural telehandler/Wheel loader

18-wheeled chips

Cane/Dump Wagon truck and trailer

b) Chopping logistics system

Figure 5. List of agricultural machines used in a) baling and b) chopping logistics scenarios (Stinger Inc. 2016; Morris Industries 2014; Shah 2013; Gutesa 2013; AGCO 2015 Eisenbies et al. 2014) 
Table 3. Major Producers of Agricultural Machines Used in Baling and Chopping Logistics Scenarios

\begin{tabular}{|l|l|l|}
\hline \multicolumn{2}{|l|}{ Machinery Type } & \multicolumn{2}{|l|}{ Leading Manufactures } & $\begin{array}{l}\text { Is the United States an } \\
\text { Importer or Exporter of This } \\
\text { Equipment? }\end{array}$ \\
\hline Baling scenario & \multicolumn{2}{|l|}{} \\
\hline Shredders/windrowers & $\begin{array}{l}\text { AGCO, Hiniker, John Deere, Krone, New } \\
\text { Holland, Claas, Fendt, Kuhn, McDon, } \\
\text { Bush Hog, Gehl, Mathews. }\end{array}$ & Exporter/Importer \\
\hline $\begin{array}{l}\text { Round and square } \\
\text { balers }\end{array}$ & $\begin{array}{l}\text { AGCO, John Deere, Krone, Vermeer, } \\
\text { Case NH, Claas, Kuhn }\end{array}$ & Exporter/importer \\
\hline $\begin{array}{l}\text { Bale } \\
\text { collectors/stackers }\end{array}$ & $\begin{array}{l}\text { NH, Pronovost, Stinger, ProAg, } \\
\text { Group Anderson }\end{array}$ & Exporter/importer \\
\hline Loaders & Caterpillar, Tigercat, Bell, Komatsu, HSM & Exporter/importer \\
\hline $\begin{array}{l}\text { Tractor trucks and } \\
\text { flatbed trailers }\end{array}$ & $\begin{array}{l}\text { Tycrop, Trailex, Lode King, Peterbilt, Hi } \\
\text { Boy Trailer, Stephens Trailer, Aden Brook }\end{array}$ & Exporter/importer \\
\hline $\begin{array}{l}\text { Tractors to pull } \\
\text { the implement }\end{array}$ & $\begin{array}{l}\text { John Deere, Massey Ferguson, Case IH, } \\
\text { New Holland Tractors, Fendt, Deutz, } \\
\text { Claas, Kubota, JCB. }\end{array}$ & Exporter/Importer \\
\hline Chopping scenario & \multicolumn{2}{|l}{} \\
\hline Forage harvesters & $\begin{array}{l}\text { John Deere, Krone, New Holland, Claas, } \\
\text { Fendt, Kuhn }\end{array}$ & Exporter/importer \\
\hline $\begin{array}{l}\text { Dump wagons and } \\
\text { silage trucks }\end{array}$ & $\begin{array}{l}\text { John Deere, Mack, Meyer, Case IH, } \\
\text { Richardton }\end{array}$ & Exporter/importer \\
\hline $\begin{array}{l}\text { Loaders } \\
\text { chip trailers }\end{array}$ & $\begin{array}{l}\text { John Deere, Gehl, Caterpillar, Tigercat, } \\
\text { Bell, Komatsu, HSM }\end{array}$ & Exporter/importer \\
\hline $\begin{array}{l}\text { Tycrop, Trailex, Innovative Trailer, Pitts } \\
\text { Western Trailer, Pinnacle, Keith }\end{array}$ & Exporter/importer \\
\hline
\end{tabular}




\section{Required Number of Agricultural Machinery for Baling and Chopping Logistics}

Given the baseline baling and chopping logistics scenarios and the size and number of potential future biorefineries, the IBSAL simulation model is applied to quantify the number of logistical resources needed. The dynamics and stochastic nature of the biomass logistics systems are considered in the IBSAL model. Some of the input parameters in the baseline logistics scenarios are considered variable to reflect temporal and spatial variations. These input parameters include biomass yield, harvest window, harvest moisture content, bulk density, dry matter loss, equipment capacity and its efficiency, machine breakdown and repair time, winding factor and road transportation time. Due to the variability in the input data, IBSAL is run for multiple replications. Each replication represents the performance of the logistics system under a specific set of input data.

IBSAL is a push/pull simulation model in which the entire logistics system is planned and scheduled based on the daily biomass demand of the biorefinery (pull scheduling) and the harvest schedule (push scheduling). The push part is comprised of the field operations. The agricultural practices and local conditions dictate the timeliness of the field operations. Biomass is usually available to harvest within a short window and it must be collected and removed from fields. The rest of the logistics system acts as a pull system meaning that only when the biorefinery needs biomass, the required amount is pulled either from fields or storage sites. Therefore, the push part of the logistics system harvests and collects sufficient quantities of biomass during the harvest season to assure the fulfillment of the annual biomass demand, whereas the pull part only processes the amount of biomass required to fulfill the daily biomass demand of a biorefinery year-round. This structure of the agricultural biomass logistics system dictates the number of machinery required to meet the feedstock demand of a biorefinery over its lifetime. Figure 6 depicts the simulated baseline baling and chopping logistics scenarios in IBSAL.

Based on the availability of biomass resources from agricultural lands, the project team selected five major biomass resources for the analysis of feedstock equipment and manufacturing requirements: corn stover, perennial grasses (i.e., switchgrass and miscanthus), and short rotation woody crops (i.e., hybrid poplar and willow). The team considered two types of field operations to harvest and collect these biomass resources, including baling and chopping. In the baling scenario, corn stover, miscanthus, and switchgrass are densified at the field using round/rectangular balers. In the chopping scenario, a modified forage harvester is used to chop biomass crops such as switchgrass, miscanthus, hybrid poplar, and willow in the field. 


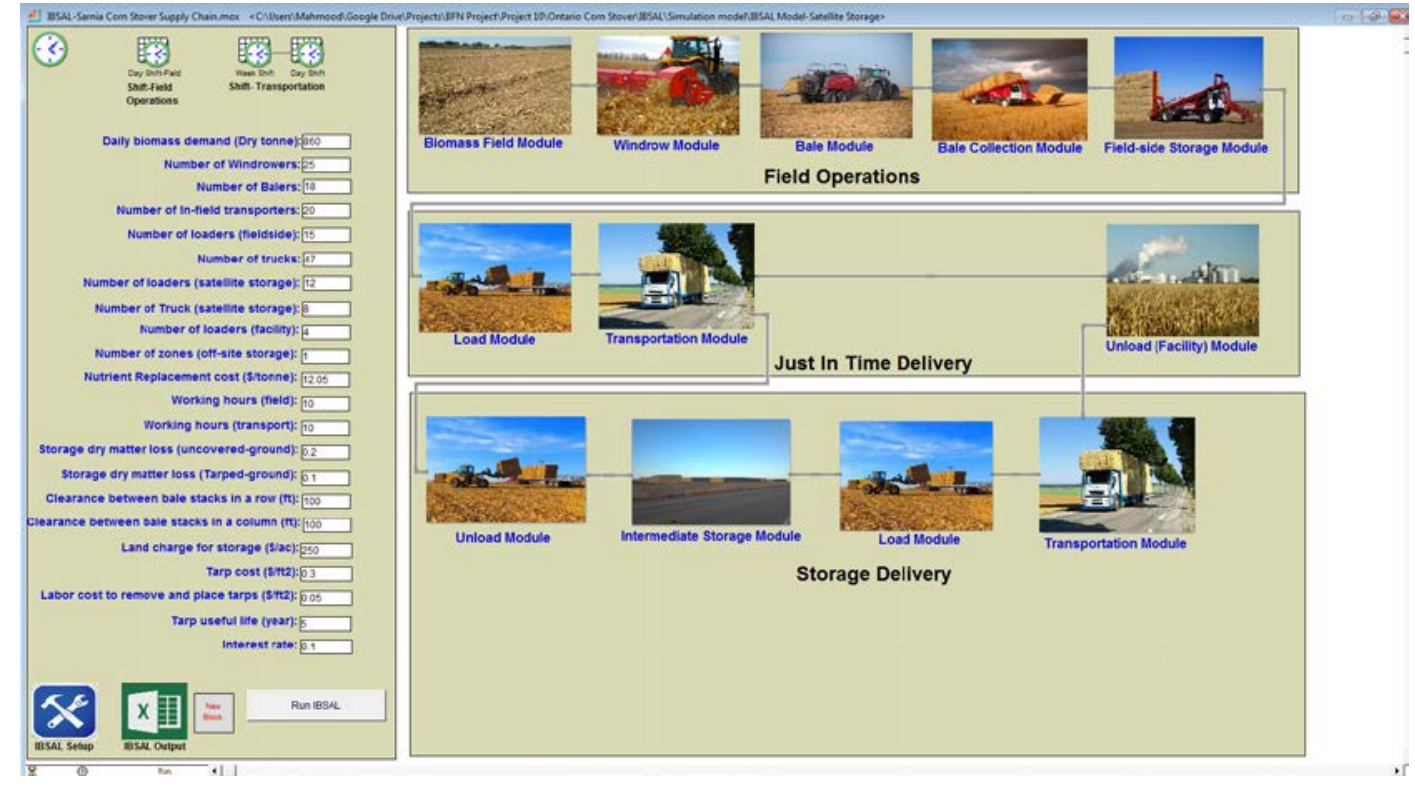

a) Baling scenario

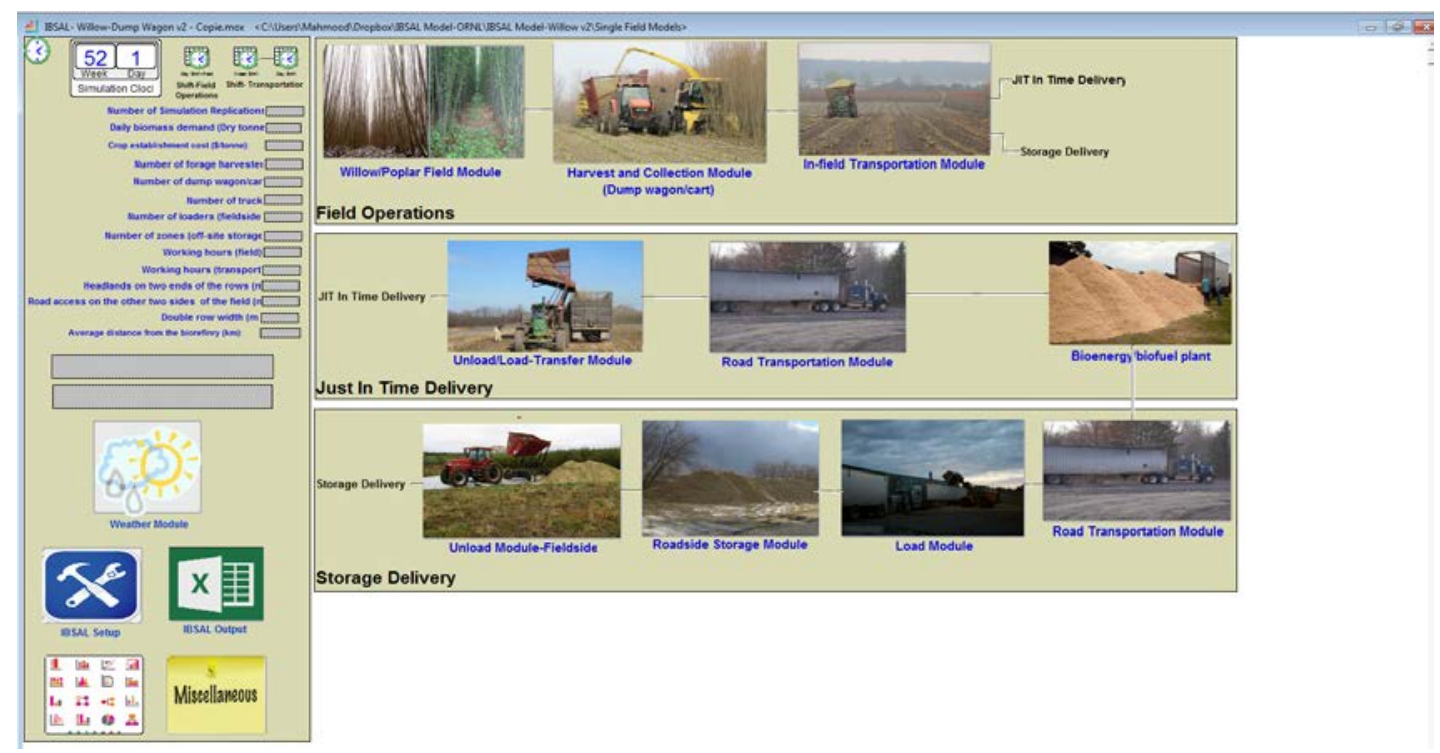

b) Chopping scenario

Figure 6. Simulated baseline a) baling and b) chopping logistics scenarios in the IBSAL model (Ebadian et al. 2017)

The required number of logistical machinery depends on the characteristics of the biorefinery. Table 4 lists these characteristics. Some of these characteristics vary from region to region because of differences in temporal and spatial conditions (Golecha and Gan 2015; Hess et al. 2009). Using large quantities of lignocellulosic biomass, such as corn stover for biofuel production, is a new industrial practice, and there are limited data available on the biorefinery characteristics, especially at the operational level. In this report, the team developed these characteristics based on the data available from the three pioneering cellulosic ethanol plants in the United States and the relevant literature. 
Table 4. General Profile of a Commercial-Scale Cellulosic Ethanol Plant Modeled in the IBSAL Model (Ebadian et al. 2017)

\begin{tabular}{|l|l|}
\hline Biorefinery Characteristic & Value \\
\hline Annual ethanol production capacity & 63 million gallons \\
\hline Conversion yield & 79 gallons/dry ton \\
\hline Annual biomass demand & 800,000 dry tons \\
\hline Operating days in a year & 330 days \\
\hline Daily biomass demand & 2,500 dry tons \\
\hline Supply radius & 50 miles \\
\hline $\begin{array}{l}\text { Farm participation rate (ratio of contracted acres to the total acres } \\
\text { in the supply radius) }\end{array}$ & $23 \%$ \\
\hline Average length of harvest season & $\begin{array}{l}75 \text { days for crop residues and } \\
110 \text { days for energy crops }\end{array}$ \\
\hline $\begin{array}{l}\text { Average number of days suitable for fieldwork within the harvest } \\
\text { season }\end{array}$ & 5 days/week \\
\hline Working hours in a day & 10 hours \\
\hline $\begin{array}{l}\text { Percentage of the total time to mobilize logistics equipment } \\
\text { between corn fields (unproductive time) }\end{array}$ & $20 \%$ \\
\hline $\begin{array}{l}\text { Maximum time that collected bales can be temporarily stored at the } \\
\text { roadside of fields }\end{array}$ & 2 months \\
\hline
\end{tabular}

Table 5 shows the required number of logistical machinery to supply biomass to a biorefinery with an annual biomass demand of 800,000 dry tons for baling and chopping scenarios, respectively. In a baling scenario, the total required number of logistical machinery is estimated to be 880 and 303 in the cases of corn stover and herbaceous biomass crops (i.e., miscanthus/switchgrass), respectively. Higher yield, a smaller supply area, a longer harvest window, and higher capacity of the harvester would result in fewer numbers of machinery in a case of herbaceous biomass crops compared with corn stover.

In a chopping scenario, the total required number of logistical machinery is estimated to be 361 and 320 in the cases of herbaceous biomass crops (i.e., miscanthus/switchgrass) and woody biomass crops (i.e., willow/poplar), respectively. Higher yield and a smaller supply area, along with higher capacity of the harvester, would result in fewer numbers of machinery in a case of woody biomass crops compared with herbaceous biomass crops. 
Table 5. Required Number of Logistical Machinery to Supply Biomass to a Biorefinery with an Annual Biomass Demand of 800,000 Dry Tons

\begin{tabular}{|c|c|c|}
\hline \multicolumn{3}{|l|}{ Baling Scenario } \\
\hline Machinery Type & Corn Stover & $\begin{array}{l}\text { Herbaceous Biomass Crops (i.e., } \\
\text { Miscanthus/Switchgrass) }\end{array}$ \\
\hline Shredder/windrowers & 150 & 9 \\
\hline $\begin{array}{l}\text { Round and square } \\
\text { balers }\end{array}$ & 120 & 58 \\
\hline $\begin{array}{l}\text { Bale } \\
\text { collector/stackers }\end{array}$ & $\begin{array}{l}120 \text { ( } 60 \text { self-propelled stinger stacker } \\
\text { and } 60 \text { wagons) }\end{array}$ & $\begin{array}{l}60 \text { (30 self-propelled stinger stacker } \\
\text { and } \\
30 \text { wagons) }\end{array}$ \\
\hline Loaders & 30 & 18 \\
\hline $\begin{array}{l}\text { Tractor trucks and } \\
\text { flatbed trailers }\end{array}$ & 130 (65 trucks and 65 trailers) & 70 (35 trucks and 35 trailers) \\
\hline Tractors & 330 & 88 \\
\hline Total & 880 & 303 \\
\hline \multicolumn{3}{|l|}{ Chopping Scenario } \\
\hline Machinery Type & $\begin{array}{l}\text { Herbaceous Biomass Crops (i.e., } \\
\text { Miscanthus/Switchgrass) }\end{array}$ & $\begin{array}{l}\text { Woody Biomass Crops (i.e., } \\
\text { Willow/Poplar) }\end{array}$ \\
\hline Forage harvester & 24 & 20 \\
\hline Dump wagons & 73 & 59 \\
\hline Silage/dump trucks & 48 & 39 \\
\hline Loaders & 15 & 15 \\
\hline $\begin{array}{l}\text { Chip trucks and } \\
\text { trailers }\end{array}$ & 128 (64 trucks and 64 chip trailers) & 128 (64 trucks and 64 chip trailers) \\
\hline Tractors & 73 & 59 \\
\hline Total & 361 & 320 \\
\hline
\end{tabular}

The total required number of field machinery depends on the lifetime of the biorefinery and the economic life of the equipment. The expected lifetime of the biorefinery is assumed to be 25 years (Ebadian et al. 2017). The economic life of a field machine is often less than the machine's service life, because most farmers and custom harvester groups trade a machine for a different one before it is completely worn out. The economic life depends on the annual use, the maintenance program, the salvage value, and the introduction of new technology or major design changes. The economic life of most farm machinery is 6-12 years and for tractors is 1215 years (Turhollow et al. 2009; Edwards 2015). In this report, it is assumed the economic life of farm machines and tractors are 8 years and 12 years, respectively. For transportation, each truck comprises two pieces of equipment: a semitrailer truck and a 53-foot flatbed trailer. To estimate the number of trucks and trailers and their economic values, it is assumed that the economic life of these machines is 10 years (Turhollow et al. 2009). 
Not all pieces of logistical machinery need to be manufactured. The 2012 U.S. Census of Agriculture conducted by the USDA (USDA 2014) shows that there is an existing 100+ horsepower tractor fleet size of over 1.1 million units (Table 6). Out of which, 0.2 million units were manufactured in the period of 2008-2012 and the rest were manufactured before 2008. The total required number of tractors in biomass supply chains to support the development of a sustainable bioeconomy in the United States is estimated to be in a range of $62,002-77,879$.

Table 6. Existing Agricultural Machinery Fleet in the United States (USDA 2014)

\begin{tabular}{|l|l|}
\hline Equipment Type & Number of Units \\
\hline $100+$ hp tractor & $\begin{array}{l}1.1 \text { million units, } 0.2 \text { million units manufactured in the period of 2008- } \\
2012 \text { and the rest before 2008 }\end{array}$ \\
\hline $\begin{array}{l}\text { Hay baler (small round and } \\
\text { square balers) }\end{array}$ & $\begin{array}{l}\text { More than } 0.7 \text { million units, 0.08 million units manufactured in the } \\
\text { period of } 2008-2012 \text { and the rest before 2008 }\end{array}$ \\
\hline Large square baler & 1,600 units \\
\hline $\begin{array}{l}\text { Self-propelled forage } \\
\text { harvester }\end{array}$ & $\begin{array}{l}72,389 \text { units, } 8,692 \text { units manufactured in the period of 2008-2012 and } \\
\text { the rest before } 2008\end{array}$ \\
\hline Truck fleet & $\begin{array}{l}3.3 \text { million units, more than 0.5 million units manufactured in the period } \\
\text { of 2008-2012 and the rest before 2008 }\end{array}$ \\
\hline
\end{tabular}

Figure 7 shows the maximum required number of logistical machinery over the lifetime of the potential future biorefineries. The maximum number is estimated based on the assumption that each biorefinery owns the machinery fleet in the biomass supply chain. However, farmers and custom harvester groups may manage a portion of, or the entire, biomass supply chain. Local farmers can use the harvest and collection equipment that is already used for harvesting hay or other biomass types, such as wheat straw, if there is no conflict in the harvest seasons. The custom harvester groups can usually mobilize their equipment across the country and provide service for more than one biorefinery depending on the location of the biorefinery, its proximity to other biorefineries, and the time and duration of the harvest season. However, both farmers and custom harvester groups require trained and skilled operators who are capable of operating in different field and climate conditions.

In addition, the current hay baler fleet exceeds 0.7 million units. About 0.08 million units were manufactured in the period of 2008-2012, and the rest were manufactured before 2008. Most of these balers are small round and square balers, which are more suitable for small-scale farm operations. Large square balers have been manufactured specifically for the biomass market to harvest high-tonnage biomass fields and to make large and dense bales in order to reduce the logistics costs. The market for large square balers is currently about 1,600 units (AGCO 2015). The total required number of large balers in biomass supply chains to support the development of a sustainable bioeconomy in the United States is estimated to be in a range of 32,98839,924 .

The estimated current fleet size of forage harvesters is more than 72,380 units, of which 8,692 units were manufactured in the period of 2008-2012, and the rest were manufactured before 2008. The total required number of balers in biomass supply chains is estimated to be between 
6,554 and 11,262. The 2012 U.S. Census of Agriculture also shows that there is a truck fleet size of 3.3 million units. More than 0.5 million units were manufactured in the period of 2008-2012, and the rest were manufactured before 2008. The total required number of tracker truck and flatbed trailers in biomass supply chains is estimated to be between 73,148 and 108,360 .

To our knowledge, there are no official publications on the existing fleet of flail chopper, selfpropelled windrowers, biomass collectors/stackers, dump wagons, silage trucks, and loaders in the United States. The manufacturing of these pieces of equipment has been ramped up as the new biomass markets are emerging. The existing fleet of agricultural machinery can meet a portion of the equipment demand created by future biorefineries and their suppliers. The use of the existing equipment fleet depends on their age, efficiency, and availability in the supply region, the introduction of new technology or major changes in the equipment design, the supply chain models of the biorefineries and their suppliers (e.g., ownership, leased, or rental), and feedstock specifications of biorefineries.

Figure 8 shows the total estimated fleet size of agricultural machinery to deliver 230 million340 million tons of corn stover and energy crops, including herbaceous crops (i.e., switchgrass and miscanthus) and woody crops (i.e., willow, poplar, and pine) to future biorefineries in short and long runs. This range is estimated based on the availability of biomass in short term and the potential increase in the production of biomass resources in the long term. The maximum number is estimated based on the assumption that each biorefinery owns the machinery fleet in the biomass supply chain. However, farmers and custom harvester groups may manage a portion of, or all of, the logistics equipment. Local farmers can use the harvest and collection equipment that they already own for harvesting hay or other biomass types, such as wheat straw, if there is no conflict in the harvest seasons. The custom harvester groups usually are able to mobilize their equipment across the country and provide service for more than one biorefinery, depending on the location of the biorefinery, its proximity to other biorefineries, and the time and duration of the harvest season. However, both farmers and custom harvester groups require trained and skilled operators who are capable of operating in different field and climate conditions. 


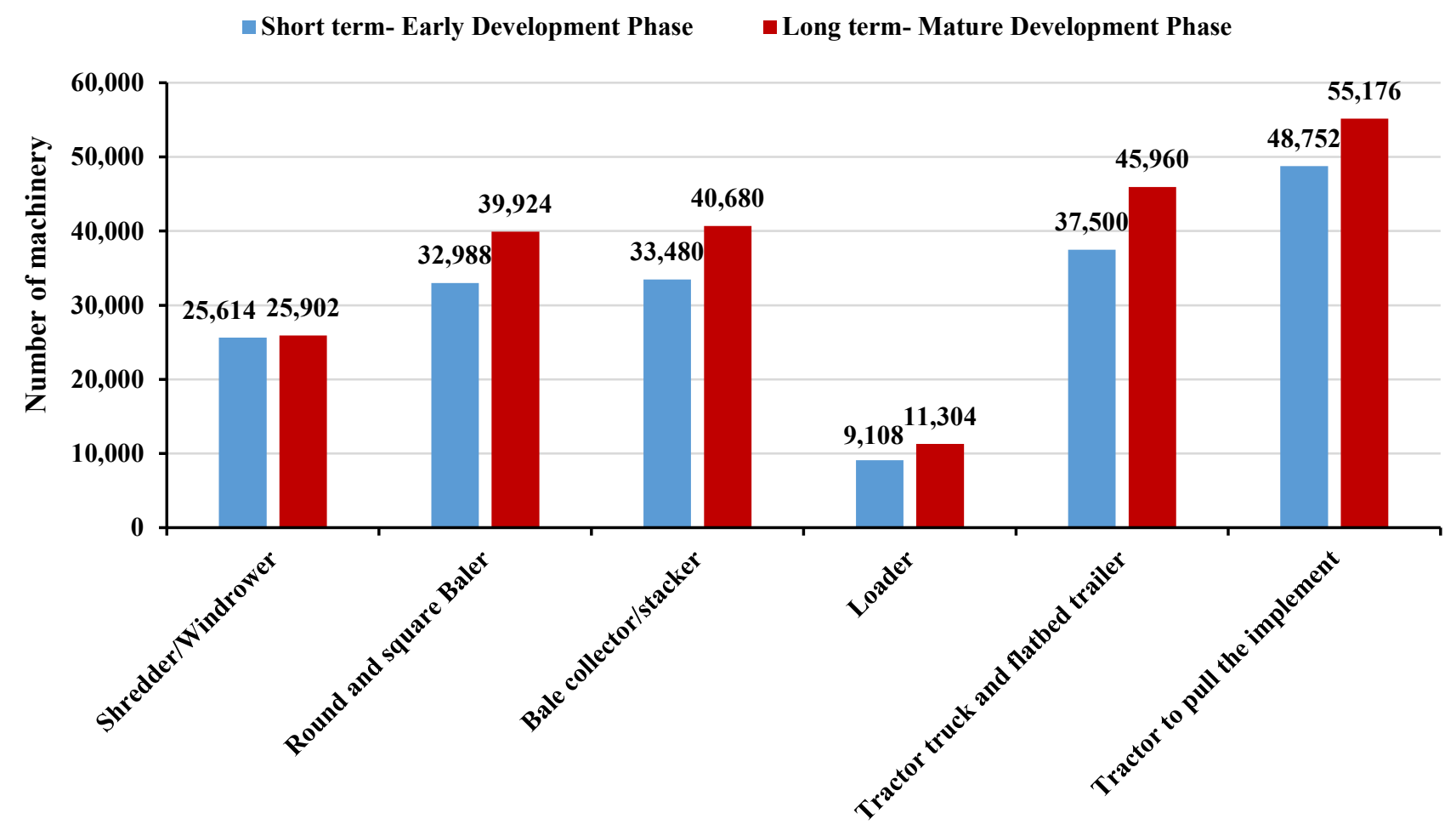

a) Baling scenario

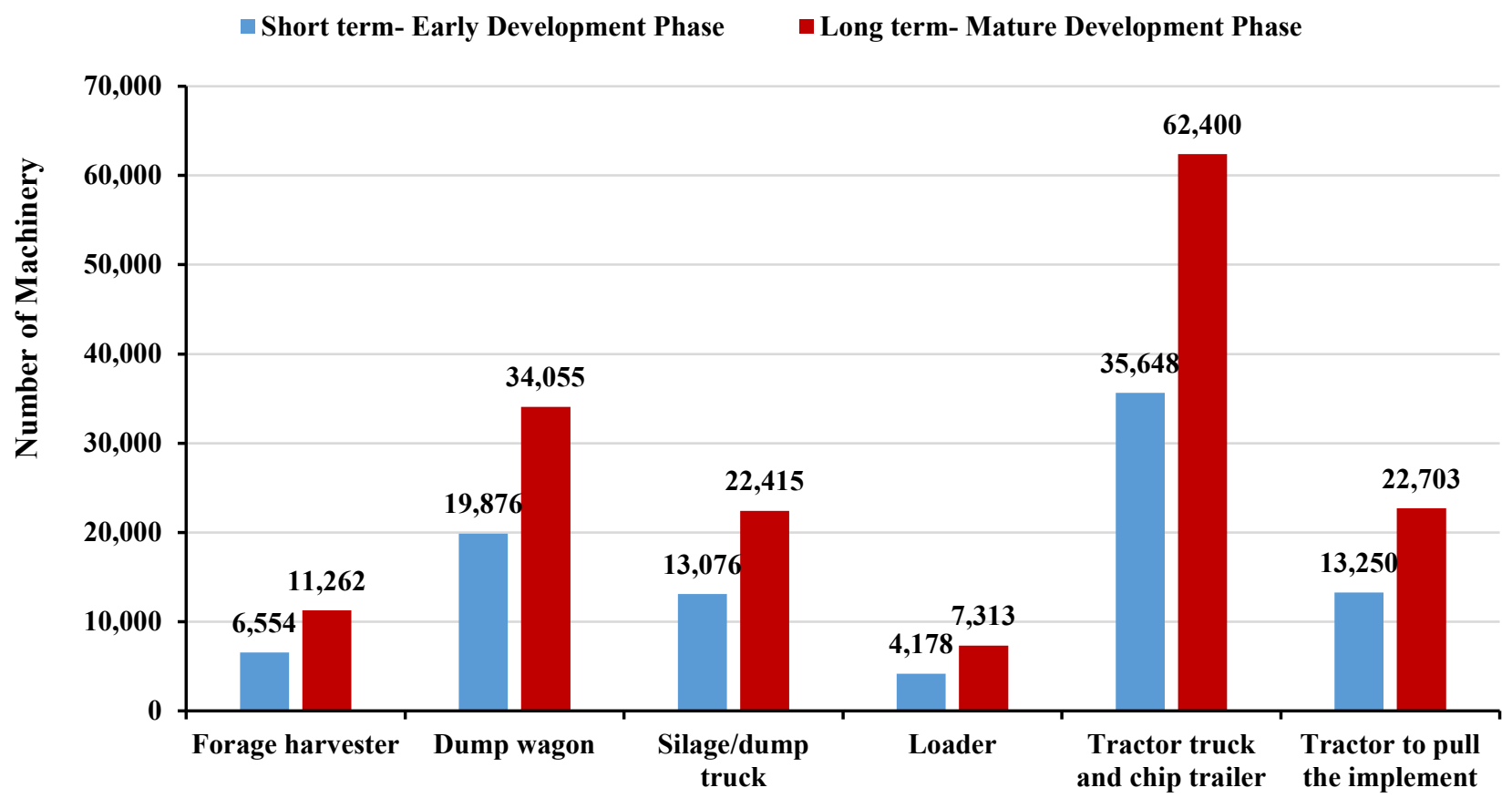

b) Chopping scenario

Figure 7. Estimated number of logistical machinery required to deliver $\mathbf{2 3 0}$ million-340 million tons of selected biomass resources to future biorefineries in short term and long term 
- Short term- Early Development Phase

- Long term- Mature Development Phase

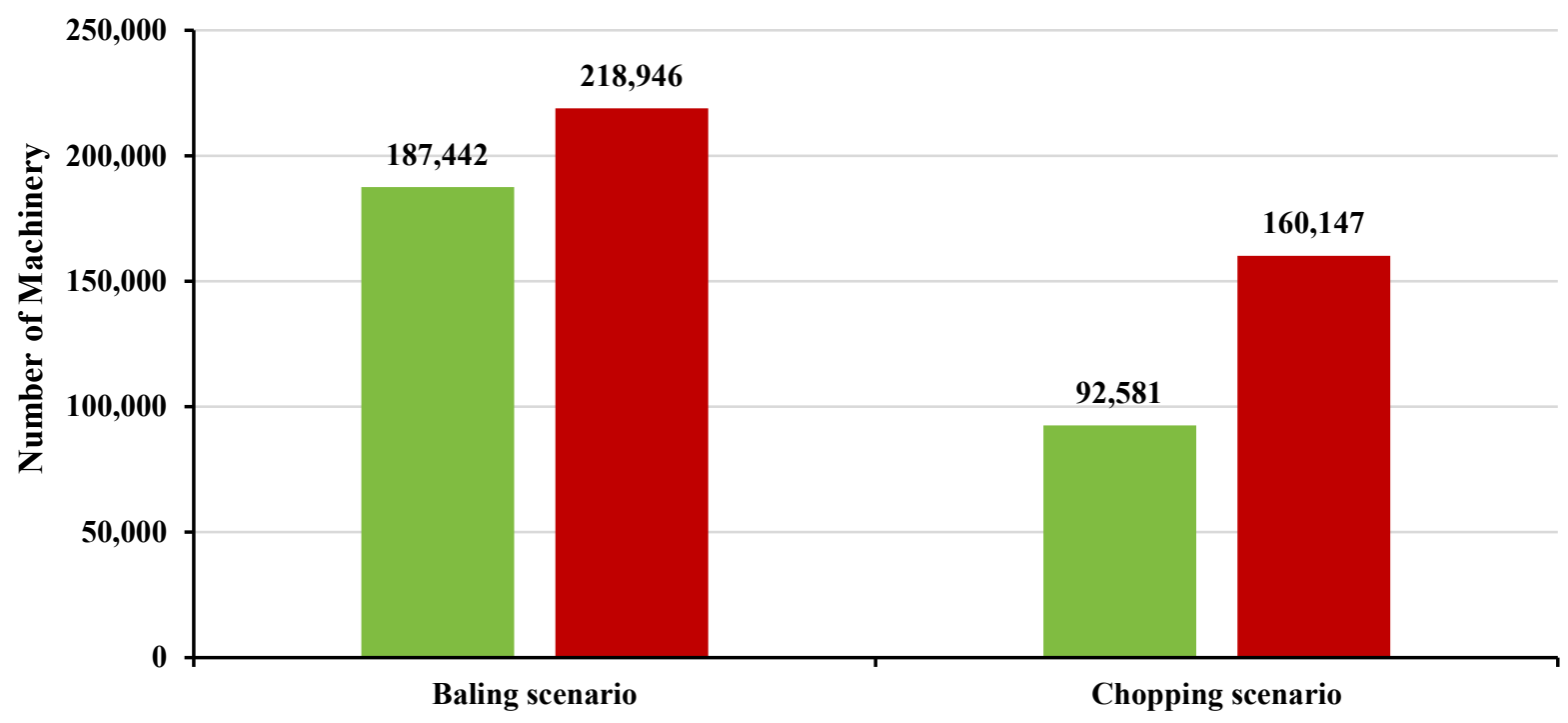

Figure 8. Total number of agricultural machinery in baling and chopping scenarios in short and long terms. In the short term, it is estimated that about 280,000 pieces of equipment would be required. This number is estimated to be about 380,000 pieces in the long term. 


\section{Equipment Requirements for a Baled Herbaceous System (Biochemical Conversion Pathway)}

\subsection{Process Description and Equipment Suppliers}

Flatbed trucks deliver large square bales and large round bales of corn stover to the staging area of the biorefinery. Upon arrival, low-profile truck scales weigh the trucks at the gate. Upon leaving, scales weigh the empty trucks to record the weight of delivered bales. Major suppliers of truck scales include: Fairbanks Scales, Cardinal Scale Manufacturing, Walz Scale, and Rice Lake. Forklifts or telehandlers equipped with bale clamps unload the bales from the trucks and stack them in piles or place them on the drag chain conveyors feeding the bale destackers (also called singulators). The inventory of bales at the plant is normally 3-5 days. There are four parallel lines, and each processes an average of 550 dry tons/day. Each line is depicted in the simplified block flow diagram (Figure 9). The rate-limiting equipment consists of the bale destacker and the continuous reactor plug screw feeder. Square bales and round bales are processed on lines specifically designed for them, because the destackers and destringers (for square bales) and the net-wrap remover (for round bales) are of different design. The square bales are placed two wide and three high on the conveyor feeding the bale destacker to reduce the number of trips between the bale staging area and the conveyors. Currently, no public information is found regarding automated destacking of large round bales on conveyors.

The bales are destacked and placed in a single line by the destacker. Suppliers of bale destackers include: West Salem Manufacturing (WSM), Vermeer, Hunterwood, and Kelderman, (note: not all commercial equipment suppliers are listed in this study). In-line moisture sensors (e.g., Gazeeka model 870) and load cells measure the moisture content and weight of each bale. If the moisture or the weight is higher than a target value set by the operator (which indicates the bale is either too wet or contains too much dirt and other heavy contaminants), a bale rejector (a hydraulic-driven bale pusher) pushes the rejected bale to a side conveyor and a forklift removes it to a bale reject area for further processing (e.g., letting the bale dry out or sold as feed roughage). 


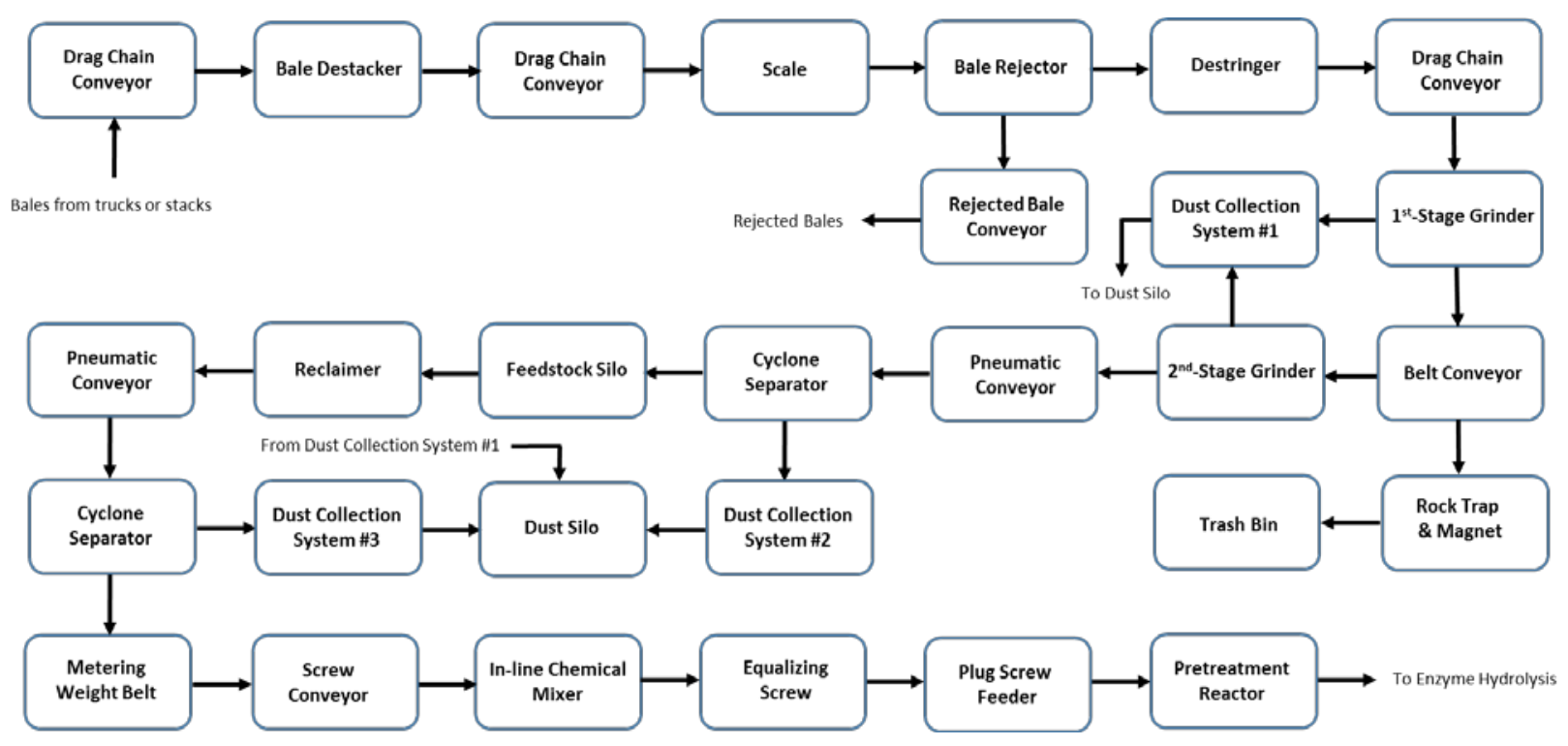

Figure 9. Baled herbaceous preprocessing system

The bales are conveyed, in a single line, from the destacker to the destringer or net-wrap remover where the strings and net wraps are removed and dropped into waste bins. The bales are then conveyed to the first-stage grinder. The bale strings and net wraps are either recycled or combusted in the biomass boiler (if it is available nearby). Several types of size reduction equipment can be used as the first-stage grinder: a drum chopper (WSM), a horizontal grinder (Vermeer, Rotochopper, Schutte Buffalo, Warren \& Baerg) or a tub grinder (Vermeer, Morbark). The two primary purposes of the first-stage size reduction are: (1) reducing the particle size to less than about 4 inches long to enable fine grinding in the second-stage size reduction and (2) loosening the bale structure sufficiently so that large contaminants such as rock and metal objects can be removed before second-stage grinding to minimize the potential for fire and explosion, because the dust level is generally higher there.

An alternative method for unloading large square bales, storing bales at the biorefinery, loading bales onto conveyors, and destacking bales is an automated crane system (Konecranes, Danish Crane Building A/S), commonly found in biomass power plants in Europe. Because large round bales are more common than large square bales in the United States, this project will not study the automated crane system for square bales.

The coarsely chopped/ground corn stover particles are generally conveyed, via a belt conveyor, into the inlet of the second-stage size reduction step. A rock trap and a magnet, located near the end of the belt conveyor discharge, remove large gravel, rock, and metal pieces, which are then diverted into a waste bin. The major suppliers of belt conveyors for biomass include: Andritz, Metso, KWS Manufacturing, FEECO International, and Kase Custom Conveyors.

Shredders and hammer mills are commonly for the second-stage size reduction. The major suppliers of industrial hammer mills and shredders for biomass include: Bliss Industries, Schutte Buffalo, Andritz Feed \& Biofuel, WSM, and PALLMANN Industries. Because it is critically important to obtain tight distribution of particle size of biomass feedstock, the type of 
equipment and operating protocol have a major impact on the quality of the feedstock. For CFSSs, the quality of the final feedstock is not actively managed. As a result, the properties of feedstock vary according to the varying properties of incoming biomass.

Milled biomass feedstock is pneumatically conveyed from the second-stage size reduction equipment into a surge bin. The surge bin generally has a storage capacity of several hours to dampen the effect of temporary process and equipment upsets upstream, as well as downstream, of the bin. At the bottom of the surge bin is a reclaimer that withdraws feedstock from the bin and conveys the material to the pretreatment reactor metering bin. Major suppliers of large feedstock storage bins and associated reclaimers include: Laidig, Andritz, Metso, KWS, and Terra Source Global.

To meet the requirement regarding airborne dust emission, dust collection systems capture dust generated from size reduction and pneumatic equipment. The dust from baghouse filters is conveyed into a dust storage bin for disposal. Major suppliers of dust collection and fire and dust explosion suppression systems include: Kice Industries, U.S. Air Filtration Inc., Boss Products America, and Fike.

Feedstock is automatically conveyed from the surge bin to the live bottom metering bin as needed. The metering bin is designed to evenly and precisely discharge feedstock across the bottom of the bin into a collection screw conveyor. The collection screw conveyor conveys the feedstock into the feed box of the pretreatment reactor plug screw feeder. There are many suppliers of metering bins; some of the well-known suppliers include: Andritz, Valmet, Kamengo, and Bulk Handling Systems. Suppliers of plug screw feeders and continuous steam pretreatment reactors include: Andritz, Valmet, AdvanceBio, and Refiner Manufacturing Products. For processes requiring the addition of chemical catalysts (e.g., acid or alkali), an inline continuous pug mill mixer is used before the plug screw feeder.

\subsection{Requirements from Equipment Manufacturers}

There are many equipment manufacturers who can supply all the equipment needed in the conventional feedstock supply and preprocessing systems, because equipment specifications and capacity required for biorefineries are similar to those used in forest products, the pulp and paper industry, and the agricultural sector. However, corn stover is one of the most difficult types of biomass to handle because of its heterogeneous composition (stalk, leaves, and pith) and variability in physical and mechanical properties. Equipment used in the wood pulp industry may not be suitable for handling bulky corn stover material. Pioneer biorefineries have lengthy startup periods with frequent plugging of equipment, low capacity, and a high rate of abrasive wear of equipment. Further, corn stover feedstock produced does not consistently meet the conversion specifications (e.g., high ash content, wide particle size distribution).

The key requirement from the equipment manufacturers is to design new equipment or modify the current design to provide reliable operation and produce feedstock that meets conversion specifications. This would require close collaboration among equipment manufacturers, conversion technology developers, and biorefinery operators. 


\subsection{Estimated Number of Equipment}

Table 7 lists the estimated number of major equipment and turnkey systems for baled herbaceous preprocessing system and leading equipment manufacturers. The number of equipment and parallel equipment trains are determined by the maximum capacity of the plug screw feeder (about 550 dry tons/day for milled herbaceous feedstock)

Table 7. Estimated Number of Major Equipment and Turnkey Systems for a Baled Herbaceous Preprocessing System (800,000 Dry Tons/Year per Biorefinery)

\begin{tabular}{|c|c|c|c|c|}
\hline Equipment & $\begin{array}{l}\text { Quantity per } \\
\text { Biorefinery }\end{array}$ & $\begin{array}{l}\text { Short-Term } \\
\text { Total } \\
\text { Quantity }\end{array}$ & $\begin{array}{l}\text { Long-Term } \\
\text { Total } \\
\text { Quantity }\end{array}$ & Leading Manufacturers \\
\hline Truck scale & 2 & 268 & 352 & $\begin{array}{l}\text { Fairbanks Scales, Cardinal Scale } \\
\text { Manufacturing, Walz Scale, Rice } \\
\text { Lake }\end{array}$ \\
\hline Telehandler & 4 & 536 & 704 & $\begin{array}{l}\text { Caterpillar, John Deere, Tigercat, } \\
\text { Komatsu }\end{array}$ \\
\hline Front-end loader & 2 & 268 & 352 & $\begin{array}{l}\text { Caterpillar, John Deere, Tigercat, } \\
\text { Komatsu }\end{array}$ \\
\hline Bale destacker & 4 & 536 & 704 & $\begin{array}{l}\text { WSM, Hunterwood, Vermeer, } \\
\text { Konecranes, Kelderman }\end{array}$ \\
\hline $\begin{array}{l}\text { Drag chain } \\
\text { conveyor }\end{array}$ & 9 & 1,206 & 1,584 & $\begin{array}{l}\text { Andritz, Hapman, CDM Systems, } \\
\text { Conveyor Systems \& Engineering, } \\
\text { Warren \& Baerg, Screw Conveyor } \\
\text { Corp. (SCC) }\end{array}$ \\
\hline Destringer & 4 & 536 & 704 & WSM, Vermeer, Warren \& Baerg \\
\hline Grinder & 8 & 1,072 & 1,408 & $\begin{array}{l}\text { Vermeer, Rotochopper, Warren \& } \\
\text { Baerg, Morbark, Bliss Industries, } \\
\text { Schutte Buffalo, Andritz, WSM, } \\
\text { Valmet, PALLMANN Industries, } \\
\text { Balemaster }\end{array}$ \\
\hline $\begin{array}{l}\text { Dust collection } \\
\text { system }\end{array}$ & 12 & 1,608 & 2,112 & $\begin{array}{l}\text { Kice Industries, Process Barron, } \\
\text { U.S. Air Filtration Inc., Camfil Air } \\
\text { Pollution Control, Schenk Process }\end{array}$ \\
\hline $\begin{array}{l}\text { Fire and dust } \\
\text { explosion } \\
\text { suppression }\end{array}$ & 12 & 1,608 & 2,112 & $\begin{array}{l}\text { Kice Industries, U.S. Air Filtration } \\
\text { Inc., Boss Products America, Fike }\end{array}$ \\
\hline $\begin{array}{l}\text { Pneumatic } \\
\text { conveyor }\end{array}$ & 8 & 1,072 & 1,408 & $\begin{array}{l}\text { Dynamic Air, Schenk Process, } \\
\text { Flexicon }\end{array}$ \\
\hline Cyclone separator & 8 & 1,072 & 1,408 & $\begin{array}{l}\text { Kice Industries, U.S. Air Filtration } \\
\text { Inc. }\end{array}$ \\
\hline
\end{tabular}




\begin{tabular}{|l|l|l|l|l|}
\hline Equipment & $\begin{array}{l}\text { Quantity per } \\
\text { Biorefinery }\end{array}$ & $\begin{array}{l}\text { Short-Term } \\
\text { Total } \\
\text { Quantity }\end{array}$ & $\begin{array}{l}\text { Long-Term } \\
\text { Total } \\
\text { Quantity }\end{array}$ & Leading Manufacturers \\
\hline Belt conveyor & 4 & 536 & 704 & $\begin{array}{l}\text { Andritz, Metso, KWS } \\
\text { Manufacturing, FEECO } \\
\text { International, Kase Custom } \\
\text { Conveyors }\end{array}$ \\
\hline Feedstock silo & 4 & 536 & 704 & $\begin{array}{l}\text { Laidig, Andritz, Valmet, KWS, Terra } \\
\text { Source Global }\end{array}$ \\
\hline $\begin{array}{l}\text { Feedstock } \\
\text { reclaimer }\end{array}$ & 4 & 536 & 704 & $\begin{array}{l}\text { Laidig, Andritz, Valmet, KWS, Terra } \\
\text { Source Global }\end{array}$ \\
\hline Dust silo & 1 & 134 & 176 & $\begin{array}{l}\text { Laidig, Andritz, Valmet, KWS, Terra } \\
\text { Source Global }\end{array}$ \\
\hline $\begin{array}{l}\text { Metering weight } \\
\text { belt }\end{array}$ & 4 & 536 & 704 & $\begin{array}{l}\text { Balemaster, Coperion K-Tron, } \\
\text { Acrison, Thayer, Merrick, Bulk Pro } \\
\text { Systems }\end{array}$ \\
\hline Screw conveyor & 8 & 1,072 & 1,408 & $\begin{array}{l}\text { Martin Sprocket, KWS, SCC, } \\
\text { Conveyor Engineering \& } \\
\text { Manufacturing }\end{array}$ \\
\hline Plug screw feeder & 8 & 1,072 & 1,408 & $\begin{array}{l}\text { Andritz, Valmet, Material Science } \\
\text { Technology (MST), AdvanceBio, } \\
\text { Refiner Products Manufacturing } \\
\text { (RPM) }\end{array}$ \\
\hline
\end{tabular}




\section{Equipment Requirements for Chopped Herbaceous System (Biochemical Conversion Pathway)}

\subsection{Process Description and Equipment Suppliers}

In general, an ensiled storage will be utilized to minimize loss as a result of microbial degradation and fire. If the chopped biomass has moisture content lower than about $40 \%$, water will be added so the material can be compacted to reduce storage volume and then effectively ensiled. Ensiled storage of herbaceous biomass has been practiced in the animal feed industry for many years; therefore, equipment and skilled operators are generally available near the biomass growing areas. Figure 10 shows the block flow diagram of a typical large-scale feedstock preprocessing system utilizing ensiled storage.

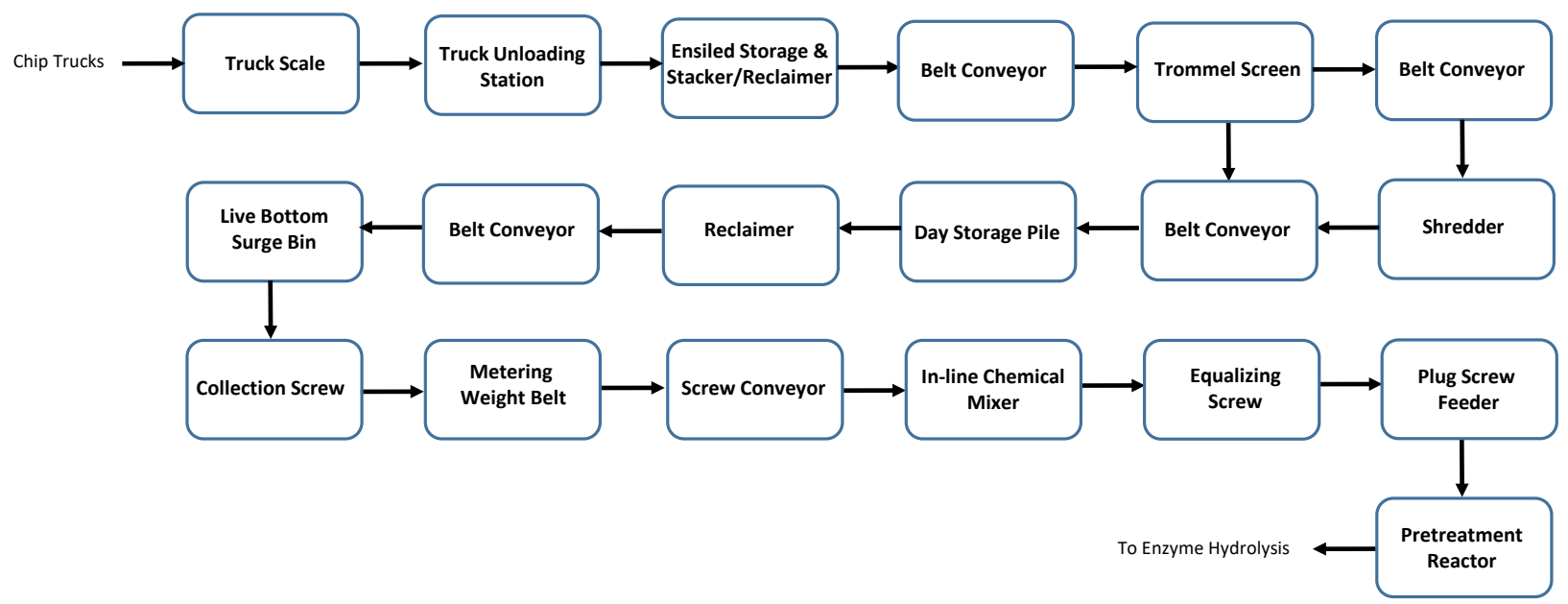

Figure 10. Chopped herbaceous preprocessing system

Field chopped herbaceous materials (e.g., miscanthus, switchgrass, and biomass sorghum) are delivered to biorefineries or feedstock preprocessing depots adjacent to a biorefinery. Truck scales weigh the trucks upon arrival and after the biomass has been unloaded. Truck dumpers or tippers quickly unload the chopped biomass from the trucks. Ensiled storage piles are built using stackers and front-end loaders and compacted using compacting tractors. The piles are covered with tarps. Major suppliers of storage pile management systems include: Andritz, Bruks, and Valmet. These suppliers can offer turnkey systems from biomass receiving to feedstock conveyed into the biorefinery. Chopped biomass are reclaimed from large ensiled storage piles and screened to remove contaminants. Major suppliers of trommel screens include: WSM, Vermeer, Peterson, CP Manufacturing, Morbark, and Kraus Manufacturing. Oversized biomass particles are size-reduced using shredders or choppers. The on-specs materials from the screens and the shredded materials are then combined and conveyed to a day storage pile. If field chopped material meets the required feedstock quality, screening and shredding operations are not required. A reclaimer transfers feedstock from the day pile onto a belt conveyor (or similar equipment), which conveys the material into the live bottom surge bin. The live bottom discharges feedstock evenly across the bin bottom into a collection screw that feeds the metering weight belt. The pretreatment reactor feeder is of the same design as the unit for the baled herbaceous system. 


\subsection{Requirements from Equipment Manufacturers}

Similar to the baled herbaceous system, there are many equipment manufacturers that can supply all the equipment needed in the conventional feedstock supply and preprocessing systems for the chopped herbaceous system. Manufacturers of the stacker and reclaimer for large ensiled storage pile may have to modify the design of the equipment to handle herbaceous materials, because conventional equipment designed for handling wood chips may not work as well.

\subsection{Estimated Number of Equipment}

Table 8 lists the estimated number of equipment and turnkey systems for chopped herbaceous preprocessing systems and leading equipment manufacturers.

Table 8. Estimated Number of Major Equipment and Turnkey Systems for Chopped Herbaceous Preprocessing Systems (800,000 Dry Tons/Year per Biorefinery)

\begin{tabular}{|l|l|l|l|l|}
\hline Equipment & $\begin{array}{l}\text { Qty per } \\
\text { Biorefinery }\end{array}$ & $\begin{array}{l}\text { Short-Term } \\
\text { Total Quantity }\end{array}$ & $\begin{array}{l}\text { Long-Term } \\
\text { Total Quantity }\end{array}$ & Leading Manufacturers \\
\hline Truck scale & 2 & 164 & 252 & $\begin{array}{l}\text { Fairbanks Scales, Cardinal } \\
\text { Scale Manufacturing, Walz } \\
\text { Scale, Rice Lake }\end{array}$ \\
\hline Front-end loader & 2 & 164 & 252 & $\begin{array}{l}\text { Caterpillar, John Deere, } \\
\text { Tigercat, Komatsu }\end{array}$ \\
\hline $\begin{array}{l}\text { Pile compactor } \\
\text { Truck unloading } \\
\text { system }\end{array}$ & 4 & 328 & 504 & $\begin{array}{l}\text { Caterpillar, John Deere, } \\
\text { Tigercat, Komatsu }\end{array}$ \\
\hline $\begin{array}{l}\text { Ensiled storage } \\
\text { and stackerl } \\
\text { reclaimer }\end{array}$ & 2 & 164 & 252 & $\begin{array}{l}\text { Andritz, Valmet, Bruks, Terra } \\
\text { Source Global }\end{array}$ \\
\hline Belt conveyor & 16 & 164 & 252 & $\begin{array}{l}\text { Andritz, Valmet, Bruks, Terra } \\
\text { Source Global }\end{array}$ \\
\hline $\begin{array}{l}\text { Trommel screen } \\
\text { Shredder }\end{array}$ & 4 & 1,312 & 2,016 & $\begin{array}{l}\text { Andritz, Metso, KWS } \\
\text { Manufacturing, FEECO } \\
\text { International, Kase Custom } \\
\text { Conveyors }\end{array}$ \\
\hline
\end{tabular}




\begin{tabular}{|l|l|l|l|l|}
\hline Equipment & $\begin{array}{l}\text { Qty per } \\
\text { Biorefinery }\end{array}$ & $\begin{array}{l}\text { Short-Term } \\
\text { Total Quantity }\end{array}$ & $\begin{array}{l}\text { Long-Term } \\
\text { Total Quantity }\end{array}$ & Leading Manufacturers \\
\hline $\begin{array}{l}\text { Live bottom } \\
\text { surge bin }\end{array}$ & 4 & 328 & 504 & $\begin{array}{l}\text { Laidig, Andritz, Valmet, KWS, } \\
\text { Terra Source Global, } \\
\text { Kamengo }\end{array}$ \\
\hline Screw conveyor & 12 & 984 & 1,512 & $\begin{array}{l}\text { Martin Sprocket, KWS, SCC, } \\
\text { Conveyor Engineering \& } \\
\text { Manufacturing }\end{array}$ \\
\hline $\begin{array}{l}\text { Metering weight } \\
\text { belt }\end{array}$ & 4 & 328 & 504 & $\begin{array}{l}\text { Balemaster, Coperion K-Tron, } \\
\text { Acrison, Thayer, Merrick, Bulk } \\
\text { Pro Systems }\end{array}$ \\
\hline Plug screw feeder & 4 & 328 & 504 & $\begin{array}{l}\text { Andritz, Valmet, MST, } \\
\text { AdvanceBio, RPM }\end{array}$ \\
\hline
\end{tabular}




\section{Equipment Requirements for Chopped Woody Biomass System (Thermochemical Conversion Pathway)}

\subsection{Process Description and Equipment Suppliers}

This preprocessing system is similar to the chopped herbaceous system described above, except for the following differences:

- Pile storage does not involve ensiling, because the biomass does not degrade significantly under normal pile storage conditions (similar to storing chips in the pulp mills or biomass power plants).

- Grinding and drying unit operations are added to produce small particle-sized and lowmoisture feedstock.

Figure 11 shows the block flow diagram of a typical large-scale feedstock preprocessing system for chopped woody biomass. Scales weigh the chip trucks, and the chips are then dumped into the receiver of the stacker, which conveys the chips onto the piles. The reclaimer transfers wood chips from the storage piles into the first-stage grinders. The chips are dried in rotary dryers and then milled in the second-stage grinders to produce chips that meet the specified particle size (2-6 mm) and moisture (10\%) specifications (Jones et al. 2013). The feedstock is stored in silos. The pyrolyzer feeding system is similar to that of the chopped herbaceous system, except that there is no in-line chemical mixer. Depending on the operating pressure of the pyrolyzer, the feeder design may need modifications.

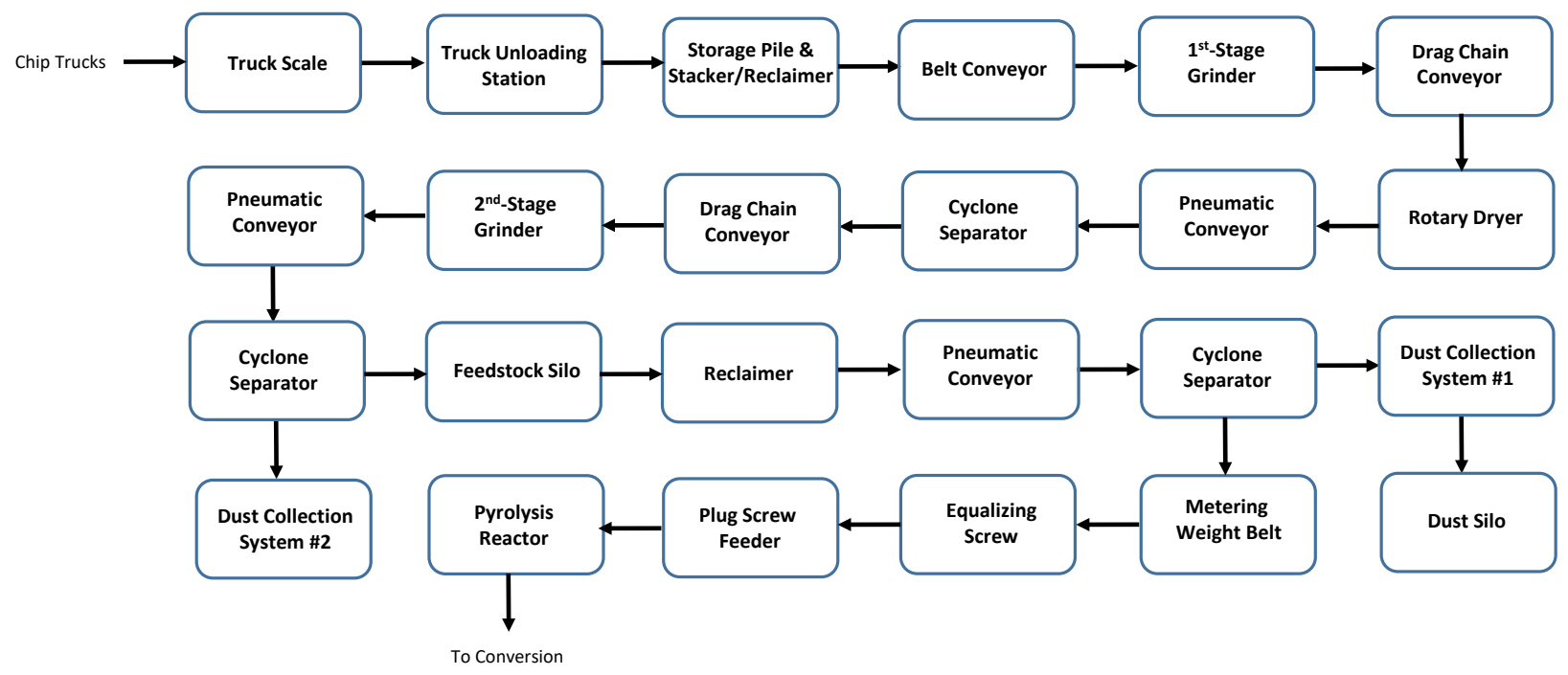

Figure 11. Chopped woody biomass preprocessing system

\subsection{Requirements from Equipment Manufacturers}

Much of the equipment used in the chopped woody preprocessing system is similar to that used in wood pellet production plants. The only piece of custom design equipment is the 
pyrolyzer feeder, which requires collaboration between the technology developer and the feeder fabricator to design and build reliable feeders.

\subsection{Estimated Number of Equipment}

Table 9 lists the estimated number of major equipment and turnkey systems for chopped woody biomass preprocessing systems and leading equipment manufacturers. The number of equipment and parallel equipment trains is determined by the maximum capacity of the plug screw feeder (about 550 dry tons/day for $<1 / 4$ inch milled woody feedstock).

Table 9. Estimated Number of Major Equipment and Turnkey Systems for Chopped Woody Biomass Preprocessing Systems (800,000 Dry Tons/Year per Biorefinery)

\begin{tabular}{|c|c|c|c|c|}
\hline Equipment & $\begin{array}{l}\text { Quantity per } \\
\text { Biorefinery }\end{array}$ & $\begin{array}{l}\text { Short-Term } \\
\text { Total Quantity }\end{array}$ & $\begin{array}{l}\text { Long-Term } \\
\text { Total Quantity }\end{array}$ & Leading Manufacturers \\
\hline Truck scale & 2 & 48 & 112 & $\begin{array}{l}\text { Fairbanks Scales, Cardinal } \\
\text { Scale Manufacturing, Walz } \\
\text { Scale, Rice Lake }\end{array}$ \\
\hline Front-end loader & 2 & 48 & 112 & $\begin{array}{l}\text { Caterpillar, John Deere, } \\
\text { Tigercat, Komatsu }\end{array}$ \\
\hline $\begin{array}{l}\text { Truck unloading } \\
\text { system }\end{array}$ & 2 & 48 & 112 & $\begin{array}{l}\text { Andritz, Valmet, Bruks, Terra } \\
\text { Source Global }\end{array}$ \\
\hline $\begin{array}{l}\text { Storage and } \\
\text { stacker/reclaimer } \\
\text { system }\end{array}$ & 2 & 48 & 112 & $\begin{array}{l}\text { Andritz, Valmet, Bruks, Terra } \\
\text { Source Global }\end{array}$ \\
\hline Belt conveyor & 4 & 96 & 224 & $\begin{array}{l}\text { Andritz, Metso, KWS } \\
\text { Manufacturing, FEECO } \\
\text { International, Kase Custom } \\
\text { Conveyors }\end{array}$ \\
\hline Grinder & 8 & 192 & 448 & $\begin{array}{l}\text { WSM, Vermeer, Morbark, } \\
\text { Warren \& Baerg, Krause } \\
\text { Manufacturing }\end{array}$ \\
\hline $\begin{array}{l}\text { Drag chain } \\
\text { conveyor }\end{array}$ & 8 & 192 & 448 & $\begin{array}{l}\text { Vermeer, Rotochopper, } \\
\text { Warren \& Baerg, Morbark, } \\
\text { Bliss Industries, Schutte } \\
\text { Buffalo, Andritz, WSM, Valmet, } \\
\text { PALLMANN Industries }\end{array}$ \\
\hline Rotary dryer & 4 & 96 & 224 & $\begin{array}{l}\text { Baker-Rullman, FEECO } \\
\text { International, Thompson } \\
\text { Dryers, Onix, ICM }\end{array}$ \\
\hline $\begin{array}{l}\text { Storage silo } \\
\text { and reclaimer }\end{array}$ & 4 & 96 & 224 & $\begin{array}{l}\text { Andritz, Valmet, Bruks, Terra } \\
\text { Source Global }\end{array}$ \\
\hline $\begin{array}{l}\text { Pneumatic } \\
\text { conveyor }\end{array}$ & 12 & 288 & 672 & $\begin{array}{l}\text { Dynamic Air, Schenk Process, } \\
\text { Flexicon }\end{array}$ \\
\hline
\end{tabular}




\begin{tabular}{|l|l|l|l|l|}
\hline Equipment & $\begin{array}{l}\text { Quantity per } \\
\text { Biorefinery }\end{array}$ & $\begin{array}{l}\text { Short-Term } \\
\text { Total Quantity }\end{array}$ & $\begin{array}{l}\text { Long-Term } \\
\text { Total Quantity }\end{array}$ & Leading Manufacturers \\
\hline $\begin{array}{l}\text { Dust collection } \\
\text { system }\end{array}$ & 8 & 192 & 448 & $\begin{array}{l}\text { Kice Industries, Process } \\
\text { Barron, U.S. Air Filtration Inc., } \\
\text { Camfil Air Pollution Control, } \\
\text { Schenk Process }\end{array}$ \\
\hline $\begin{array}{l}\text { Dust silo } \\
\text { Fire and dust } \\
\text { explosion } \\
\text { suppression } \\
\text { system }\end{array}$ & 1 & 24 & 56 & $\begin{array}{l}\text { Laidig, Andritz, Valmet, KWS, } \\
\text { Terra Source Global }\end{array}$ \\
\hline $\begin{array}{l}\text { Screw conveyor } \\
\text { Setering weight }\end{array}$ & 4 & 192 & 448 & $\begin{array}{l}\text { Kice Industries, U.S. Air } \\
\text { Filtration Inc., Boss Products } \\
\text { America, Fike }\end{array}$ \\
\hline $\begin{array}{l}\text { Meth } \\
\text { belt }\end{array}$ & 4 & 96 & 224 & $\begin{array}{l}\text { Martin Sprocket, KWS, SCC, } \\
\text { Conveyor Engineering \& } \\
\text { Manufacturing }\end{array}$ \\
\hline $\begin{array}{l}\text { Plug screw } \\
\text { feeder }\end{array}$ & 4 & 96 & 224 & $\begin{array}{l}\text { Balemaster, Coperion K-Tron, } \\
\text { Acrison, Thayer, Merrick, Bulk } \\
\text { Pro Systems }\end{array}$ \\
\hline
\end{tabular}




\section{Economic Impact of Agricultural Machinery Manufacturing to Support Feedstock Supply for a Large-Scale Biofuel and Bioproducts Industry}

\subsection{U.S. Farm Equipment Inventory Value}

After real estate, farm equipment is the second-largest asset class on the farm sector's balance sheet, totaling \$244 billion at the end of 2012 (USDA 2014, Table 47). During periods of prosperity, U.S. farmers typically increase their investments in farm equipment. From 2002 to 2012 , net cash farm incomes increased by $166 \%$. U.S. Census of Agriculture data indicate the total market value of the inventory of U.S. farm equipment grew by $79 \%$, from $\$ 107$ billion in 2002 to $\$ 244$ billion in 2012 (Figure 12). Although substantial, this increase is less than the 93\% rise in inventory values that occurred from 1974 to 1982, another period of farm prosperity. During the farm recession that followed 1982, farm inventory values fell as farmer investment waned and existing inventory lost value (USDA 2014; Koenig 2016).

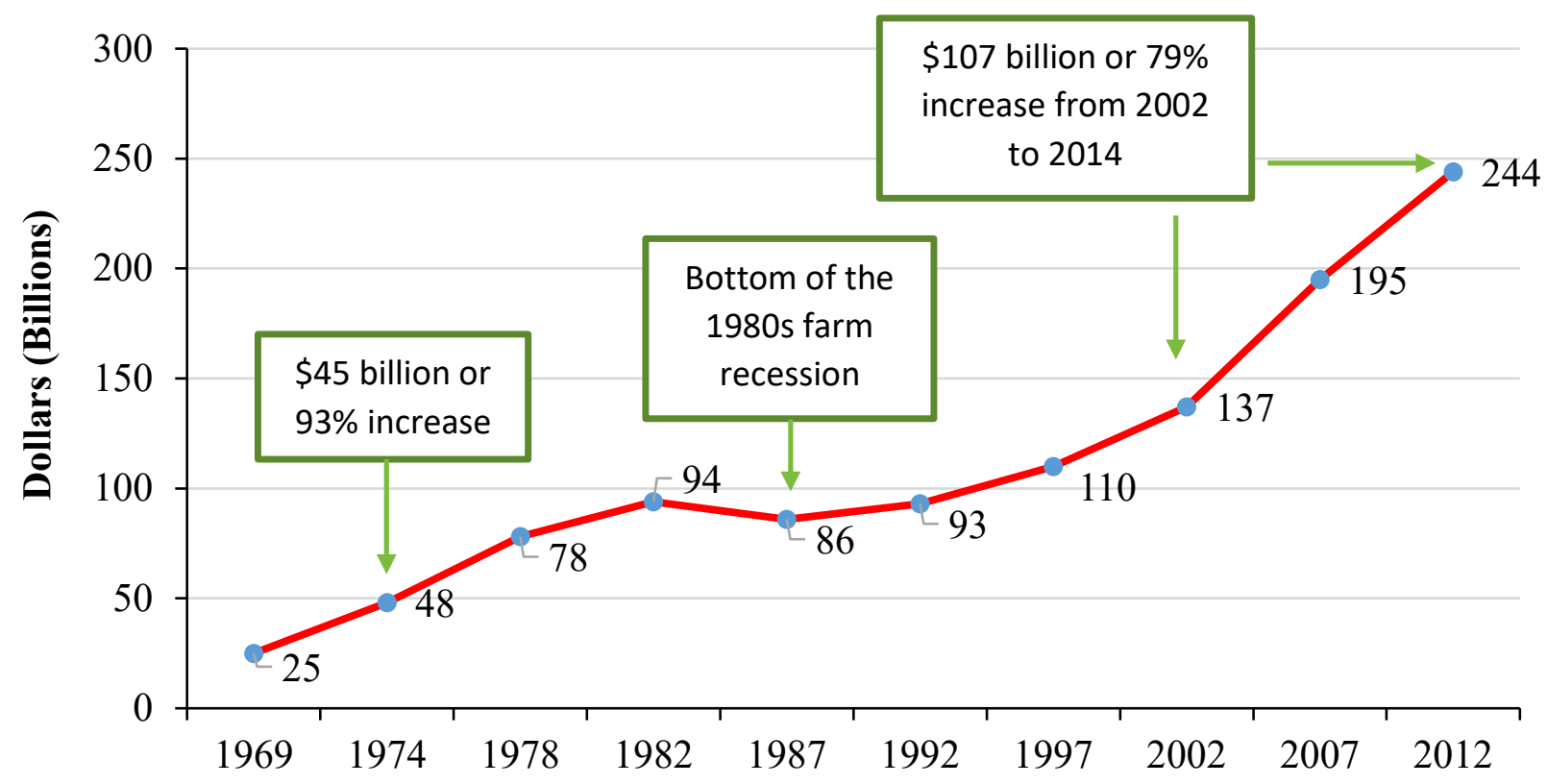

Census of Agriculture Year

Figure 12. U.S. farm equipment inventory value trend (Farm Credit Administration/Office of Regulatory Policy, data compiled from the 2012 U.S. Census of Agriculture 2014; Koenig 2016). Farm equipment includes tractors, trucks, harvesting equipment, implements, irrigation systems, milking equipment, and similar investments used in the production of food and fiber.

Regardless of what portions of equipment demand are met through the existing fleet and the brand-new fleet, the utilization of this large number of logistics equipment will create jobs and wealth in the upstream of the bioeconomy.

At the end of 2012, two-thirds of the $\$ 244$ billion in equipment inventory was located on crop farms, and one-third was located on livestock farms. Figure 13 shows that farms where grains 
and oilseeds are the primary enterprises accounted for $46 \%$ of the total equipment value in 2012. Grain and oilseed farms have even higher shares of the inventory of higher powered farm tractors and self-propelled combines. At the end of 2012, these farms accounted for $54 \%$ of all farm tractors, with at least $100 \mathrm{hp}$ and $75 \%$ of all self-propelled combines. Therefore, much of the variability in the demand, supply, and values of farm equipment is tied closely to the economics of the major crop enterprises (Koenig 2016).

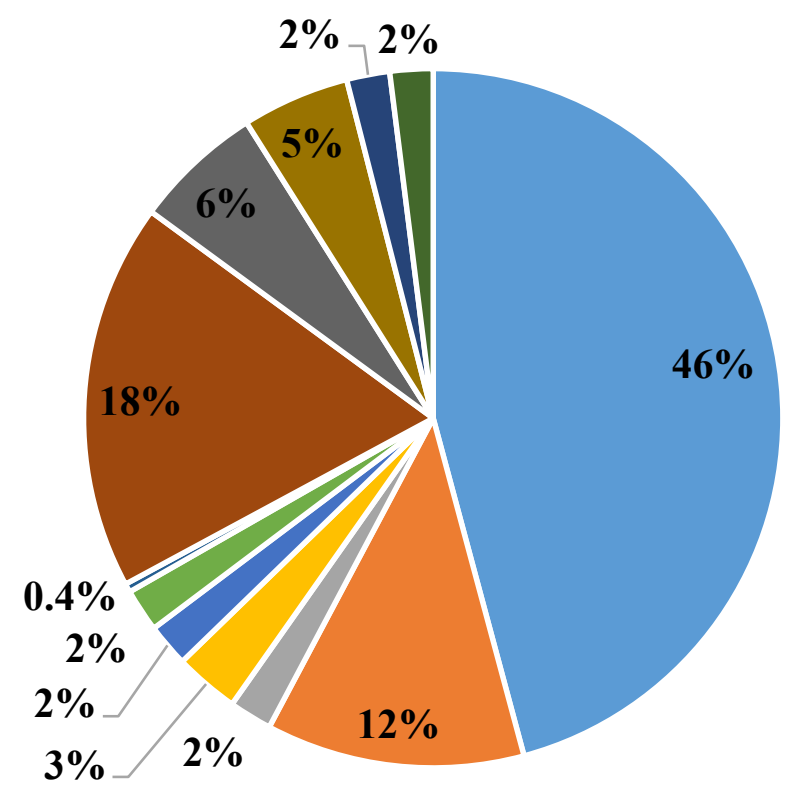

- Oilseed and Grains

- All Other Field Crops

- Vegetable \& Mellons

$\because$ Fruit \& Tree Nuts

- Greenhouse, Nursery, \&

Floriculture

- Cotton

- Tobacco

- Cattle

- Dairy

- All Other Animal Production

- Hogs

- Poultry \& Eggs

Figure 13. Farm equipment inventory value based on farm type. Inventory value is greatest on grain and oilseed farms, nearly half of the total farm equipment value (Farm Credit Administration/Office of Regulatory Policy, data compiled from the 2012 U.S. Census of Agriculture 2014; Koenig 2016). As expected from the predominate location of oilseed and grain farms, the total inventory value of farm equipment was concentrated in Midwestern states in 2012 (Figure 14).

Table 10 shows that more than half of the total U.S. farm equipment inventory value was in just 10 states. California is the only state in the top 10 that is outside the Midwest. lowa and Illinois, the two top corn and soybean producing states, together accounted for more than $14 \%$ of the U.S. total (Koenig 2016). 


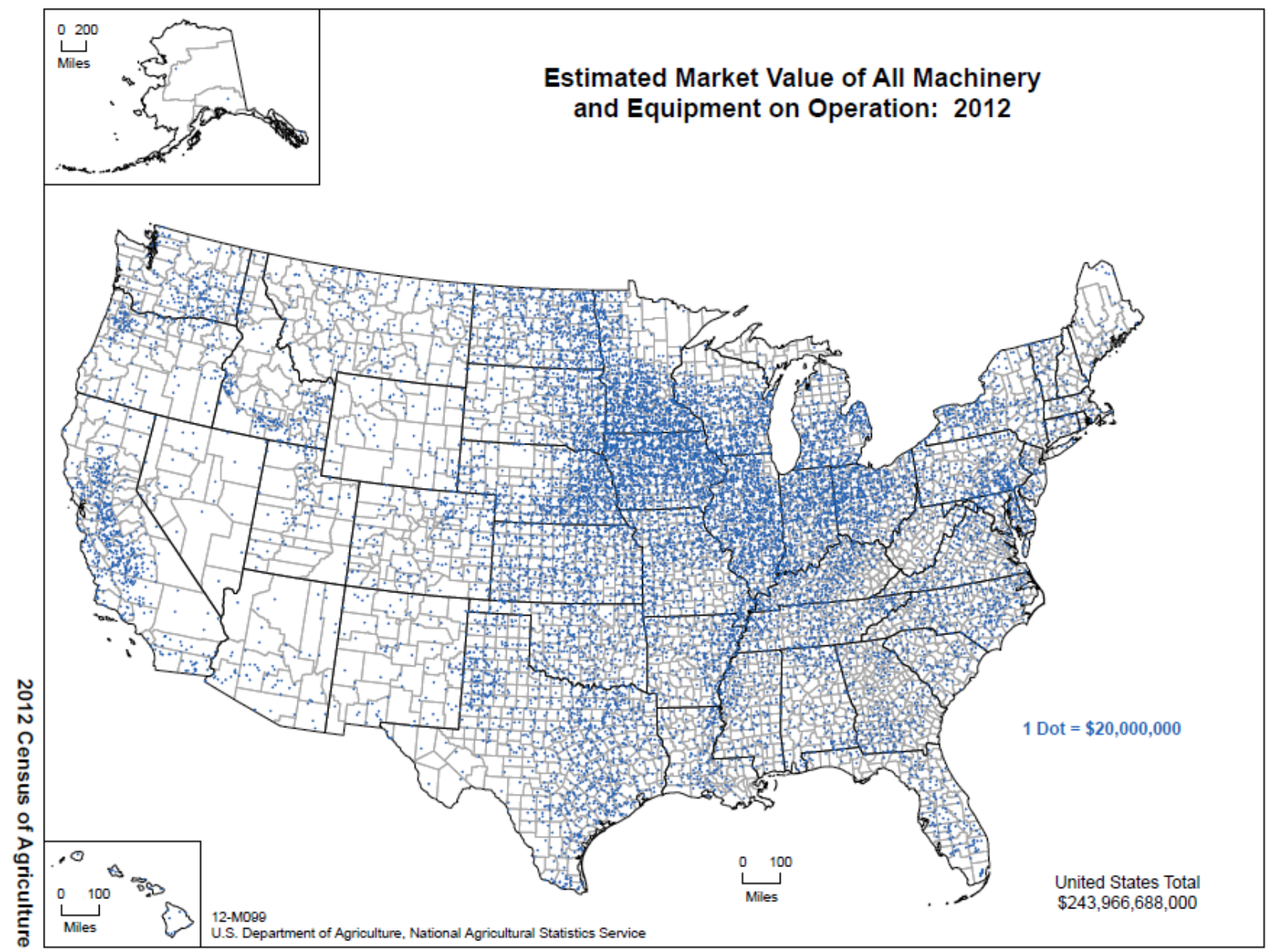

Figure 14. Estimated market value of all farm machinery and equipment on operations in 2012 (USDA 2014). The total market value was estimated to be about $\$ 244$ billion.

Given the structure of U.S. agriculture, the total value of U.S. farm equipment inventory primarily resides on farms with large production volumes. Large farms, those with at least $\$ 500,000$ in total farm sales, accounted for nearly half of the total $\$ 244$ billion value at the end of 2012 (Table 11). These 110,000 farms accounted for just 5\% of the total 2.1 million U.S. farms in the U.S. Census of Agriculture that year. Large farms have average equipment inventories of nearly $\$ 1.1$ million, compared with just $\$ 63,000$ for the other 2 million U.S. farms.

Not only is the majority of inventory value held on large farms, but these farms also accounted for most of the $25 \%$ growth ( $\$ 50$ billion) in total inventory values that occurred between 2007 to 2012 . Equipment inventory on large farms rose $86 \%$, from $\$ 63.5$ billion to $\$ 118$ billion, whereas inventory value on all other farms actually fell $4 \%$ over those same 5 years. Figure 15 provides the estimated market of farm machinery and equipment in operation and the average value per farm. 
Table 10. Top 10 States by Value of Farm Equipment in 2012. Inventory is geographically concentrated in the Midwest because of vast production of oilseed and grains, such as soybean and corn (Farm Credit Administration/Office of Regulatory Policy, data compiled from the 2012 U.S. Census of Agriculture 2014; Koenig 2016

\begin{tabular}{|l|l|l|l|}
\hline State & $\mathbf{\$ ( 0 0 0 )}$ & Cumulative \$ (000) & $\begin{array}{l}\text { Cumulative Share } \\
\text { of the Total (\%) }\end{array}$ \\
\hline lowa & $18,954,910$ & $18,954,910$ & 7.8 \\
\hline Texas & $17,958,942$ & $36,913,852$ & 15.1 \\
\hline Illinois & $15,256,459$ & $52,170,311$ & 21.4 \\
\hline Minnesota & $14,737,084$ & $66,907,395$ & 27.4 \\
\hline Nebraska & $11,503,486$ & $78,410,881$ & 32.1 \\
\hline California & $9,709,545$ & $88,120,426$ & 36.1 \\
\hline Kansas & $9,682,116$ & $97,802,542$ & 40.1 \\
\hline North Dakota & $9,297,134$ & $107,099,676$ & 43.9 \\
\hline Wisconsin & $9,037,376$ & $116,137,052$ & 47.6 \\
\hline Missouri & $8,822,239$ & $124,959,291$ & 51.2 \\
\hline All other states & $119,007,394$ & $243,966,685$ & 100.0 \\
\hline
\end{tabular}

Table 11. Farm Equipment Inventory Value by Farm Size. The inventory value is concentrated on large farms (2012 U.S. Census of Agriculture 2014; Koenig 2016).

\begin{tabular}{|l|l|l|l|l|l|}
\hline $\begin{array}{l}\text { 2012 Agricultural } \\
\text { Census }\end{array}$ & $\begin{array}{l}\text { Number of } \\
\text { Farms }\end{array}$ & $\begin{array}{l}\text { Share of } \\
\text { All } \\
\text { Farms }\end{array}$ & $\begin{array}{l}\text { Farm Equipment } \\
\text { Inventory Value } \\
\mathbf{( \$ , 0 0 0 )}\end{array}$ & $\begin{array}{l}\text { Share of } \\
\text { Total } \\
\text { Inventory } \\
\text { Value }\end{array}$ & $\begin{array}{l}\text { Average } \\
\text { Inventory } \\
\text { per Farm (\$) }\end{array}$ \\
\hline $\begin{array}{l}\text { Farms with } \$ 500,000 \text { or } \\
\text { more in farms sales }\end{array}$ & 110,176 & $5.2 \%$ & $118,360,074$ & $48.5 \%$ & $1,074,282$ \\
\hline $\begin{array}{l}\text { Farms with less than } \\
\$ 500,000 \text { in farm sales }\end{array}$ & $1,998,330$ & $94.8 \%$ & $125,606,614$ & $51.5 \%$ & 62,856 \\
\hline All U.S. Farms & $2,108,506$ & $100 \%$ & $243,966,688$ & $100 \%$ & 115,706 \\
\hline
\end{tabular}




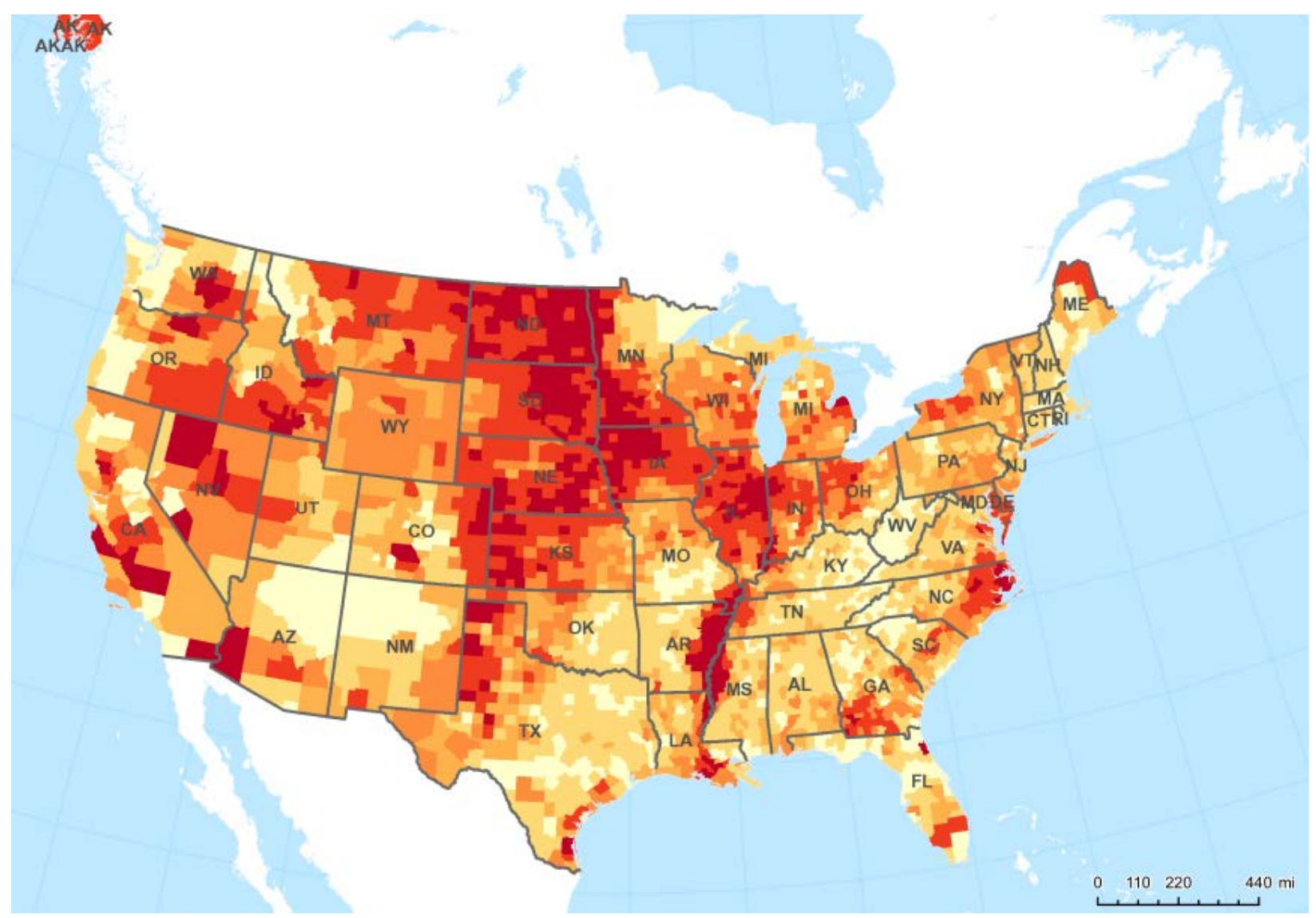

Units: Dollars

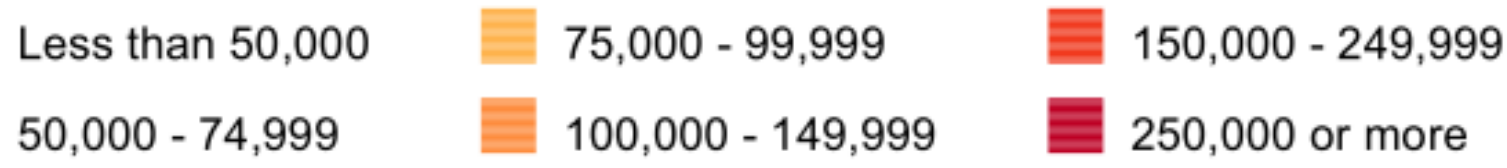

Figure 15. Estimated market value of all farm machinery and equipment in operation, average per farm, in U.S. dollars (2012). Inventory is geographically concentrated in the Midwest (USDA, 2014).

Figure 16 shows farms and their value of production by farm type. Gross cash farm income (GCFI) includes income from commodity cash receipts, farm-related income, and government payments. Family farms (where the operator and individuals related to the operator own the majority of the business) of various types together accounted for nearly $99 \%$ of U.S. farms in 2016. Small family farms (less than $\$ 350,000$ in GCFI) account for $90 \%$ of all U.S. farms. Largescale family farms ( $\$ 1$ million or more in GCFI) account for about $3 \%$ of farms but $45 \%$ of the value of production. Nonfamily farms are those in which neither the principal operator, nor individuals related to the operator, own a majority of the farm business. 


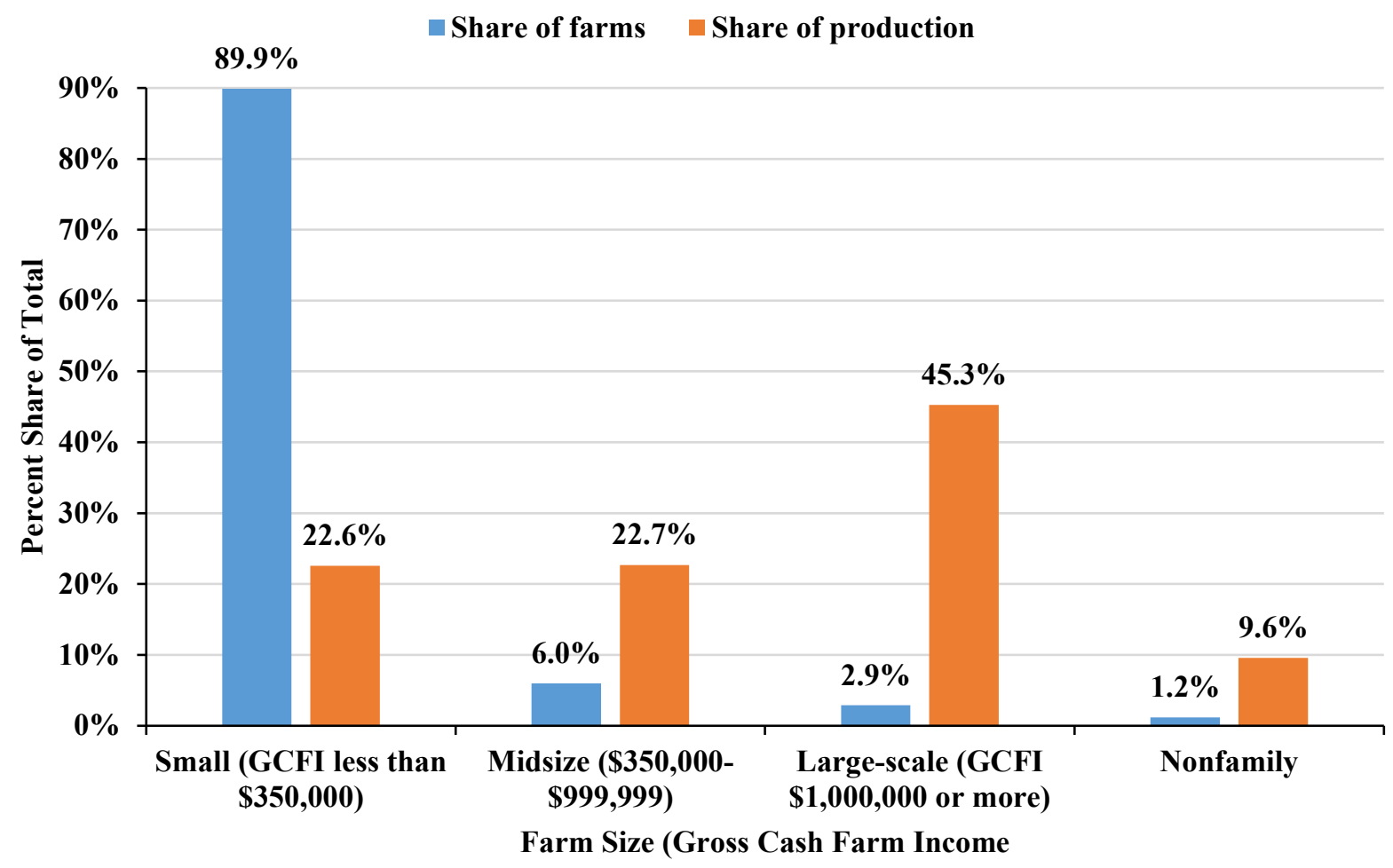

Figure 16. Farms and their value of production by farm type, 2016 (USDA 2016)

The number of farms and average size of farms in 2012 are graphically shown in Figure 17 and Figure 18, respectively. According to the Farm Credit Association (2016), "Numerous factors influenced the long rise of sales from the mid-2000s to 2013, including strong farm incomes, federal tax incentives that encourage capital investment, low capitalization rates (low interest rates), and abundant credit. Yet, the biggest driving factor in the rise and the collapse after 2013 in farm equipment investments is farm profitability." 


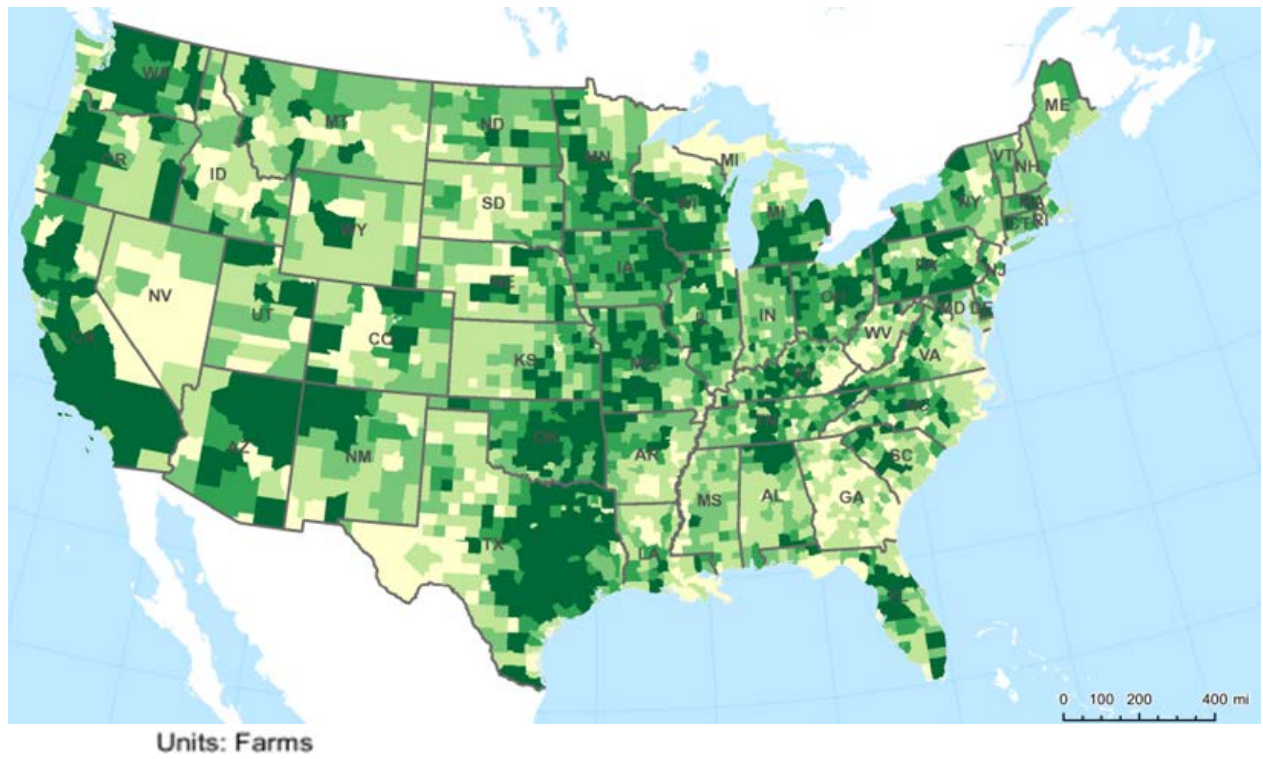

Less than 250

$500-749$

1,000 or more

$250-499$

$750-999$

Figure 17. Number of farms, 2012 (USDA 2014)

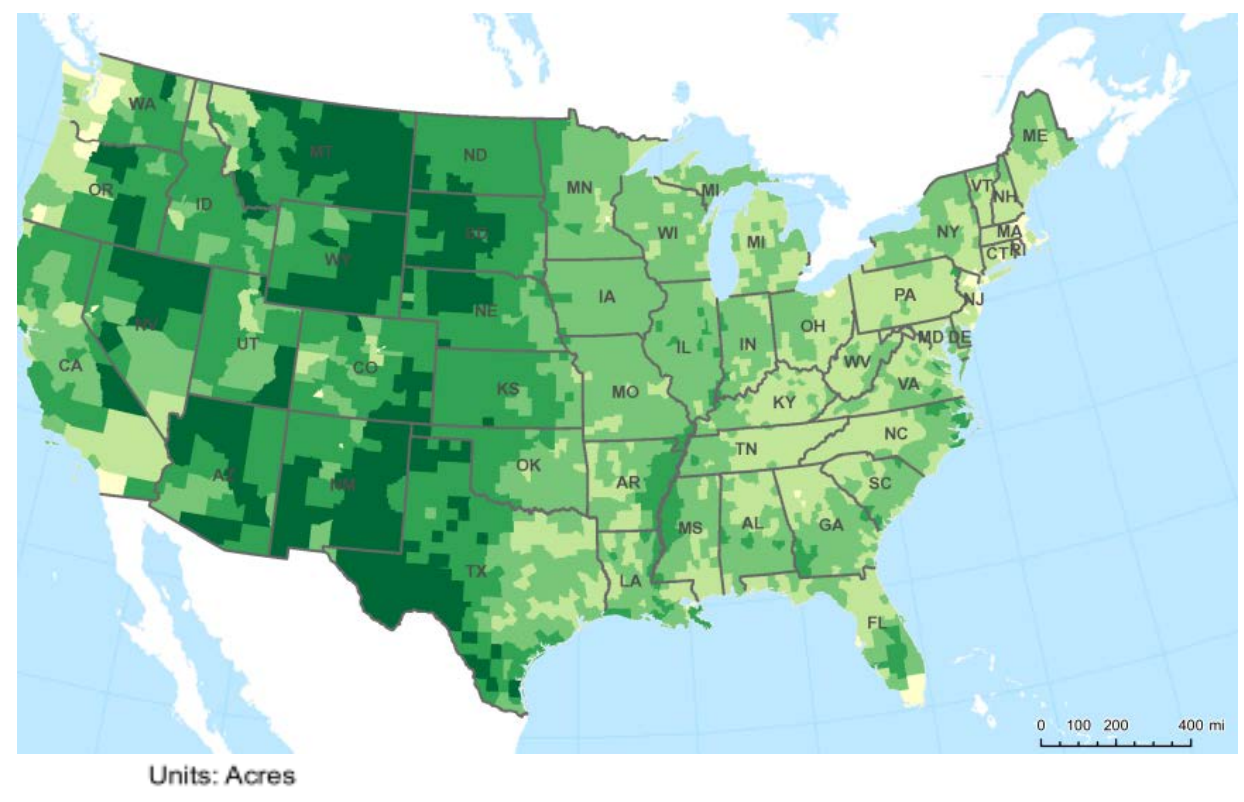
Less than 50
$180-499$
2,000 or more
$50-179$
$500-1,999$

Figure 18. Average size of farms in acres, 2012 (USDA 2014) 


\subsection{Agricultural Equipment Manufacturing Industry}

Agricultural equipment manufacturing is a global industry, with demand topping $\$ 140$ billion worldwide in 2014 (Freedonia Group 2016). Figure 19 shows world trade flow data for agricultural equipment by region from 2014, and Figure 20 shows projected data for 2019. Asia Pacific, Western Europe, and North America are the major manufacturing hubs for agricultural equipment.

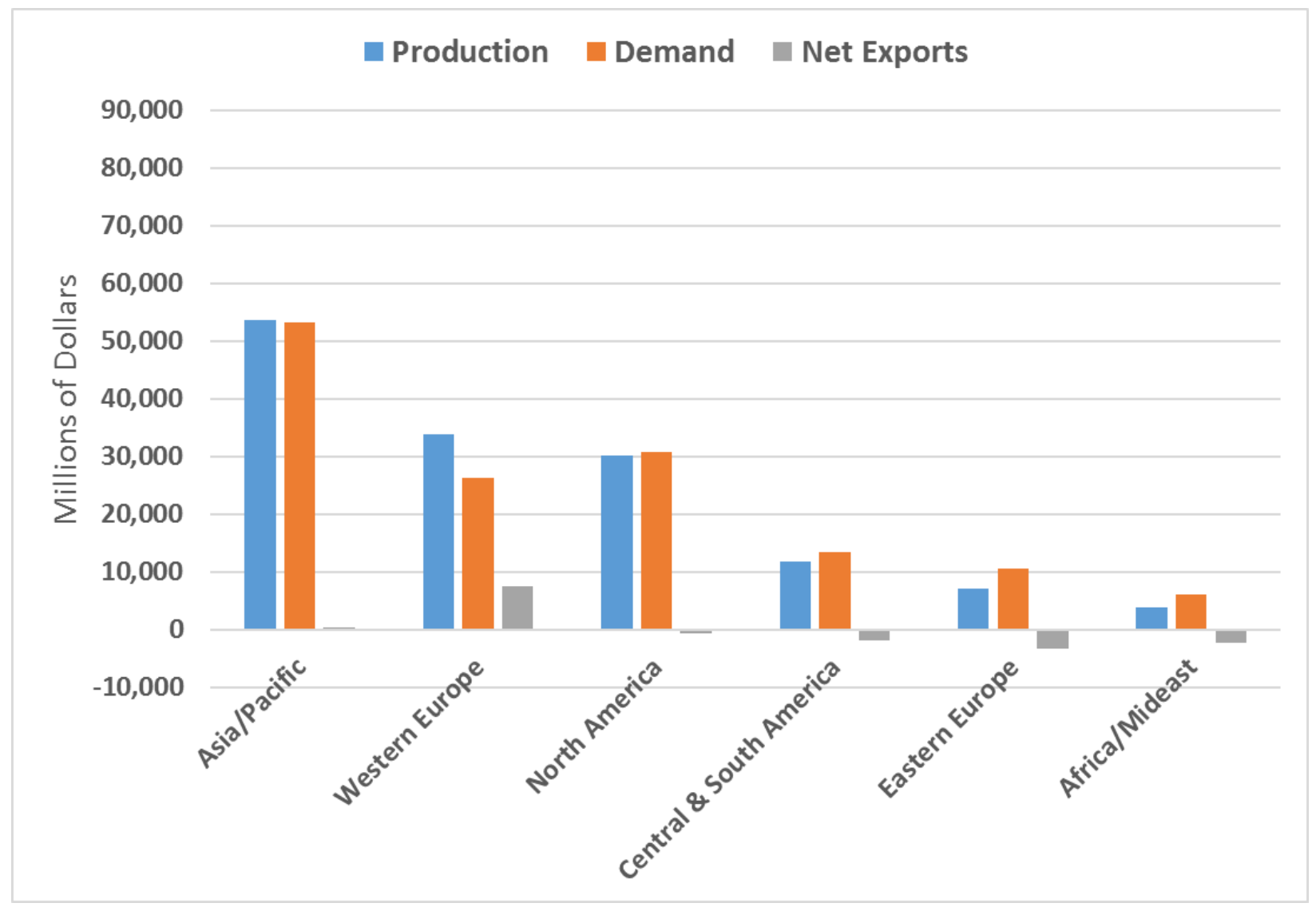

Figure 19. 2014 agricultural equipment world trade flow data (Freedonia Group 2016) 


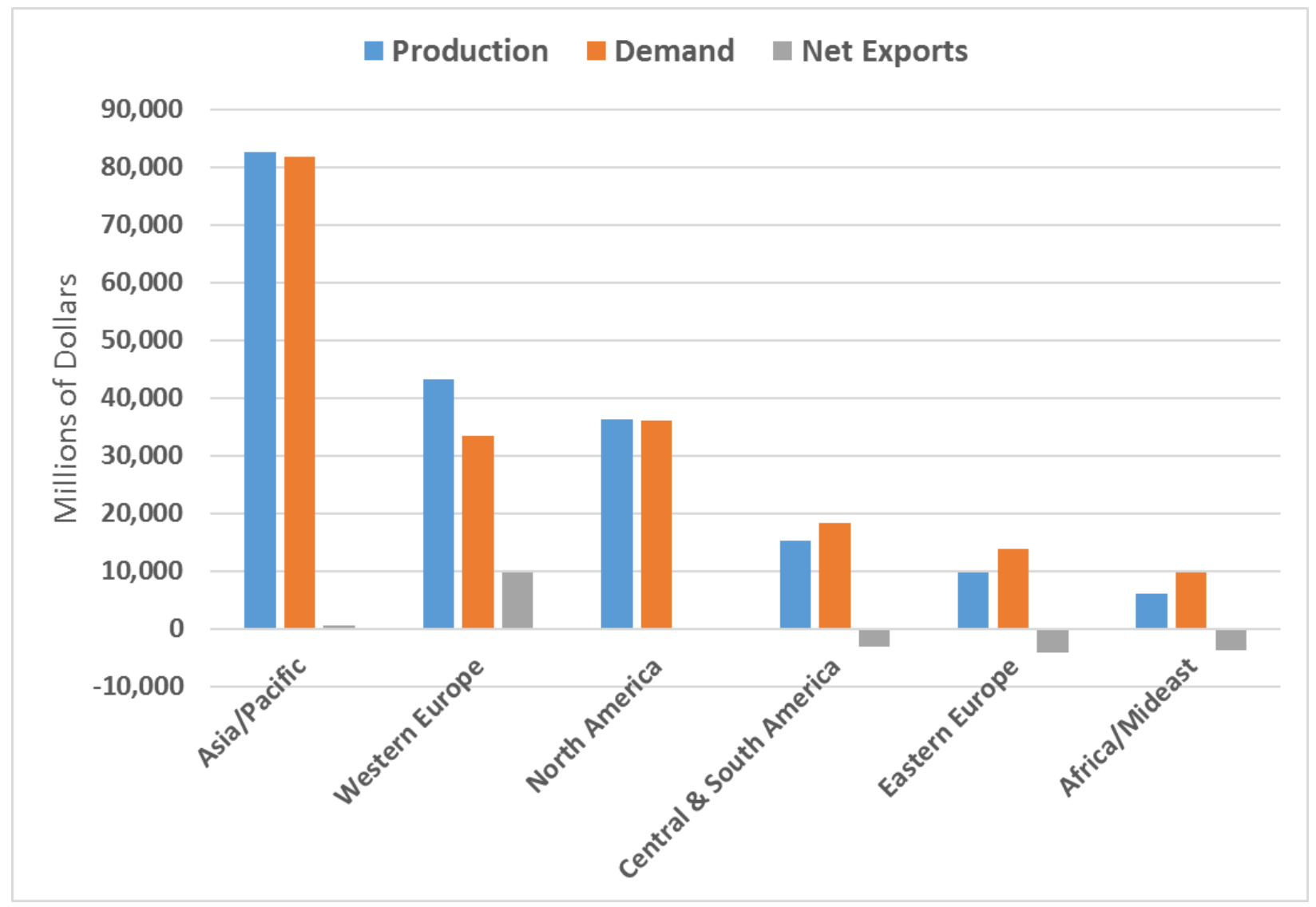

Figure 20. Projected 2019 agricultural equipment world trade flow data (Freedonia Group 2016)

Figure 21 and Figure 22 show the present and projected world trade flow data by country for some of the major agricultural equipment manufacturers. The United States is the secondlargest manufacturer of agricultural equipment by dollar value after China. Although China is projected to increase its lead in terms of agricultural equipment manufacturing in the future, the United States is expected to remain a world leader in agricultural manufacturing. Manufacturers of agriculture-related equipment directly employed 114,000 people in 2016 and contributed nearly $\$ 21$ billion to the U.S. gross domestic product (GDP). Farm machinery manufacturing accounts for approximately $27 \%$ of the equipment manufacturing industry in the United States (IHS Markit 2017). 


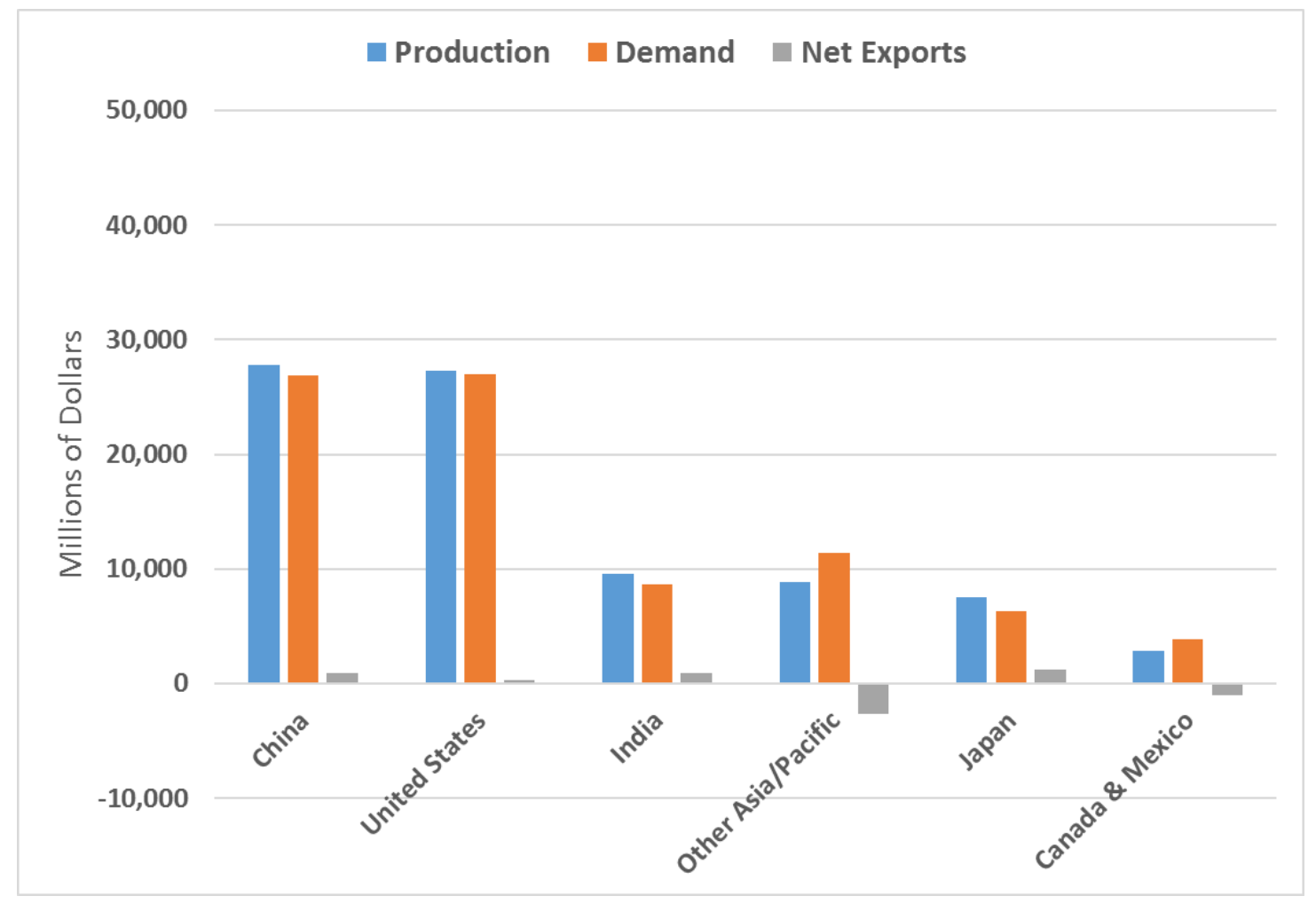

Figure 21. 2014 world agricultural equipment trade flow data by country (Freedonia Group 2016)

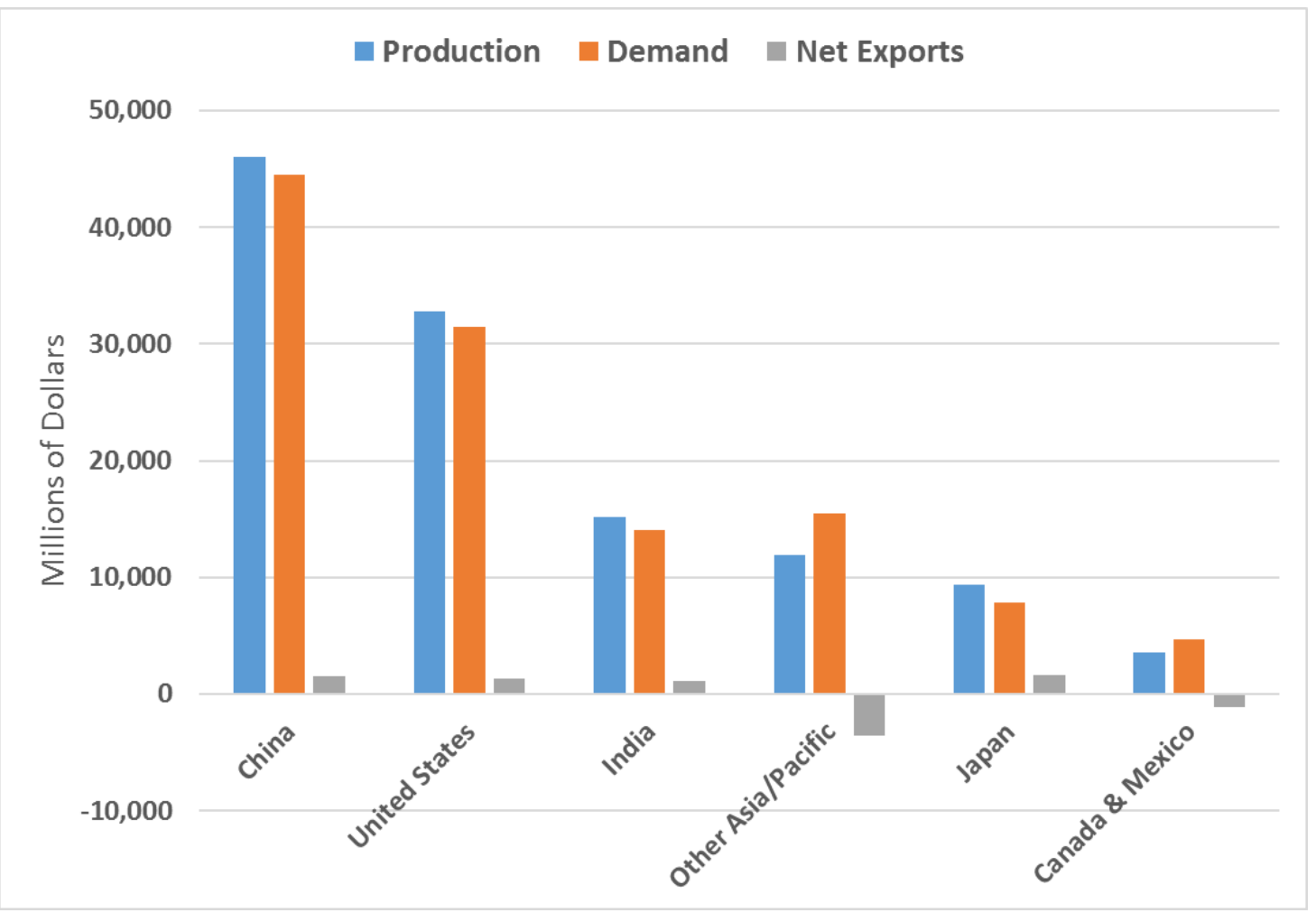

Figure 22. 2019 projected world agricultural equipment trade flow data by country (Freedonia Group 2016) 
For this study and its potential impact on the U.S. agricultural equipment manufacturing industry, key questions are how much agricultural equipment will be required to meet the future biomass demand in the BT16 scenarios (Figure 7 and Figure 8) and how much of that equipment will be manufactured in the United States. Data from the annual Manufacturing and International Trade Report (MITR) (U.S. Census Bureau 2016, U.S. Census Bureau 2018) can be used to infer how much of the agricultural equipment demand in the United States is currently met by U.S. manufacturing. The MITR reports manufacturing, import, and export data on goods organized by North American Industry Classification System (NAICS) codes. Table 12 summarizes the value of farm machinery and equipment (NAICS code 333111) manufactured, imported, and exported in the United States from 2013 to 2016. These values were used to estimate the total U.S. demand for agricultural equipment and how much of this demand was met by U.S. production. Total demand was calculated as the sum of production and imports minus exports. The percentage of U.S. demand met by U.S. production was calculated as the ratio of U.S. production less exports to total U.S. demand. MITR data suggest that for the years studied, around $75 \%$ of farm machinery and equipment demand in the United States was supplied by U.S. manufacturers annually.

Table 12. Value of Farm Machinery and Equipment (NAICS Code 333111) Production and Demand in the United States (Thousands of Dollars)

\begin{tabular}{|l|l|l|l|l|l|}
\hline Year & Production & & & & \\
Imports $^{\mathbf{b}}$ & Exports $^{\mathbf{c}}$ & $\begin{array}{l}\text { Total U.S. } \\
\text { Demand }^{\mathbf{d}}\end{array}$ & $\begin{array}{l}\text { U.S. Demand Met } \\
\text { by U.S. Production }^{\mathbf{e}}\end{array}$ \\
\hline 2013 & $\$ 37,781,639$ & $\$ 8,670,215$ & $\$ 8,463,901$ & $\$ 37,987,953$ & $77 \%$ \\
\hline 2014 & $\$ 37,696,293$ & $\$ 8,831,886$ & $\$ 7,778,499$ & $\$ 38,749,680$ & $77 \%$ \\
\hline 2016 & $\$ 29,670,190$ & $\$ 8,062,534$ & $\$ 6,643,771$ & $\$ 31,088,953$ & $74 \%$ \\
\hline
\end{tabular}

Source of shaded data: MITR (U.S. Census Bureau 2016, U.S. Census Bureau 2018)

a Production refers to "Value of Product Shipments" in MITR and includes the total value of all products produced and shipped by all producers.

bImports refers to "Consumption Import Value of Goods" in MITR.

"Exports refers to "Domestic Export Value of Goods" in MITR.

${ }^{\mathrm{d}}$ Total U.S. Demand calculated as Production + Imports - Exports.

e U.S. Demand Met by U.S. Production calculated as (Production - Exports)/(Total U.S. Demand).

U.S. agricultural equipment production and supply can be broken down further by type of equipment using NAICS codes in the MITR. Figure 23 and Figure 24 show production, imports, exports, and demand for 2015 and 2016, respectively, by type of farm and machinery equipment, and Table 13 tabulates the demand calculations. The data show that tractors dominate production and demand for farm machinery and equipment, which account for about one-third of all production. The percentage of tractors estimated to be supplied by U.S. production closely matches the value for all farm and machinery equipment. Specialty equipment used in the baling and chopping of biomass, such as harvesting and haying equipment, is domestically supplied to an even higher degree. 


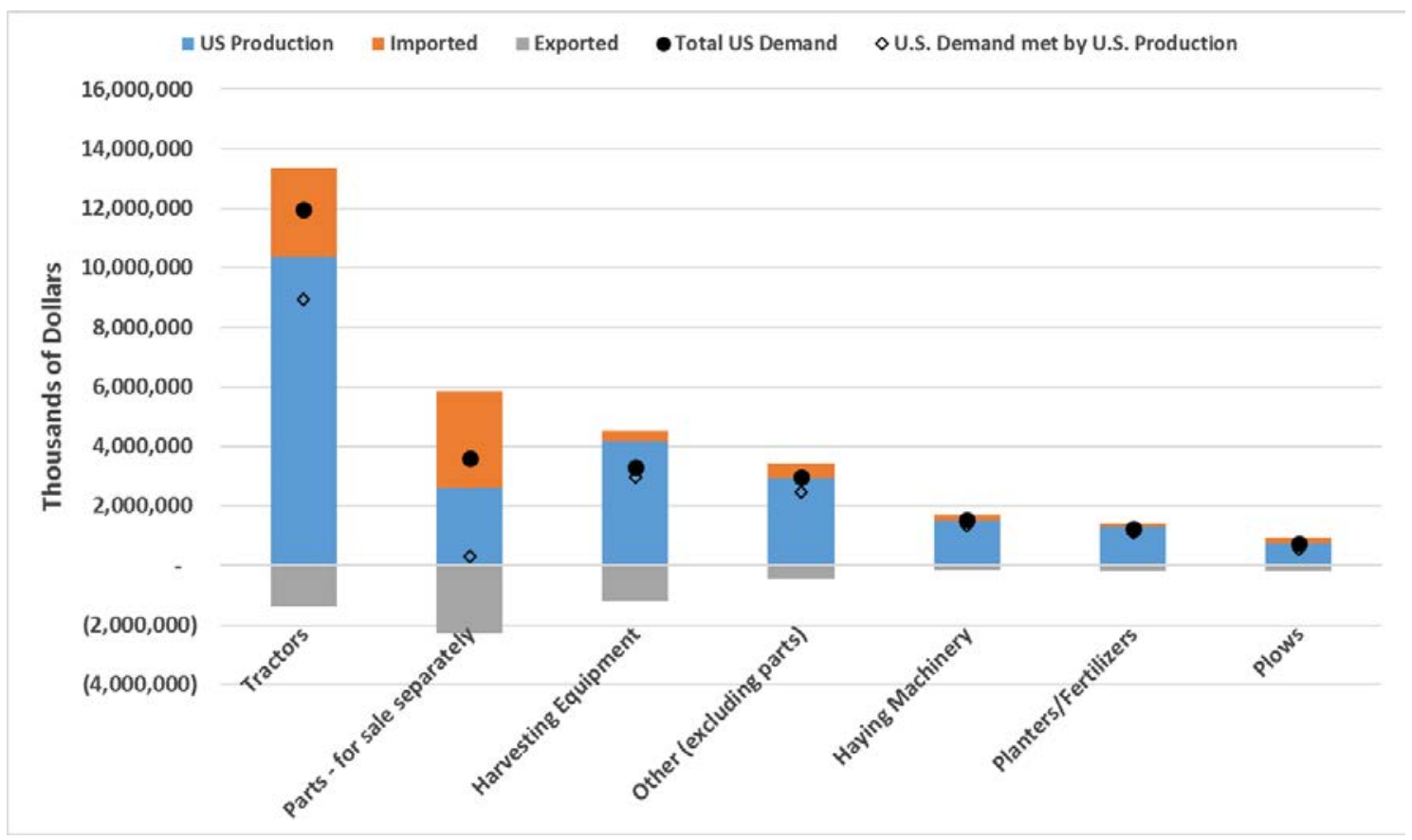

Figure 23. 2015 value of farm machinery and equipment production and demand by type (NAICS codes $333111 x$ ) in the United States (thousands of dollars) (U.S. Census Bureau 2018). See Table 12 and Table 13 for definitions of terms.

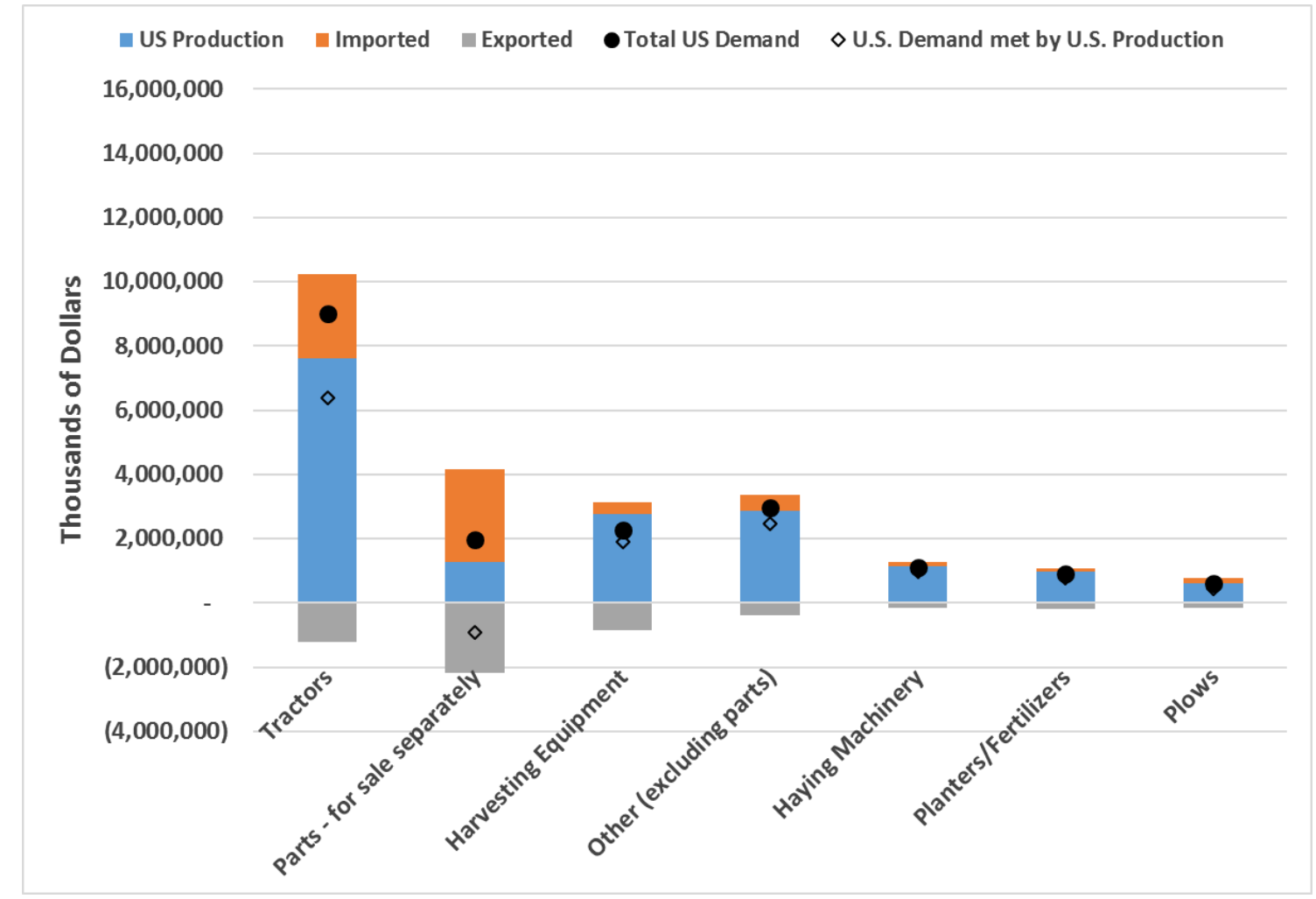

Figure 24. 2016 value of farm machinery and equipment production and demand by type (NAICS codes $333111 x$ ) in the United States (thousands of dollars) (U.S. Census Bureau 2018). See Table 12 and Table 13 for definitions of terms. 
Table 13. 2015 and 2016 Value of Total U.S. Demand and Percent Supplied by U.S. Production for Farm Machinery and Equipment Production and Demand by Type (NAICS Codes 333111x) in the United States (Thousands of Dollars) (U.S. Census Bureau 2018)

\begin{tabular}{|l|l|l|l|l|l|}
\hline & \multicolumn{4}{|l|}{$\mathbf{2 0 1 5}$} & $\mathbf{2 0 1 6}$ \\
\hline $\begin{array}{l}\text { NAICS } \\
\text { Code }\end{array}$ & Description & $\begin{array}{l}\text { Total U.S. } \\
\text { Demand }\end{array}$ & $\begin{array}{l}\text { \% Supplied } \\
\text { by U.S. } \\
\text { Production }\end{array}$ & $\begin{array}{l}\text { Total U.S. } \\
\text { Demand }\end{array}$ & $\begin{array}{l}\% \text { Supplied } \\
\text { by U.S. } \\
\text { Production }\end{array}$ \\
\hline 3331111 & Tractors & $\$ 11,944,949$ & $75 \%$ & $\$ 8,999,425$ & $71 \%$ \\
\hline 3331119 & Harvesting equipment & $\$ 3,312,046$ & $90 \%$ & $\$ 2,256,574$ & $84 \%$ \\
\hline $333111 \mathrm{~J}$ & Turf/grounds equipment & $\$ 3,083,553$ & $94 \%$ & $\$ 2,701,128$ & $93 \%$ \\
\hline $333111 \mathrm{G}$ & Other (excluding parts) & $\$ 2,960,393$ & $84 \%$ & $\$ 2,964,933$ & $83 \%$ \\
\hline $333111 \mathrm{C}$ & Parts-for sale separately & $\$ 3,587,832$ & $9 \%$ & $\$ 1,974,120$ & $-46 \%$ \\
\hline 3331114 & $\begin{array}{l}\text { Dairy, sprayers, dusters, } \\
\text { blowers }\end{array}$ & $\$ 1,564,819$ & $90 \%$ & $\$ 1,425,637$ & $89 \%$ \\
\hline $333111 \mathrm{~A}$ & Haying machinery & $\$ 1,522,325$ & $87 \%$ & $\$ 1,106,705$ & $88 \%$ \\
\hline 3331117 & Planters/fertilizers & $\$ 1,227,826$ & $90 \%$ & $\$ 889,821$ & $88 \%$ \\
\hline $333111 \mathrm{E}$ & Plows & $\$ 750,106$ & $74 \%$ & $\$ 600,375$ & $71 \%$ \\
\hline
\end{tabular}

The results in Table 12 and Table 13 are in good agreement with other reports that state that approximately $30 \%$ of U.S. agricultural equipment production is intended for export (IHS Markit 2017), and they were confirmed as accurate during an interview with a marketing manager at a major U.S.-based agricultural equipment manufacturer. ${ }^{2}$ More than half of U.S. exports go to Canada, Mexico, and Australia, which at the time this report was written had free-trade agreements with the United States. Countries with low tariffs on U.S. agricultural equipmentsuch as the European Union and Organisation for Economic Co-operation and Development (OECD)-member countries-account for another $25 \%$ of agricultural equipment exports from the United States (International Trade Administration 2017).

Trade barriers discourage exports to other regions of the world. Brazil and Argentina have high tariffs (up to $35 \%$ in Brazil) combined with other fees and taxes that discourage agricultural equipment imports. China provides subsidies to agricultural producers, which are contingent on them purchasing Chinese-made agricultural equipment, placing imported equipment at a significant disadvantage (International Trade Administration 2017). These policies have encouraged international manufacturers to establish manufacturing facilities within China and South America, because equipment manufactured abroad and imported cannot compete. ${ }^{2}$

Based on the same interview with a marketing manager at a major U.S.-based agricultural equipment manufacturer, ${ }^{2}$ these global agricultural equipment manufacturing trends are likely to continue, even under the BT16 scenario. The United States initially developed a large

2 Personal communication. Interview via phone. April 20, 2018. 
agricultural equipment manufacturing industry because it was the first, and only, market for large agricultural equipment. That manufacturing infrastructure persists. Even though shipping and freight costs are not as much of an issue anymore, any need for future added manufacturing capacity because of increased U.S. demand would likely stay in the United States in the form of expansions at existing facilities and optimize the U.S. manufacturing footprint. Even for new types of equipment, recent experience has shown that if the market for the equipment is in the United States, it is likely to be manufactured in the United States. Generally, agricultural equipment manufacturing tends to occur in its main market.

The analysis shows that, especially for the large agricultural manufacturing regions, manufacturing production is comparable to demand for equipment, and net exports are relatively small. In the United States, approximately $70 \%-80 \%$ of total agricultural equipment demand is supplied from domestic manufacturers. Without large changes in existing international trade policy and global manufacturing infrastructure status, it is reasonable to assume that U.S. agricultural equipment manufacturing under the BT16 scenarios will be similar to that status quo, with U.S. production meeting $70 \%-90 \%$ of U.S. demand for agricultural equipment pieces, depending on equipment type, and $70 \%-80 \%$ of overall agricultural equipment demand by value within the United States.

\subsection{Market Value of Required Agricultural Machinery}

Figure 25 and Figure 26 show the market value of the estimated number of agricultural machinery required to meet the future biomass demand in the BT16 scenarios (Figure 7 and Figure 8). In the short term, the market value of the agricultural machinery is estimated to be about $\$ 36$ billion. This number is estimated to be more than $\$ 47$ billion in the long term. This is about $15 \%$ and $19 \%$ of the current market value of all farm machinery and equipment in operations (i.e., \$244 billion), respectively. The historical data show that during periods of prosperity when U.S. farmers typically increase their investments in farm equipment, the agricultural equipment manufacturing industry in the United States has been able to ramp up its production lines and meet the demand of the farmers, custom harvest groups, and other users of the agricultural equipment. For example, from 2002 to 2012, net cash farm incomes increased by $166 \%$. Likewise, U.S. Census of Agriculture data indicate the total market value of the inventory of U.S. farm equipment grew by $79 \%$ (after adjusting for inflation), from \$107 billion in 2002 to \$244 billion in 2012. 


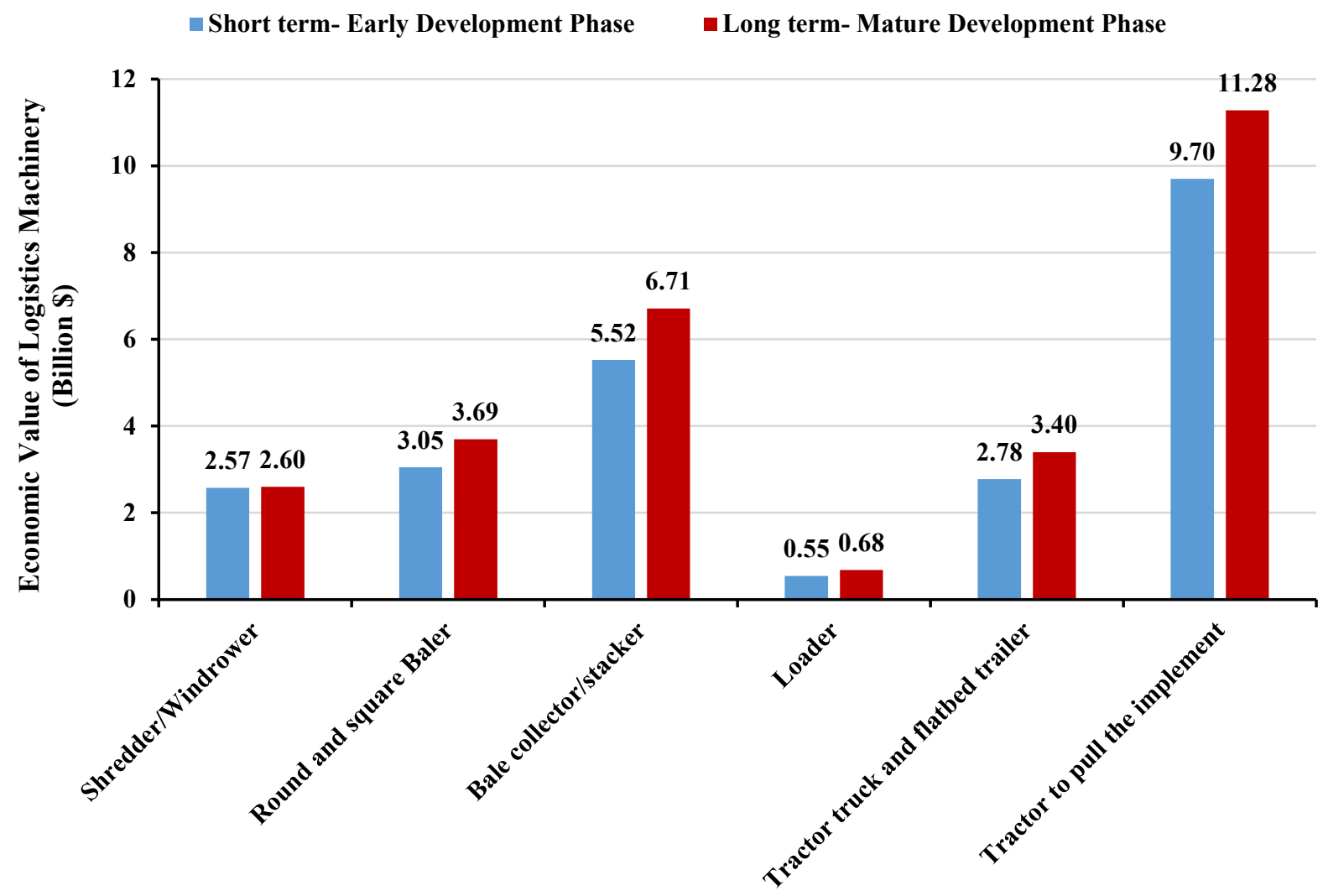

a) Baling scenario

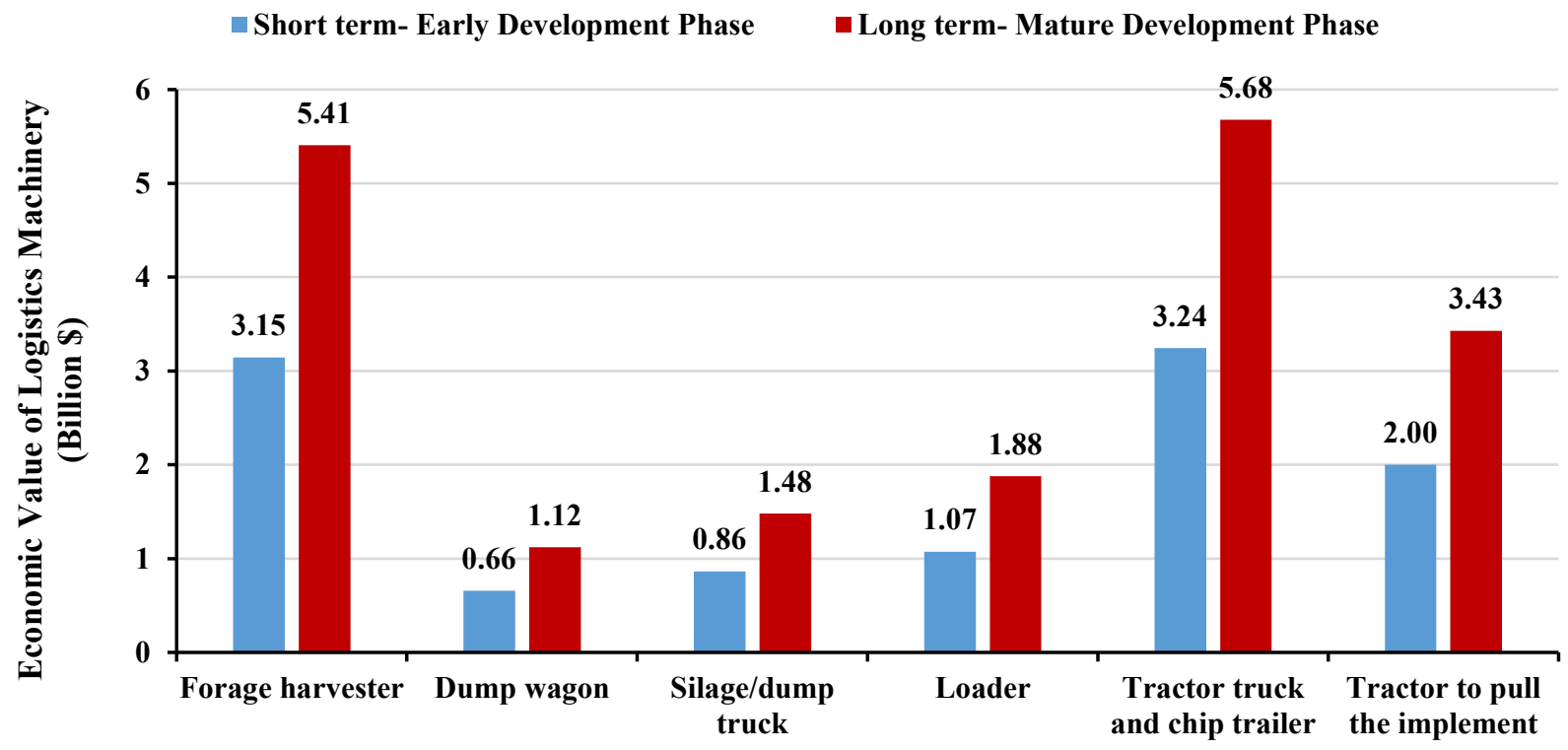

b) Chopping scenario

Figure 25. Market value of required agricultural machinery to deliver 230 million-340 million tons of selected biomass resources to future biorefineries in short and long terms 


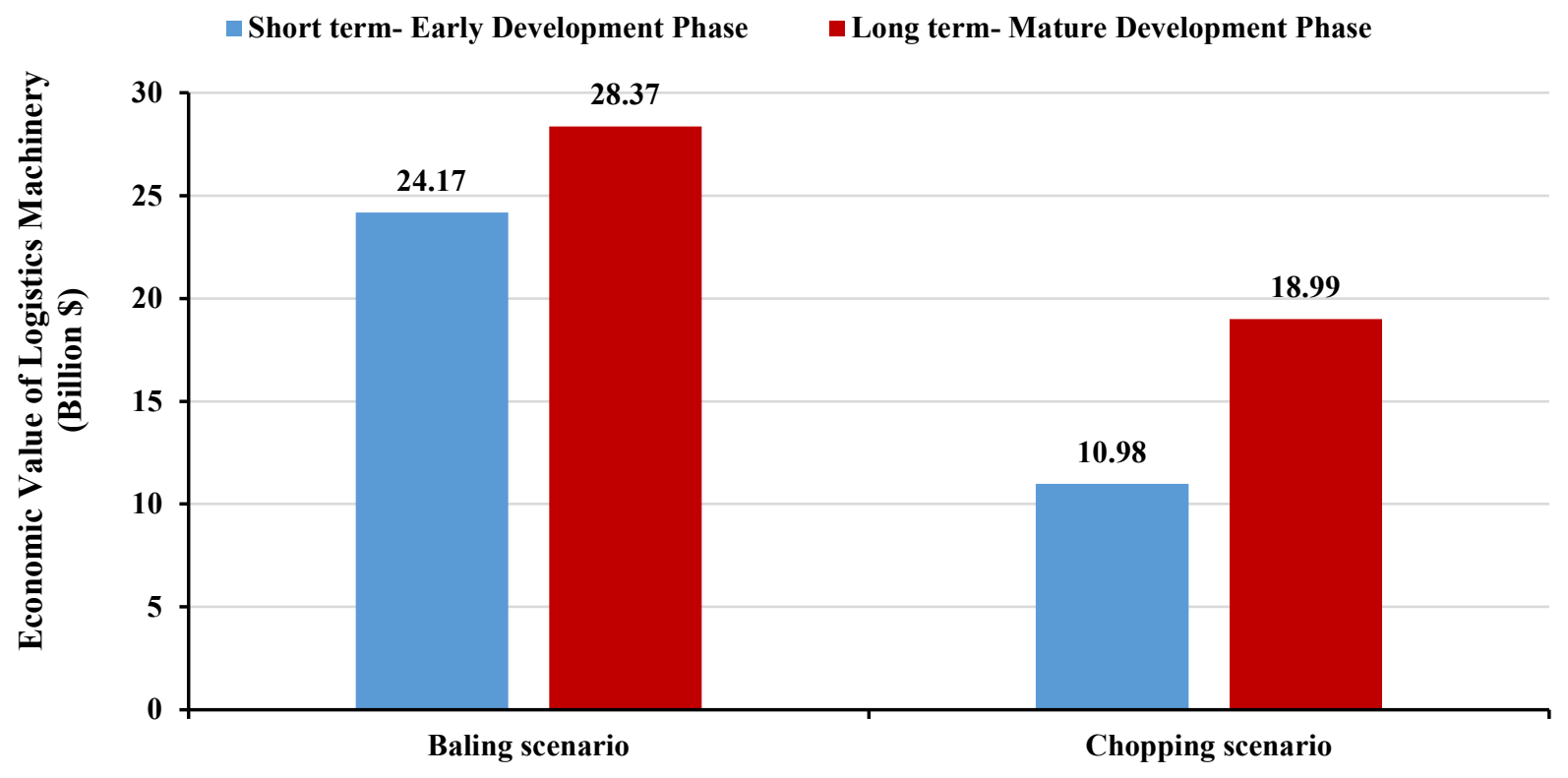

Figure 26. Total estimated market value of agricultural machinery in baling and chopping scenarios in short and long runs 


\subsection{Workforce and Economic Development Impacts of Required Agricultural Machinery}

The manufacture of the agricultural equipment required under the BT16 scenario will result in additional jobs and economic development. We estimate workforce and economic development impacts for the total estimated market value of required agricultural machinery for the biomass economy shown in Figure 26 using the Economic Impact Analysis for Planning (IMPLAN) model. ${ }^{3}$ The model is an economic impact assessment software system that uses extensive databases, economic factors, multipliers, and demographic statistics to calculate the economic impact of investments, businesses, projects, etc., to a region. The IMPLAN model relies on input-output economic models (Miller and Blair 2009) to estimate the impacts of increased expenditures in certain economic sectors. The model divides impacts into direct, indirect, and induced categories. Direct impacts occur in industries directly affected by expenditures - in this case, the agricultural equipment manufacturing industry. Indirect impacts are based on expenditures that support direct impacts such as buying goods, services, materials, and other expenditures in the manufacturing supply chain. Induced impacts are the result of reinvestment and spending of earnings by direct and indirect beneficiaries. They are the result of increased business at local restaurants, retailers, child care, and any other household spending patterns that cause increased local economic activity. The IMPLAN model's results are generally reported as employment in job years, labor income, and value added (contribution to the GDP). A job year is the equivalent of one full-time equivalent (FTE) job for 1 year. A person who works for 40 years works 40 FTE job years.

Economic impacts were estimated for each of the scenarios shown in Figure 26 using the IMPLAN model. The economic impacts are based on the total estimated market value of agricultural machinery required to deliver 230 million-340 million tons of corn residues and energy crops, including herbaceous crops and woody crops to future biorefineries in short and long term, as described in Section 8.3 above. In that section, we discuss how some of the equipment requirements could be met using the existing fleet of agricultural equipment. However, we were not able to find information on the existing fleet size of some types of equipment. Additionally, some equipment in the existing agricultural equipment fleet could be used to meet some of the logistical machinery required to deliver biomass to future biorefineries. For example, in 2012 there were more than 1.1 million $100+\mathrm{hp}$ tractors in operation in the United States (USDA 2014) that could help meet the estimated 62,002-77,879 tractors required in biomass supply chains to support the development of a sustainable bioeconomy in the United States. Conversely, the current market for large square balers is currently about 1,600 units (AGCO 2015) compared with the estimated 32,988-39,924 balers required for a sustainable bioeconomy. Determining how much of the biomass economy equipment requirements could be met using excess capacity in the existing fleet or future fleet additions to serve both current agricultural needs and the potential biomass economy was beyond the scope of this study. Therefore, we calculated the economic impacts of the total

${ }^{3}$ http://www.implan.com/ 
estimated market value of agricultural machinery required for the scenarios shown in Figure 26 and did not attempt to determine what portion is attributable to the biomass economy requirements relative to the status quo. The calculation instead represents the economic impacts of the biomass economy assuming that new manufacturing met all agricultural equipment requirements.

Based on the analysis in Section 8.2 , we assumed that $75 \%$ of the required agricultural equipment was manufactured domestically. Figure 27 shows the employment impacts, and Figure 28 shows the impacts on value added (or contribution to the GDP from these expenditures) based on results from the IMPLAN model. The figures show results for the total market value over the short and long term for the baling and chopping scenarios; they are not annual values, nor are they cumulative (i.e., the long-term scenarios include the market value from the short-term scenarios). The sum of direct long-term employment impacts from the baling and chopping scenarios is more than 56,000 FTE job years, and the sum of total longterm impacts is more than 340,000 FTE job years. By comparison, the farm machinery and equipment manufacturing industry in the United States employed more than 60,000 workers in August 2018 (U.S. Department of Labor 2018). The domestic manufacture of the required equipment would result in almost $\$ 11$ billion in direct value added and nearly $\$ 40$ billion in total value added over the long term. Total U.S. demand for agricultural equipment in 2016 was about $\$ 23$ billion (Table 12). 


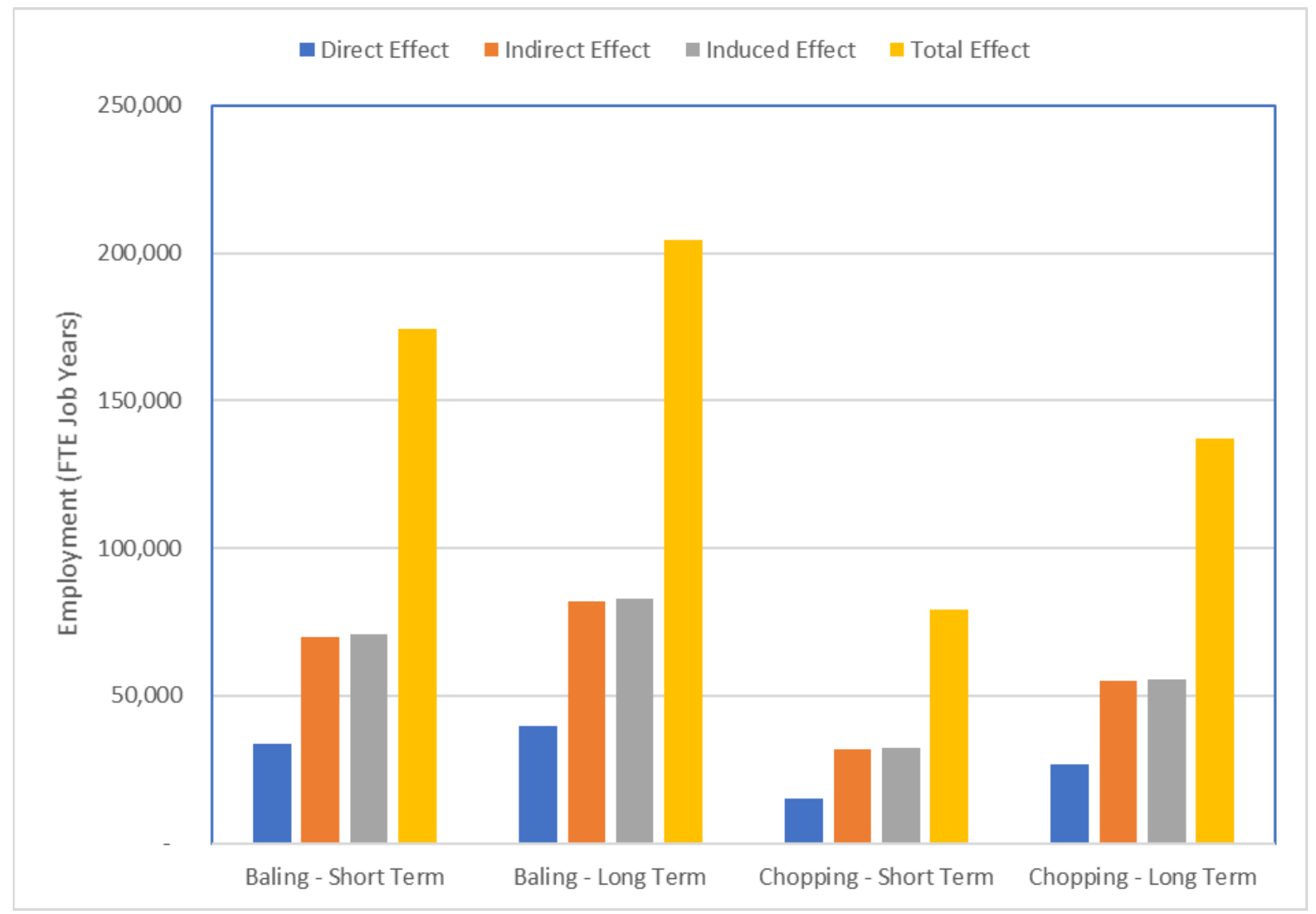

Figure 27. Employment impacts (in FTE job years) from market value of baling and chopping scenarios in short and long term in Figure 26. Impacts calculated using IMPLAN model assuming full agricultural equipment logistical requirements and assuming $75 \%$ of equipment is manufactured domestically. 


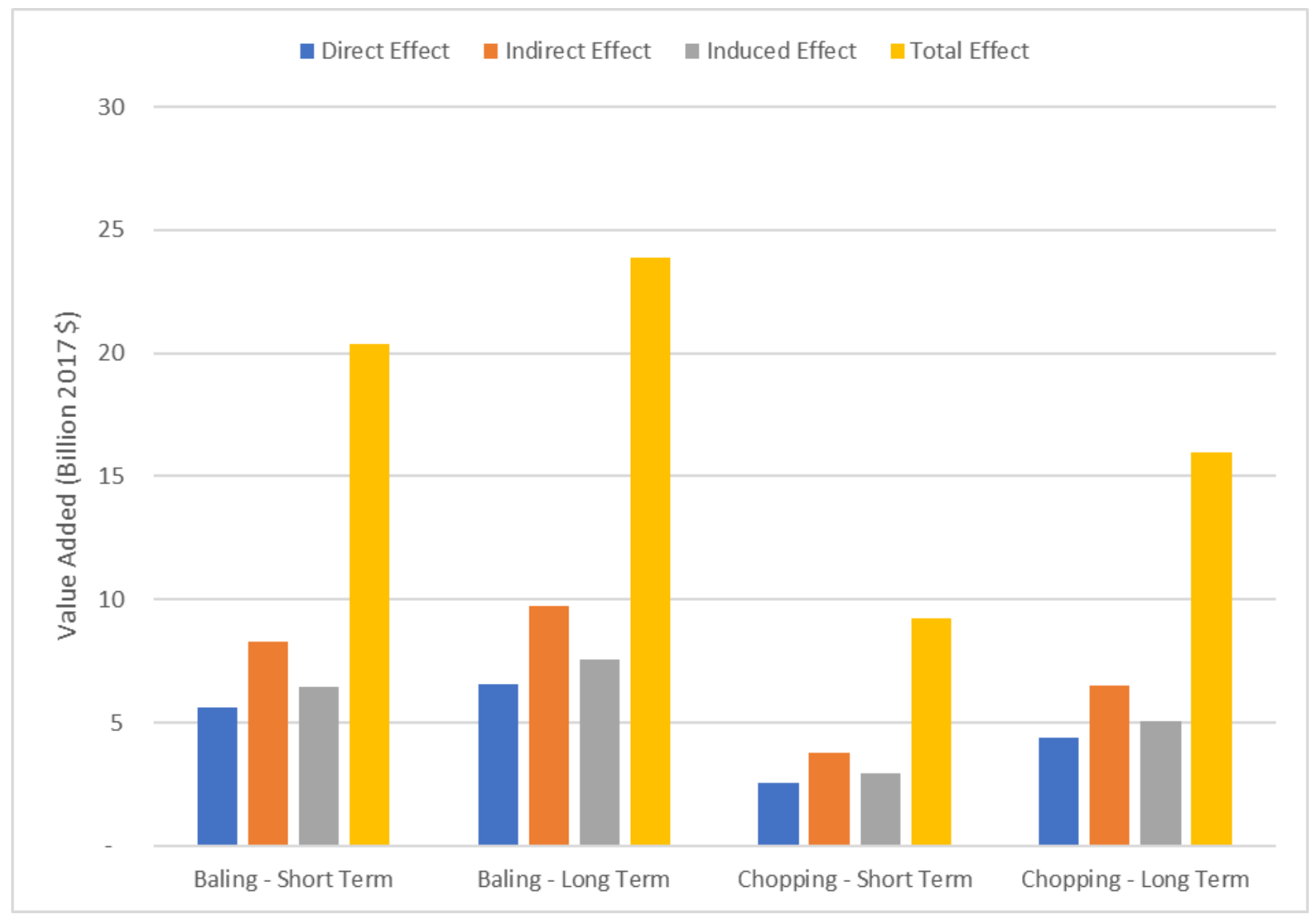

Figure 28. Value added (contribution to the GDP) impacts, in billions of U.S. dollars (2017), from market value of baling and chopping scenarios in short and long term in Figure 26. Impacts calculated using IMPLAN model assuming full agricultural equipment logistical requirements and assuming $75 \%$ of equipment is manufactured domestically.

\subsection{Potential Economic Activities in Rural Communities}

Additional potential economic activities as a result of supplying millions of tons of biomass to the future biorefineries are the operation of the agricultural machinery by the local workforce and the sale of produced biomass to the biorefineries by the farmers. Figure 29 shows the total number of operators required to run the agricultural machinery in both baling and chopping scenarios. In total, about 76,200 and 103,600 operators would be required to run the agricultural machinery in short and long terms, respectively. In addition, about 124,000 and 162,000 farmers would be selling their biomass to future biorefineries in the short and long terms, respectively (Figure 30 ). These farmers would have an annual net income of $\$ 2.48$ billion and $\$ 3.25$ billion (Figure 31). Table 14 shows the summary of the results on the size of the agricultural equipment fleet, their market value, and potential economic activities. 


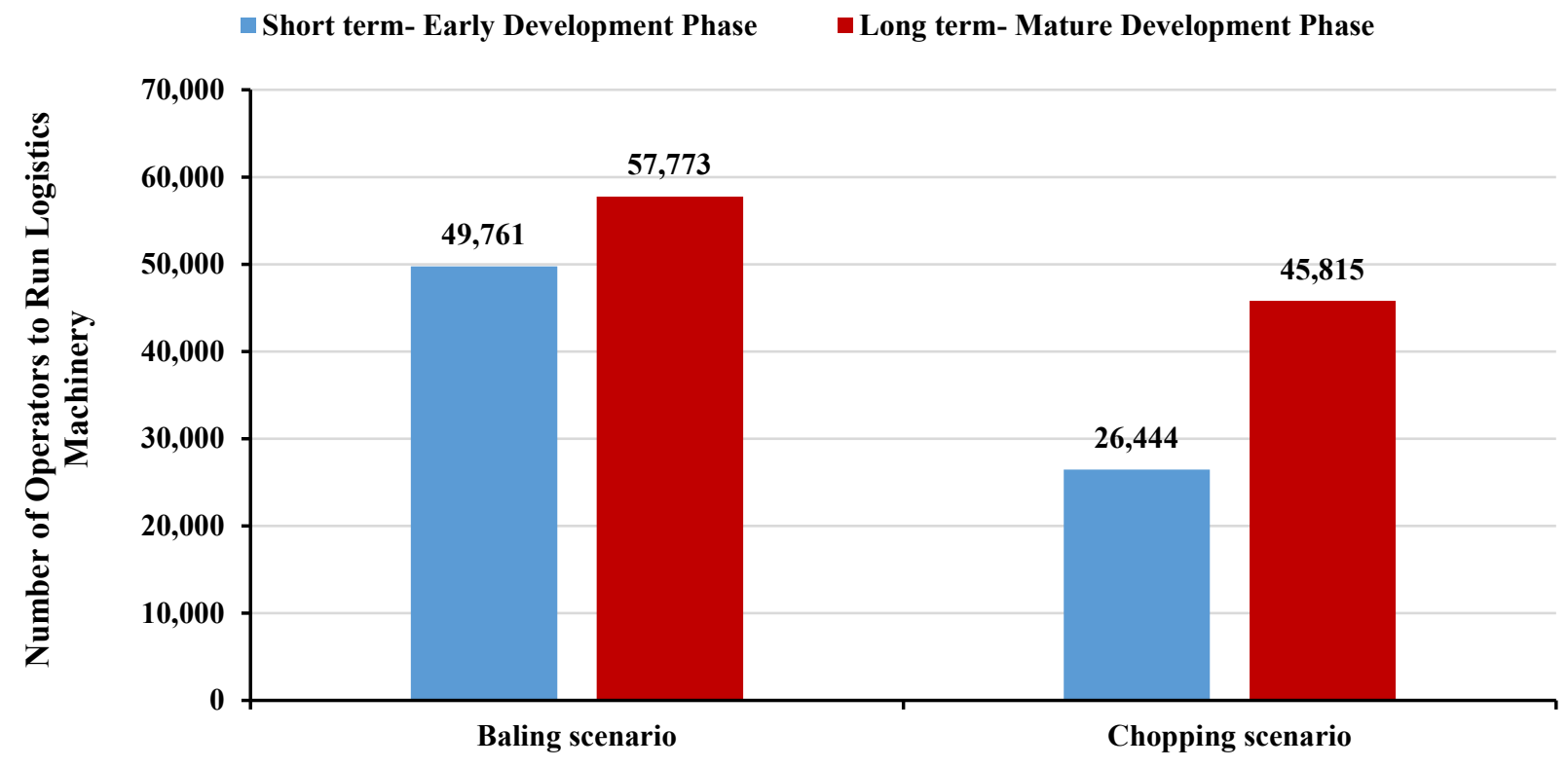

Figure 29. Estimated number of operators required to run the agricultural machinery fleet to meet the daily and annual biomass demands of biorefineries in the short and long terms

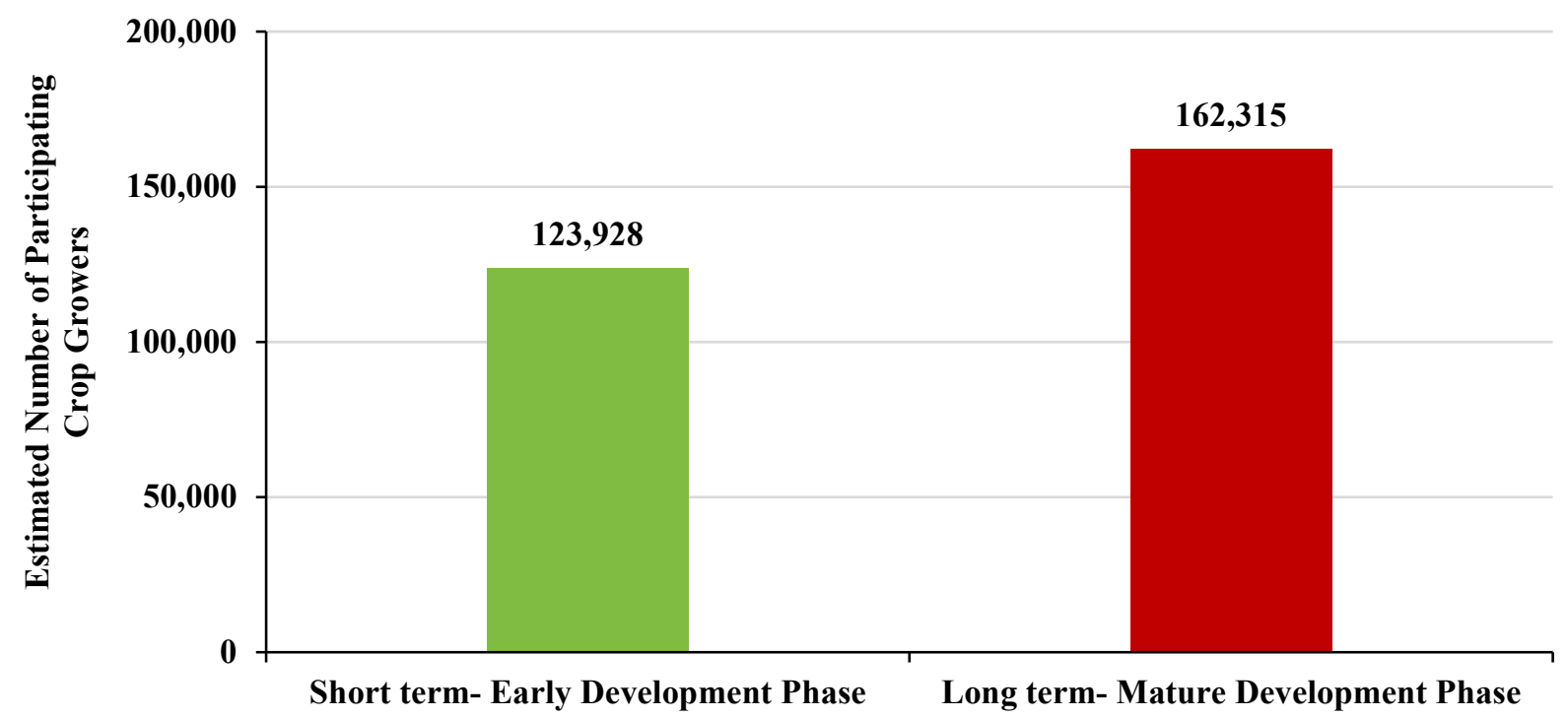

Figure 30. Estimated number of participating crop growers 


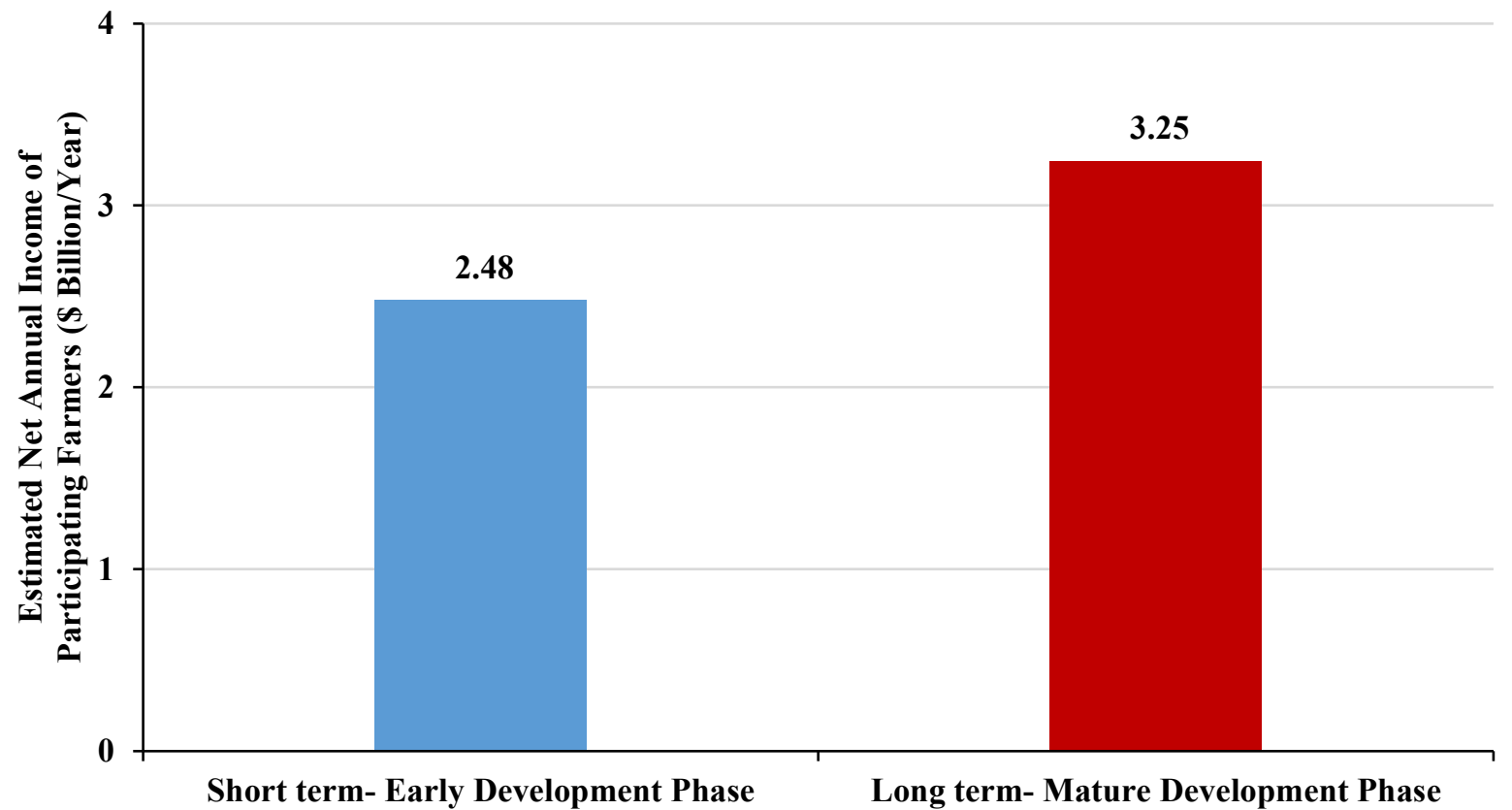

Figure 31. Estimated net annual income of crop growers by selling their biomass to the future biorefineries

Table 14. Summary of Economic Impact

\begin{tabular}{|c|c|c|}
\hline Descriptions & $\begin{array}{l}\text { Short Term (Early } \\
\text { Development Phase) }\end{array}$ & $\begin{array}{l}\text { Long Term (Mature } \\
\text { Development Phase) }\end{array}$ \\
\hline Total harvestable biomass (million tons) & 304 & 652 \\
\hline Potential number of biorefineries* & 240 & 358 \\
\hline $\begin{array}{l}\text { Estimated required number of agricultural } \\
\text { equipment: } \\
\text { Baling scenario } \\
\text { Chopping scenario }\end{array}$ & $\begin{array}{l}187,442 \\
92,581\end{array}$ & $\begin{array}{l}218,946 \\
160,147\end{array}$ \\
\hline $\begin{array}{l}\text { Estimated market value of agricultural equipment } \\
\text { (U.S. dollars): } \\
\text { Baling scenario } \\
\text { Chopping scenario }\end{array}$ & $\begin{array}{l}24.17 \\
10.98\end{array}$ & $\begin{array}{l}28.37 \\
18.99\end{array}$ \\
\hline $\begin{array}{l}\text { Estimated number of operators to run agricultural } \\
\text { equipment: } \\
\text { Baling scenario } \\
\text { Chopping scenario }\end{array}$ & $\begin{array}{l}49,761 \\
26,444\end{array}$ & $\begin{array}{l}57,773 \\
45,815\end{array}$ \\
\hline Estimated number of participating crop growers & 123,928 & 162,315 \\
\hline $\begin{array}{l}\text { Estimated net annual income of participating } \\
\text { crop growers (billions of U.S. dollars/year) }\end{array}$ & 2.48 & 3.25 \\
\hline
\end{tabular}

* The annual biorefinery demand is assumed to be 800,000 dry tons/year. 


\subsection{Limitation of the Existing Agricultural Biomass Supply Chains}

Although there is a well-established agricultural equipment manufacturing industry in the United States, the lessons learned from the three pioneering cellulosic ethanol plants reveal that the existing agricultural machinery fleet is not able to meet the cost, quantity, and quality specifications of these facilities. In order to produce biofuels at competitive prices and with the same functionality as the petrochemical counterparts, cost-efficient and effective biomass supply chains must be developed that are capable of delivering commercial quantities of biomass to biorefineries at an affordable price and with the predictable and consistent quality. Among the existing agricultural machinery, harvest equipment usually has the highest impact on the performance of the biomass supply chains. The harvest equipment in baling and chopping scenarios includes:

- Baler

- Size, shape, and density of bales impact the downstream storage and handling operations at biorefineries.

- Timing of the baling operation impacts the moisture content of bales.

- Baler design and baling operation also impact the ash content of biomass. An inefficient baling operation can pick up dirt and contamination.

- Shredder/windrower

- Shredding and windrowing impact the moisture absorption/desorption of biomass.

- Rake design and shredding/windrowing operations impact dirt content in biomass.

- Shredded and windrowed biomass impacts the efficiency of balers to pick up biomass and make bales with consistent sizes and shapes.

- Forage harvester

- This equipment impacts the size and shape of chopped materials, their flowability, and moisture absorption/desorption at pile storage and the biological degradation.

The improvement in these field operations can support the transition from the current state of the industry to future advanced feedstock supply chains that are capable of meeting cost, quantity, and quality specifications of future biorefineries. It is noteworthy that other pieces of equipment such as transportation equipment would also have a significant impact on the cost of biomass delivered to biorefineries. However, harvest equipment can also have a significant impact on the quality of biomass delivered to biorefineries. 


\section{Transition in Agricultural Equipment}

The first step to understand and evaluate transitions in agricultural equipment is to identify different stakeholders involved in the supply chains of agricultural equipment and their roles. Figure 32 shows these stakeholders in agricultural equipment supply chains, including equipment manufacturers, dealers, end users, governments and regulators, and other stakeholders such as seed producers and food companies.

\section{Governments and regulators}

Agricultural equipment manufacturers

- Full-line

- Specialty short-line

- Small family operations
Dealers

- Dependent

- Independent
End users

- Farmers/crop growers

- Custom operators

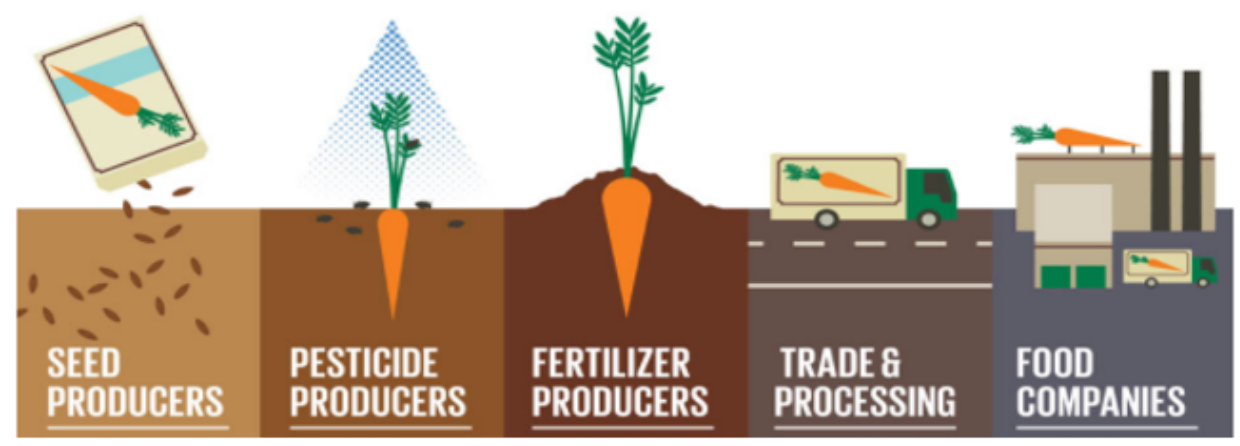

Other stakeholders

Figure 32. Stakeholders involved in agricultural equipment supply chains. These actors impact the adoption of new technologies in the farm machinery sector (adopted from Wallich 2013).

The resiliency, robustness, and economic sustainability of agricultural equipment supply chains impact the introduction of new technologies and their adoption speed and rate in the agricultural sector. The adoption of a transition will be self-sustaining if the transition creates a net gain for all the actors of the supply chain, which is not usually the case in reality. $A$ transition may create organizational conflicts. For example, the introduction of electric and autonomous farm machinery has already created a resistance among dealers, because a large portion of dealers' income comes from the maintenance and repair services they provide to customers. Another example of organizational conflicts is the introduction of self-propelled harvest equipment by full-line companies, because they manufacture both tractors and implements (e.g., balers). Introduction of self-propelled harvest equipment can create conflicts between the tractor manufacturing department and the implement department in a full-line manufacturer.

Demand is driving the adoption of new technologies in the agricultural equipment industry. Demand signals to develop new technologies are created by different factors, such as continued declines in the agricultural workforce; global population growth; increased costs of animal feeds; continued declines in natural resources, such as water; sustainable farm 
practices; growth in the organics food sector; and utilization of biomass for emerging markets, such as biofuel and biochemicals. In this segment, five recent technology developments are introduced, and drivers and barriers of these new technologies are discussed. The information on these technologies was collected through interviewing the companies that developed these technologies. Thus, the information provided about the pieces of equipment and their advantages compared with the existing equipment is quoted from the interviewers. Table 15 shows the list of these companies, their recently introduced equipment, and points of contacts.

Table 15. Recent Transitions in Agricultural Equipment Manufacturing Studied in This Report

\begin{tabular}{|l|l|l|}
\hline $\begin{array}{l}\text { Agricultural } \\
\text { Equipment }\end{array}$ & Manufacturer & Points of Contact \\
\hline $\begin{array}{l}\text { Mobile pellet } \\
\text { harvester: Premos }\end{array}$ & Krone, Germany & $\begin{array}{l}\text { Felix Reuver, sales export manager } \\
\text { Richard Shelton, national sales manager } \\
\text { André Wilmer, product management }\end{array}$ \\
\hline $\begin{array}{l}\text { ZR5 self-propelled } \\
\text { baler }\end{array}$ & Vermeer, United States & $\begin{array}{l}\text { Jay Van Roekel, biomass business unit } \\
\text { manager } \\
\text { Josh Vrieze, product manager }\end{array}$ \\
\hline $\begin{array}{l}\text { Autonomous Harvest } \\
\text { System }\end{array}$ & $\begin{array}{l}\text { Kinze Manufacturing, United } \\
\text { States }\end{array}$ & $\begin{array}{l}\text { Brian A. McKown, executive vice president } \\
\text { and chief operating officer }\end{array}$ \\
\hline $\begin{array}{l}\text { Autonomous self- } \\
\text { propelled baler }\end{array}$ & $\begin{array}{l}\text { Autonomous Tractor Corp. } \\
\text { (ATC), United States }\end{array}$ & Kraig Schulz, chief executive officer \\
\hline $\begin{array}{l}\text { Plus2 round bale } \\
\text { accumulator }\end{array}$ & John Deere, United States & John Deere website \\
\hline
\end{tabular}

The information about these new pieces of equipment was collected by interviewing via phone calls and emails. The six main questions that were addressed during the interview include:

1. What are the motivations and market drivers behind the development of the equipment?

2. What are the main barriers in the adoption of the new equipment throughout the supply chain?

3. Who are your main target consumers: individual farmers or custom harvest groups?

4. What criteria do you consider to sell the equipment to different regions of the world-in particular, North America?

5. What drives the decision regarding where equipment is manufactured (facility location)?

6. What is the range of capital cost (research and development [R\&D], manufacturing, field trials) incurred by the agricultural equipment manufacturer to adopt the new equipment in the market?

\subsection{Krone Mobile Pellet Harvester Prototype}

In 2015, Krone, the German agricultural equipment manufacturer, unveiled a prototype machine, called Premos 5000. This machine can go straight into a field of swathed hay or straw and compress it into 12 millimeter $(\mathrm{mm}) \times 30 \mathrm{~mm}$ pellets. The produced pellet can be used for 
three existing markets of animal bedding, animal feeding, and bioenergy. The pellets are typically 3.5 times the density of straw bales and take up less space. The Premos 5000 can also be used outside the normal growing season by pelletizing shredded bales (Figure 33). After the harvest season, the equipment can be used as a stationary unit with straw brought to it. Table 16 lists the drivers and barriers for adoption of the Krone Mobile Pellet Harvester.
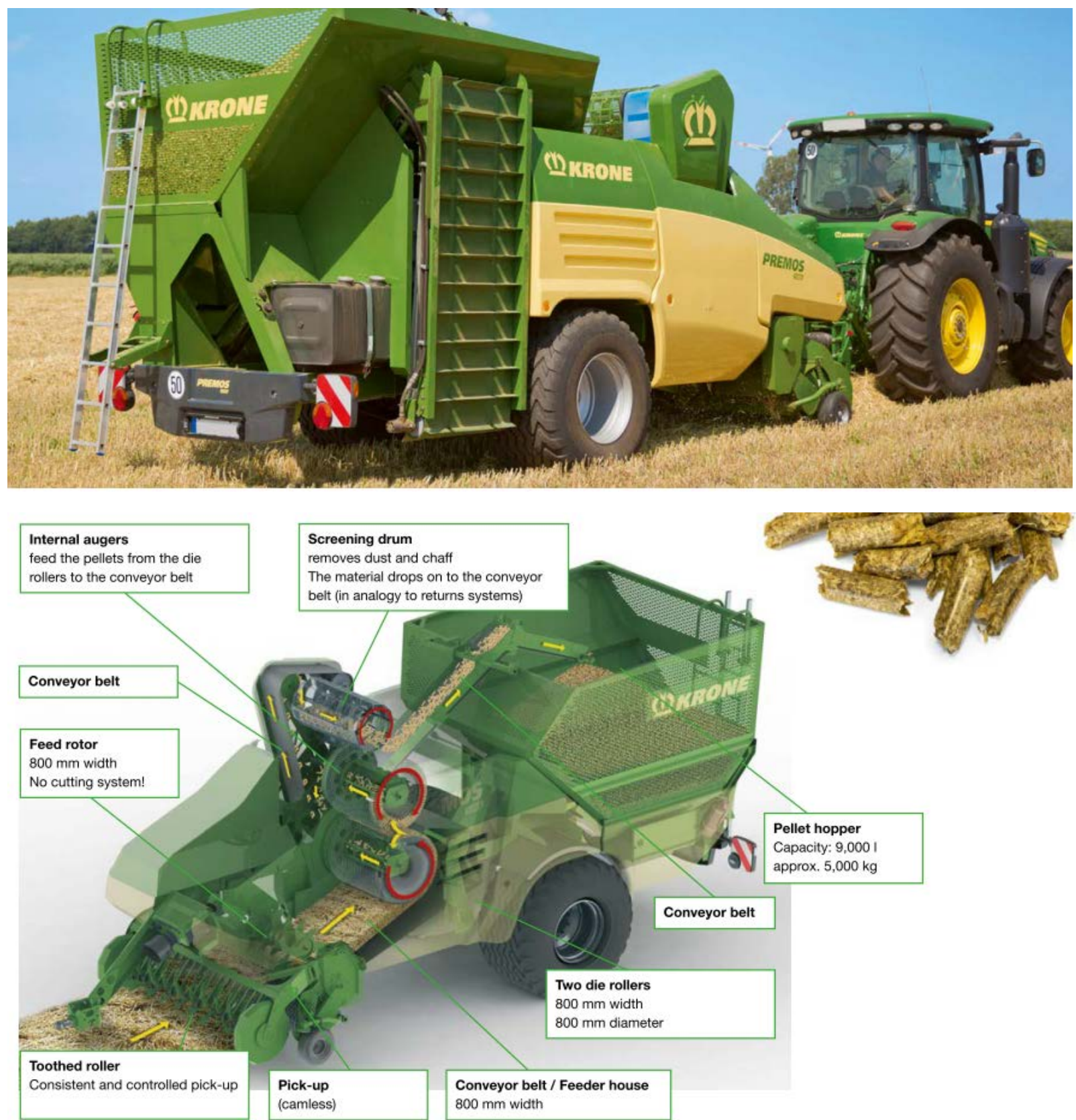

Figure 33. Krone Premos 5000-the first mobile pellet harvester prototype (Krone 2015, www.krone.de) 
Table 16. Drivers and Barriers for the Adoption of Krone Mobile Pellet Harvester, Premos $\mathbf{5 0 0 0}$ (Personal Communication with Krone, September 2017)

\begin{tabular}{|l|l|}
\hline Motivation/drivers & $\begin{array}{l}\text { 1. Offering alternative solutions for crop residue utilization } \\
\text { 2. Increasing transport efficiency } \\
\text { 3. Increasing demand for renewable energy sources. }\end{array}$ \\
\hline Barriers/challenges & $\begin{array}{l}\text { 1. Utilization of the equipment year-round (in field and stationary)- } \\
\text { lack of an established year-round market } \\
\text { 2. Production of durable pellets under changing crop conditions } \\
\text { 3. Available service and parts network } \\
\text { 4. Adoption of either the pelletizer and/or the downstream supply } \\
\text { chain (transportation, storage, pellet burners, pellet feeders). }\end{array}$ \\
\hline $\begin{array}{l}\text { Main customer groups } \\
\text { Crops/biomass pelletized }\end{array}$ & $\begin{array}{l}\text { Larger individual farmers, farmers' cooperation, custom operators } \\
\text { sain tests have been performed in different straw varieties, alfalfa, } \\
\text { and different grass varieties. Further testing will also include: corn } \\
\text { stalks, rice straw, sugarcane trash, dry manure, miscanthus, canola } \\
\text { straw, etc. }\end{array}$ \\
\hline $\begin{array}{l}\text { Criteria to sell the } \\
\text { equipment to different } \\
\text { regions of the world-in } \\
\text { particular, North America }\end{array}$ & $\begin{array}{l}\text { Market potential for the produced good (pellets), available service and } \\
\text { parts network, machine being prepared and well-tested for particular } \\
\text { market requirements (e.g., harvested crops and harvesting conditions) }\end{array}$ \\
\hline $\begin{array}{l}\text { Drivers behind the decision } \\
\text { on where equipment is } \\
\text { manufactured }\end{array}$ & $\begin{array}{l}\text { Main distribution/market opportunities, available resources in the } \\
\text { market, ability to reach desired quality output }\end{array}$ \\
\hline
\end{tabular}

\subsection{Vermeer ZR5 Self-Propelled Baler}

Vermeer developed a self-propelled baler prototype, called ZR5 (Figure 34). This machine was manufactured to address the shortage of experienced operators during the peak harvest season and to improve the field efficiency of the baling operation. It also aims to improve the efficiency of picking the bales after the baling operation by improving the position of bales in the field. A summary of the interview with Vermeer about the ZR5 self-propelled baler is provided in Table 17. 


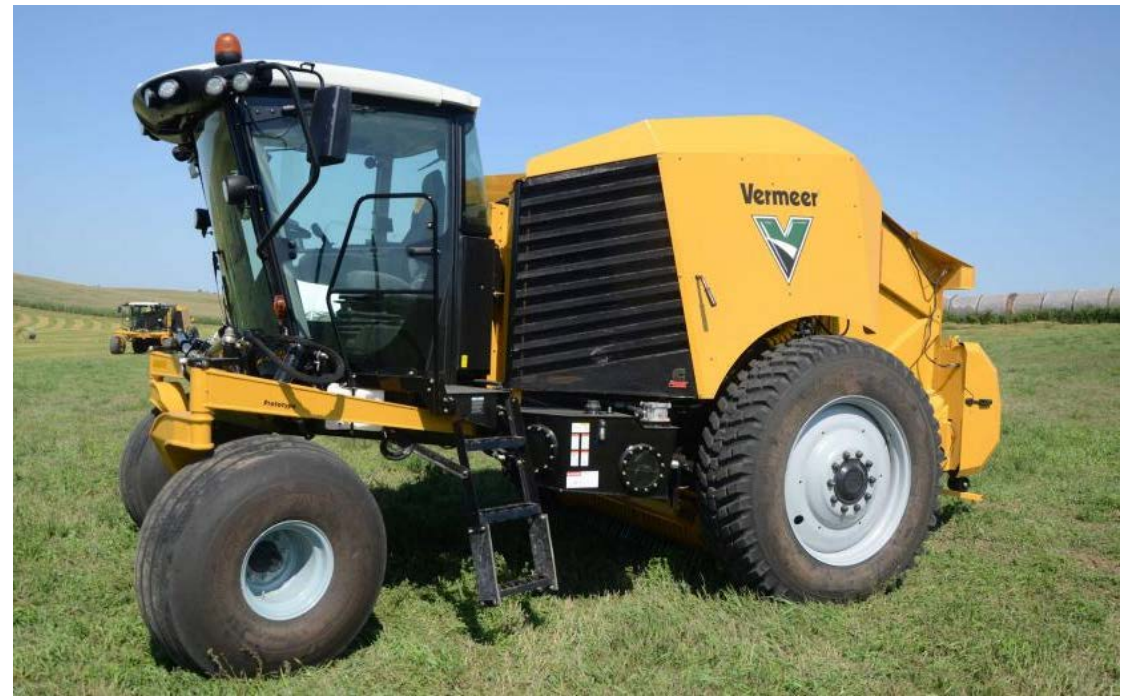

Figure 34. ZR5 self-propelled baler. Vermeer established an R\&D group called "forage innovation" to develop the prototype of this machine (Vermeer 2017)

Table 17. Drivers and barriers for the adoption of Vermeer ZR5 self-propelled baler (Personal communication with Vermeer, October 2017)

\begin{tabular}{|l|l|}
\hline Motivation/drivers & $\begin{array}{l}\text { 1. (1) Improving field efficiency of harvest and collection } \\
\text { operations }\end{array}$ \\
\hline $\begin{array}{l}\text { 2. Reducing the need for skilled labors } \\
\text { 3. Reducing operator fatigue. }\end{array}$ \\
\hline Barriers/challenges & $\begin{array}{l}\text { Service/support capabilities. For our agriculture dealers, this will } \\
\text { be the first time we have produced a machine with sophisticated } \\
\text { hydraulics. }\end{array}$ \\
\hline Main customer groups & $\begin{array}{l}\text { Custom/commercial hay growers, because they have difficulty } \\
\text { getting qualified labors to run their fleets in a short harvest season. }\end{array}$ \\
\hline $\begin{array}{l}\text { Criteria to sell the equipment to } \\
\text { different regions of the world- } \\
\text { in particular, North America }\end{array}$ & $\begin{array}{l}\text { We are currently only planning to have this machine in North } \\
\text { America. Many design changes would be needed to have it } \\
\text { accepted in other parts of the world, because they use a smaller } \\
\text { bale size outside of North America. }\end{array}$ \\
\hline $\begin{array}{l}\text { Drivers behind the decision on } \\
\text { where equipment is } \\
\text { manufactured }\end{array}$ & We have all of the facilities in Pella, lowa, to manufacture the ZR5. \\
\hline
\end{tabular}

\subsection{Kinze Manufacturing Autonomous Grain Harvest System}

The Kinze Manufacturing Autonomous Harvest System includes the combine with an operator and the tractor with a grain cart (without an operator) (Figure 35). The combine operator instructs the tractor/grain cart from a Samsung tablet computer. The tablet provides an aerial view of the field with the combine and tractor locations. It will also switch to a camera view from the tractor. The operator can give the tractor four commands from the tablet. The autonomous grain cart system allows farmers to keep their combine running during the brief harvest window without needing an extra person in the field to run the tractor and cart. A 
summary of the interview with Kinze Manufacturing about its autonomous harvest system is provided in Table 18.

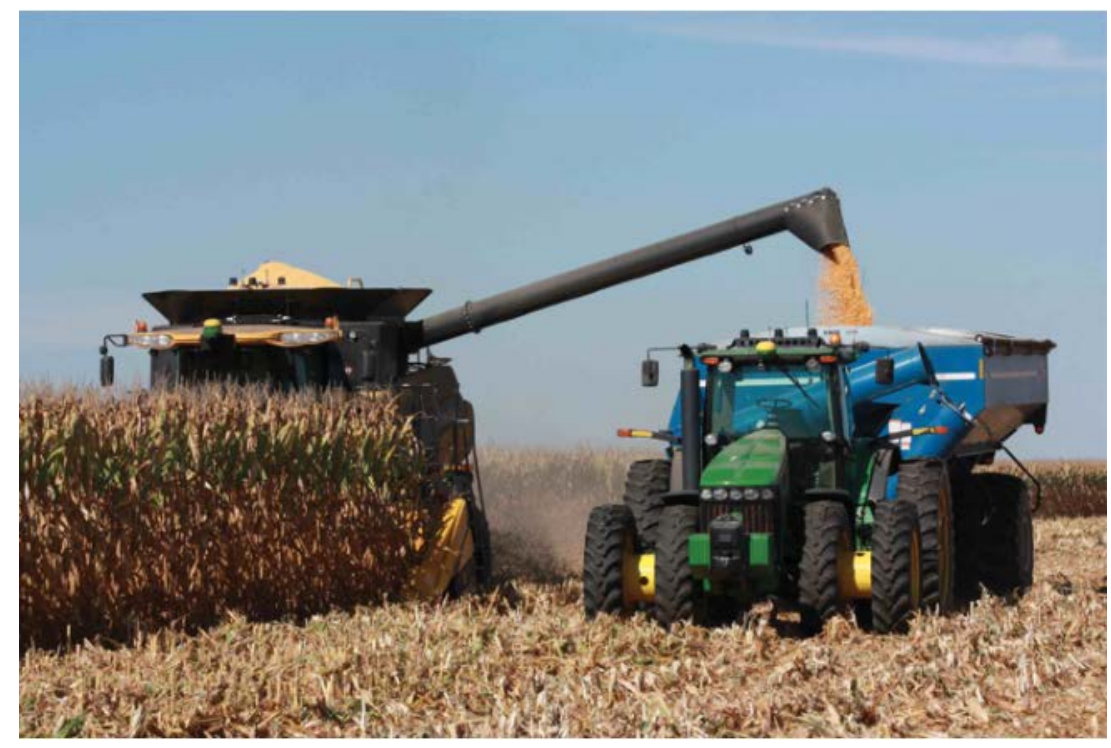

Figure 35. Kinze Manufacturing Autonomous Harvest System (Kinze Manufacturing 2014) 
Table 18. Drivers and Barriers for the Development of Kinze Manufacturing Autonomous Harvest System (Personal Communication with Kinze Manufacturing, October 2017)

\begin{tabular}{|c|c|}
\hline Motivation/drivers & $\begin{array}{l}\text { 1. Leveraging existing technology: Autonomous technology already exists in } \\
\text { other industries, which minimizes the risk of technology development and } \\
\text { adoption. For example, a Global Positioning System that is the core of the } \\
\text { autonomy is a mature technology. Advancements and demonstrations in real- } \\
\text { time image and video processing and artificial intelligence has boosted } \\
\text { regulators' confidence to develop best practices for regulating autonomous } \\
\text { vehicles on highways. In } 2017,33 \text { states have introduced legislation, and last } \\
\text { year, } 20 \text { states introduced legislation. } \\
\text { 2. Downsizing field equipment: Field operation productivity remains a challenge } \\
\text { for farmers. The large variability in field operations makes it difficult for even } \\
\text { skilled operators to experience robust performance from field to field. Given } \\
\text { the chronic shortage of skilled labors during peak planting and harvest } \\
\text { seasons, low productivity has led to significant profit losses for farmers, both } \\
\text { in terms of the amount of harvested crops (yield loss) and productive time. } \\
\text { The agricultural equipment industry has used different solutions to tackle the } \\
\text { low productivity. Kinze Manufacturing believes that farmers use high } \\
\text { horsepower tractors because of human errors in harvest and collection, which } \\
\text { result in lower field efficiency (acre/hour). One major solution involves using } \\
\text { smart devices to offset human errors, allowing an unexperienced operator to } \\
\text { do the same amount of harvest as an experienced operator without requiring } \\
\text { a higher horsepower tractor. } \\
\text { 3. Reducing fuel consumption and the associated emissions and operating } \\
\text { costs. } \\
\text { 4. Reducing wheel traffic and soil compaction by improving field operation } \\
\text { productivity. }\end{array}$ \\
\hline Barriers/challenges & $\begin{array}{l}\text { 1. High costs of new technologies such as electrification and autonomy. } \\
\text { 2. Organizational conflicts: In large, full-line manufacturers such as John Deere } \\
\text { and AGCO, adopting new technology often causes conflicts among different } \\
\text { departments. For example, John Deere has a large manufacturing facility } \\
\text { producing combustion engines. Developing electric engines and parts } \\
\text { conflicts with other parts of the organization. In addition, realizing a new } \\
\text { technology in large organizations proves to be more challenging because of } \\
\text { the complex decision-making process in such organizations compared with } \\
\text { short-line and specialty startup companies. The same issue could be true for } \\
\text { dealers. } \\
\text { 3. Local regulations: In some regions and states, local regulations can act as } \\
\text { barriers in the implementation of a new technology. }\end{array}$ \\
\hline $\begin{array}{l}\text { Main customer } \\
\text { groups }\end{array}$ & $\begin{array}{l}\text { Although Kinze Manufacturing focuses on large farm organizations in the United } \\
\text { States, Europe, and Russia, it targets customer segments that clearly } \\
\text { acknowledge there is a problem. Then the company conducts a cost-benefit } \\
\text { analysis of its new technology and demonstrates to these potential customer } \\
\text { segments that its technology can provide a cost-efficient solution to their problem. } \\
\text { This is the basis of its philosophy on targeting potential customer segments. }\end{array}$ \\
\hline $\begin{array}{l}\text { Drivers behind } \\
\text { decision regarding } \\
\text { location of } \\
\text { equipment- } \\
\text { manufacturing } \\
\text { facilities }\end{array}$ & $\begin{array}{l}\text { This decision mainly depends on the potential size of the market in a region and } \\
\text { the availability of infrastructure and workforce talent to support the supply, } \\
\text { manufacturing, and distribution facilities. For example, Kinze Manufacturing has a } \\
\text { manufacturing site in Lithuania, East Europe. They also have dealers in Europe. }\end{array}$ \\
\hline
\end{tabular}




\subsection{Autonomous Self-Propelled Baler by Autonomous Tractor Corp.}

Working with farmers, custom harvesters, and experts in biomass supply chain management, ATC conceived the Single-Pass, Autonomous, Follow-Me (SAF) Biomass Baler (Figure 36). The system uses an off-the-shelf baler powered by ATC's eDrive diesel-electric propulsion system and an off-the-shelf navigation system with "bread-crumb" or "follow-me" safety and navigation technology. The eDrive system is a novel propulsion system designed to power offroad, heavy-duty vehicles using electric motors that are placed directly in the wheel hub of the vehicle. eDrive has been field-tested and demonstrated over the past 3 years to hundreds of farmers, agricultural equipment dealers, farm managers, and academics. This design will allow the baling mechanism and the propulsion system to be powered completely independently of the combine, improving performance for the combine and allowing for faster baling processes. The follow-me navigation and safety system will allow the SAF baler to follow the combine safely in close proximity to ensure the harvest residue can be baled without hitting the ground, minimizing the ash content of the final product. The follow-me feature also allows the combine driver to maneuver in the field as he or she normally would without worrying about the attached baler behind the combine. A summary of the interview with ATC about the drivers and barriers for their semi-autonomous baler and electric-drive tractor is provided in Table 19.

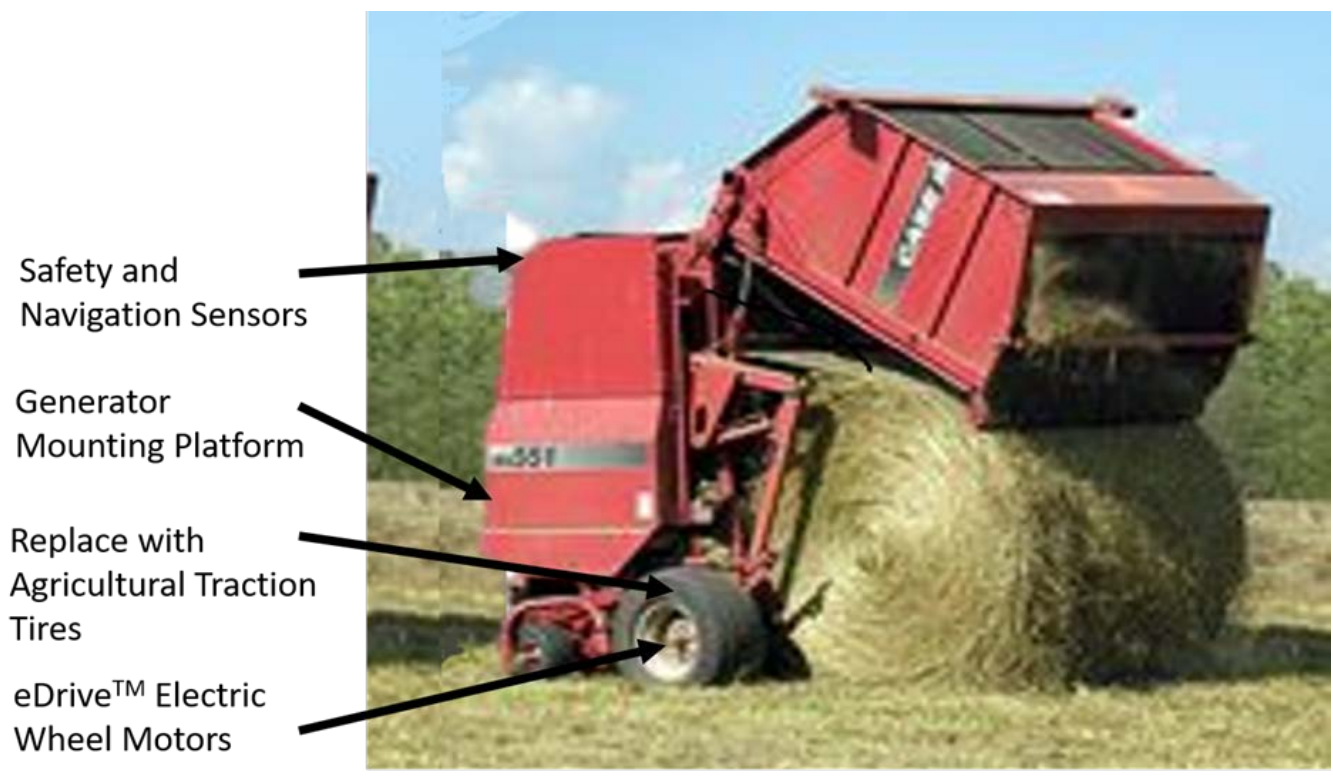

Figure 36. Proposed ATC SAF Biomass Baler (ATC 2017) 
Table 19. Drivers and Barriers for the Development of Autonomous Farm Equipment by ATC (Personal Communication with ATC, August and September 2017)

\begin{tabular}{|l|l|}
\hline Motivation/drivers & $\begin{array}{l}\text { 1. Eliminating the need for skilled labors/no need for operators at all } \\
\text { 2. Lowering equipment costs (e.g., fuel consumption, maintenance, } \\
\end{array}$ \\
& $\begin{array}{l}\text { 3. Reducing emissions } \\
\text { 4. Increasing the service life of the existing fleet } \\
\text { 5. Enhancing implement control }\end{array}$ \\
\hline Barriers/challenges & $\begin{array}{l}\text { 1. Resistance from the existing farm machinery industry and its dealers. } \\
\text { Initially, ATC is working with independent dealers. }\end{array}$ \\
& 2. Lack of availability of parts suppliers \\
\hline
\end{tabular}

\subsection{John Deere Plus2 Round Bale Accumulator}

The John Deere Plus2 round bale accumulator has the ability to carry two bales while making the third (Figure 37). The operator can drop one, two, or three bales in a strategic location in the field for easier and more efficient bale collection operation. Bales can be placed in the most strategic location to get them off of the field as quickly as possible while minimizing wheel traffic (Figure 38). Thus, bales will no longer be randomly scattered. In addition, better bale placement helps prevent them from rolling down the hill. A summary of drivers for the development of the John Deere Plus2 round bale accumulator is provided in Table 20.
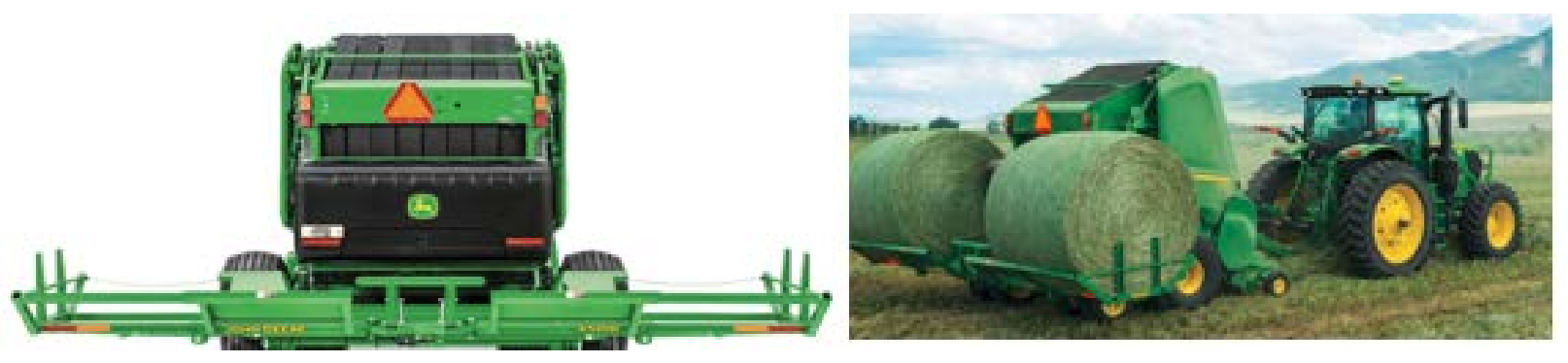

Figure 37. John Deere Plus2 round bale accumulator (John Deere 2017)

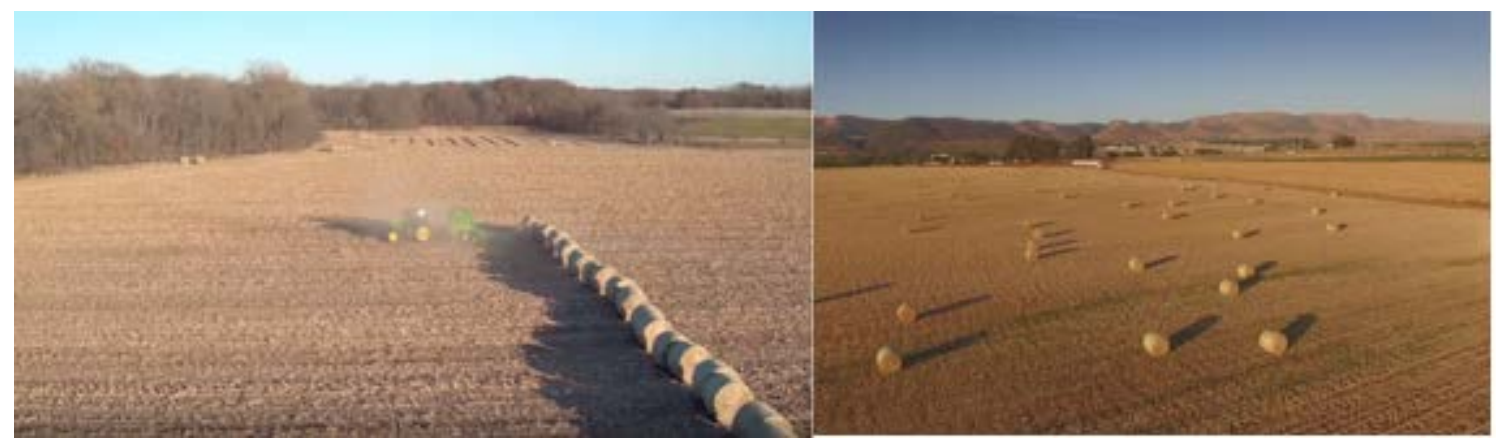

Figure 38. Left: bales collected by John Deere bale accumulators (John Deere 2017); Right: bales collected in a conventional baling operation 
Table 20. Drivers for the Development of the John Deere Plus2 Round Bale Accumulator

Motivation/drivers

1. Reducing time getting the bales off of the field

2. Reducing wheel traffic and the damage that excessive wheel traffic causes to the growth of the next crop

3. Reducing operator fatigue. 


\section{Transition from Conventional Feedstock Supply System to Advanced Feedstock Supply System}

The transition from CFSS to AFSS is unclear, mainly because the biofuel industry is still in its infancy. Further, with recent failures of several integrated biorefineries, it is unclear which technologies will emerge as long-term, viable paths for converting biomass to fuels, chemicals, and coproducts. It is generally recognized that herbaceous biomass and a few woody biomass (such as willow and poplar) are suitable feedstock for bioconversion pathways. Investors in new emerging technologies, in general, are risk-averse and will not invest in large and expensive (i.e., high capital expenditures) projects. The common mistake many pioneer biorefineries made is to build large plants (up to 1,000 tons/day biomass) without adequately proving the technologies first. Another key factor that contributed to the pioneer plants' failures is the variability of biomass properties delivered to the biorefinery. This variability arises primarily from the current agricultural practices (machine design and operation) of harvesting, collection, and storage. These practices have worked well and met the agriculture sector's needs, but they do not meet the biorefineries' needs or feedstock specifications.

This forced the biorefineries to develop mitigation methods to counter the negative impact caused by the variability of delivered biomass properties. However, the best strategy for reducing operational reliability issues and minimizing costs is to prevent the causes of the problems initially (i.e., the variability in biomass properties delivered to the biorefinery). The latter method requires significant changes to the current agricultural practice, and this often causes conflicts with traditional farming practices.

Another significant issue with conventional agricultural residue feedstocks is its low initial carbohydrate content and additional degradation during conventional storage. New generation biorefineries should use the knowledge gained from current agricultural practices to design feedstock supply systems that meet conversion technology requirements and refrain from using low-cost agricultural residues that consistently fail to meet the required quality. As mentioned previously, the latter approach has led to failures of several pioneer biorefineries. Idaho National Laboratory has developed an advanced feedstock supply system to provide stable, consistent feedstock quality to biorefineries (INL 2014). The AFSS is based on densification of feedstock. The project focuses on how to build each component of the feedstock supply chain to enable transition from the current state of the industry to a future commodity-based feedstock supply system, using emerging technologies and technology adoption as the pathway. Several feedstock densification technologies that could potentially be part of the AFSS are briefly described below.

\subsection{Advanced Feedstock Preprocessing}

Depending on the specifications of feedstock, there are two major categories for advanced feedstock preprocessing: (1) pelletized feedstock, which has high bulk density and is not susceptible to microbial degradation when properly stored (e.g., covered in silos or bunkers) and (2) ensiled storage, which has low dry matter loss (about 5\%) compared with conventional bale storage (12\%) (Wendt 2017). Storing bales in the field also leads to uneven degradation of 
bale and fiber structure integrity, which causes preprocessing difficulties (e.g., material loss during handling, equipment plugging, and inconsistent feedstock quality) (Figure 39).

Both of these advanced preprocessing and storage systems can be deployed in distributed depots. Pelletized feedstock has an average moisture content of about $12 \%$ wet basis. The moisture of ensiled feedstock is about $40 \%-60 \%$. INL has met the Bioenergy Technologies Office's 2017 cost target of \$84/ton feedstock utilizing fractional milling, high-moisture densification, and least-cost formulation/blending (Thompson 2017). To date, because of a lack of clear, uniform specifications of commercial feedstock for biochemical conversion and thermochemical conversion pathways, the R\&D effort has focused primarily on reducing the cost of feedstock for a set of standard compositions used in NREL techno-economic evaluations (Humbird et al. 2011; Jones et al. 2013).

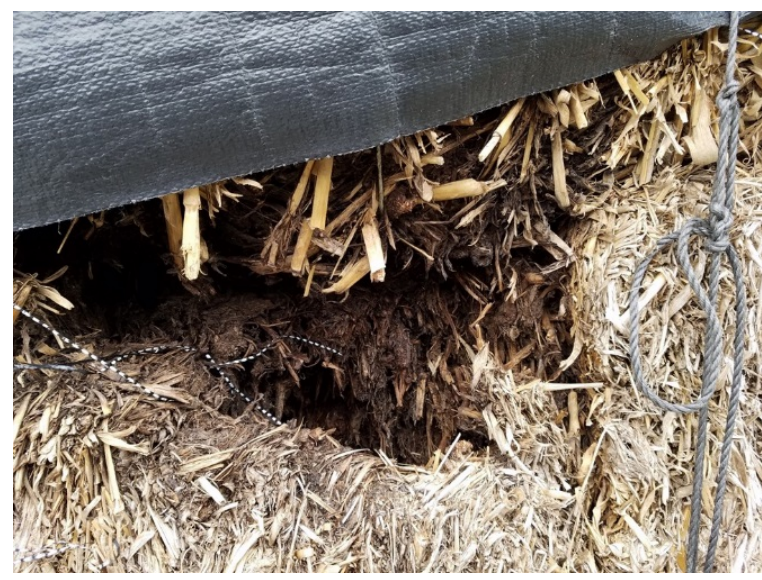

Degradation of tarped bales

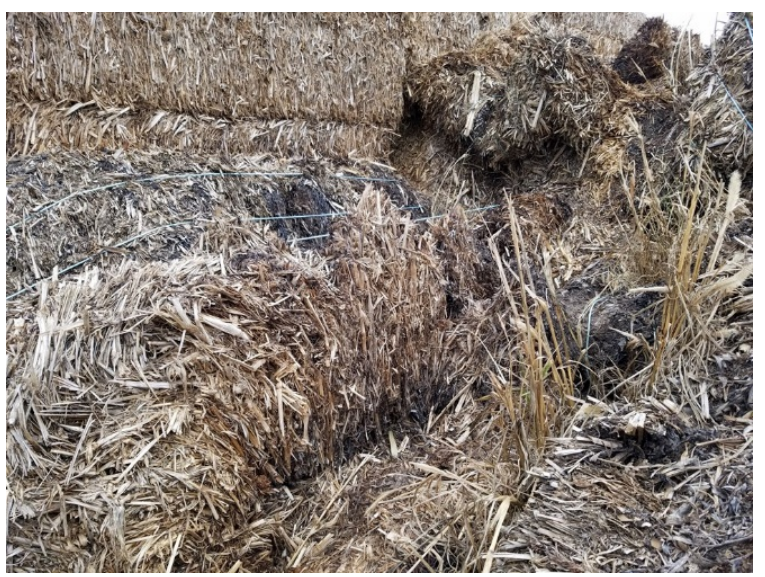

Loss of bale integrity

Figure 39. Corn stover bales after 2 years storage near Nevada, lowa

Photos courtesy of Quang Nguyen, taken Nov 1st, 2018

\subsection{Fractional Milling}

In fractional milling and pelleting (Figure 40 ), approximately $50 \%$ of first-stage ground biomass bypasses the second-stage grinder, which results in energy savings as high as $38 \%$ (Table 21 ) and lower second-stage milling equipment cost (Thompson 2017).

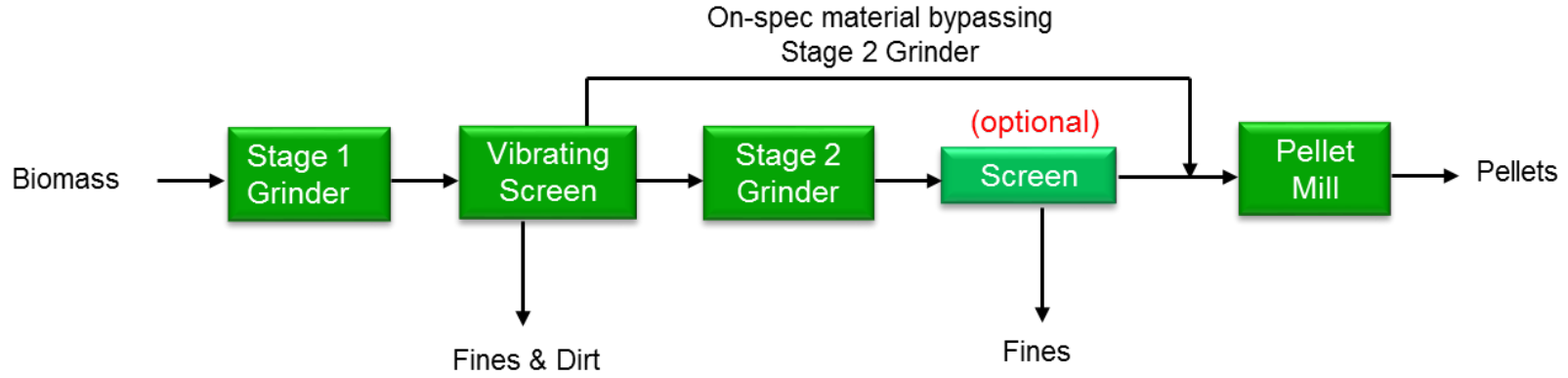

Figure 40. Fractional milling and pelleting 
Table 21. Reduction in Milling and Pelleting Energy by Fractional Milling

\begin{tabular}{|l|c|c|c|c|c|c|c|c|c|}
\hline \multicolumn{1}{|c|}{$\begin{array}{c}\text { Milling and } \\
\text { Pelleting Energy }\end{array}$} & \multicolumn{3}{c|}{$\begin{array}{c}\text { Conventional } \\
\text { Milling }\end{array}$} & \multicolumn{3}{c|}{$\begin{array}{c}\text { Fractional Milling } \\
\text { Using 1/4 In. } \\
\text { Vibrating Screen }\end{array}$} & \multicolumn{2}{c|}{$\begin{array}{c}\text { Fractional Milling } \\
\text { Using 7/16 In. } \\
\text { Vibrating Screen }\end{array}$} \\
\hline Stage 2 screen size & $\begin{array}{c}1 / 4 \\
\text { in. }\end{array}$ & $\begin{array}{c}7 / 16 \\
\text { in. }\end{array}$ & $\begin{array}{c}1 / 2 \\
\text { in. }\end{array}$ & $\begin{array}{c}1 / 4 \\
\text { in. }\end{array}$ & $\begin{array}{c}7 / 16 \\
\text { in. }\end{array}$ & $\begin{array}{c}1 / 2 \\
\text { in. }\end{array}$ & $\begin{array}{c}1 / 4 \\
\text { in. }\end{array}$ & $\begin{array}{c}7 / 16 \\
\text { in. }\end{array}$ & $\begin{array}{c}1 / 2 \\
\text { in. }\end{array}$ \\
\hline $\begin{array}{l}\text { Stage 2 milling energy (kilowatt- } \\
\text { hour [kWh]/ton) }\end{array}$ & 73 & 50 & 32 & 44 & 30 & 19 & 32 & 22 & 15 \\
\hline Pelleting energy (kWh/ton) & 36 & 52 & 62 & 36 & 52 & 62 & 36 & 52 & 62 \\
\hline Total energy (kWh/ton) & 109 & 102 & 94 & 80 & 82 & 81 & 68 & 74 & 77 \\
\hline $\begin{array}{l}\text { Reduction in energy compared with } \\
\text { conventional milling }\end{array}$ & \multicolumn{3}{|c|}{ N/A } & $27 \%$ & $20 \%$ & $14 \%$ & $38 \%$ & $27 \%$ & $18 \%$ \\
\hline
\end{tabular}

Note: Drying energy is not included.

\subsection{High-Moisture Densification}

Using conventional methods, biomass must be at about $10 \%$ moisture (wet basis) prior to being pelleted. In high-moisture densification, biomass is pelleted at up to $30 \%$ moisture (wet basis). High-moisture pelleting is feasible because the process utilizes preheating to about $110^{\circ} \mathrm{C}$ and frictional heat in the die to reduce the moisture of biomass by about $10 \%$. High-moisture pelleting also takes advantage of lower lignin glass transition temperature, which results in a reduction of total processing energy of up to $48 \%$ (Figure 41 ). The high-moisture pellets are then dried using grain belt dryers. The reduction in total cost up to $50 \%$ had been demonstrated using a 1 ton/hour pellet mill (Tumuluru 2017).
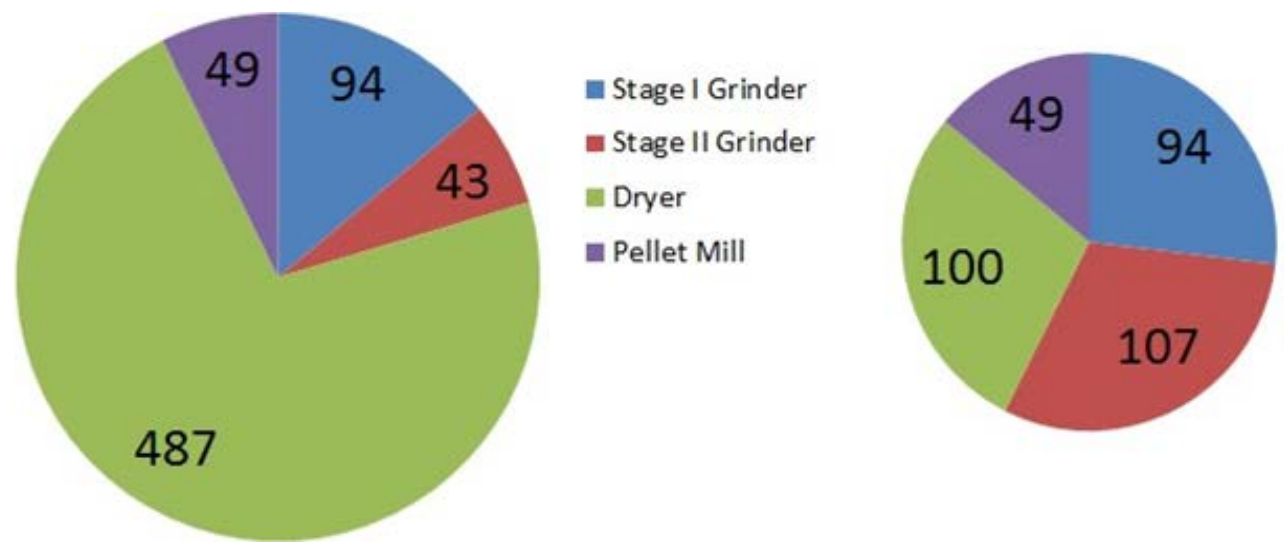

Figure 41. Energy consumptions in conventional and high-moisture pelleting of corn stover (conventional pelleting $=673 \mathrm{kWh} / \mathrm{ton}$, high-moisture pelleting $=350 \mathrm{kWh} / \mathrm{ton}$ )

The one-pass harvest and baling equipment and the mobile pellet harvester could have a major role in the transition from a CFSS to an AFSS. However, the transition may lag behind, because pioneer biorefineries tend to preprocess biomass themselves at the plants for a number of reasons: keeping the preprocessing technology proprietary, keeping the value of upgrading biomass to conversion-ready feedstock quality, and maintaining control and adjusting feedstock quality in response to changing conversion process requirements. It is reasonable to assume 
that until there are several successful biorefineries in operation, the conversion-ready feedstock specifications will not be fully known. The key properties of biomass feedstock delivered to the reactor throat are: low content of contaminants (such as dirt and ash), particle size, moisture content, and chemical composition. Each conversion technology will likely have different requirements. Table 22 provides a summary of potential drivers and barriers to transition from a CFSS to an AFSS.

Table 22. Summary of Potential Drivers and Barriers to Transition from a Conventional Feedstock Supply System to an Advanced Feedstock Supply System

\begin{tabular}{|l|l|}
\hline Motivation/drivers & $\begin{array}{l}\text { Consistent quality feedstock } \\
\text { Lower dry matter loss during storage }\end{array}$ \\
\hline Barriers/challenges & $\begin{array}{l}\text { Feedstock specifications undefined or unknown } \\
\text { Lack of performance and cost versus benefit data }\end{array}$ \\
\hline
\end{tabular}




\section{Conclusion and Discussion}

This report detailed the analysis results of agricultural and preprocessing equipment and manufacturing requirements to support the mobilization of the 2016 Billion-Ton Report (U.S. Department of Energy 2016) projections utilizing the conventional supply chain logistics. Five major biomass resources were selected for the analysis of feedstock equipment and manufacturing requirements to support the mobilization of commercial quantities of biomass resources utilizing the conventional supply chains: corn stover; perennial grasses, including switchgrass and miscanthus; hybrid poplar; and willow.

\subsection{Analyzing Results}

The analysis found the following:

- Based on the 2016 Billion-Ton Report, 304 million-652 million tons/year of five major biomass resources (corn stover; the perennial grasses switchgrass and miscanthus; coppice woody crops (such as willow); and non-coppice woody crops (such as poplar)) are available from agricultural lands in the United States.

- Using ORNL SCM, the analysis estimated that the selected biomass resources could support 240-358 potential biorefineries that convert 230 million - 340 million tons of biomass to biofuels annually.

- Using the INL IBSAL model, the number and market value of the agricultural equipment required to harvest and deliver biomass to the biorefineries is estimated to be:

- About 280,000 pieces of equipment with a market value of $\$ 36$ billion in the short term.

- About 380,000 pieces of equipment with a market value of more than $\$ 47$ billion in the long term.

- U.S. agricultural equipment manufacturing industry analysis suggests:

○ Approximately $70 \%-80 \%$ of total U.S. agricultural equipment demand is supplied from domestic manufacturers.

- Without large changes in existing international trade policy and global manufacturing infrastructure status, it is reasonable to assume that, under the 2016 Billion-Ton Report scenarios, the manufacturing will be similar to that status quo, with U.S. production meeting $70 \%-90 \%$ of U.S. demand, depending on equipment type, and $70 \%-80 \%$ of overall demand.

- Economic impacts from the required agricultural equipment were estimated using the IMPLAN model.

- Assuming $75 \%$ of all agricultural equipment is manufactured domestically, the sum of direct long-term employment impacts for the baling and chopping scenarios is more than 56,000 FTE job years and would result in almost $\$ 11$ billion in direct value added (contribution to the GDP). The sum of total long- 
term impacts is more than 340,000 FTE job years and nearly $\$ 40$ billion in total value added.

- These estimates assume that all required agricultural equipment is newly manufactured, and they do not account for the use of the existing agricultural equipment fleet to harvest and deliver biomass.

\subsection{Pinpointing Drivers}

Demand is driving the adoption of new technologies in the agricultural equipment industry. The demand can be created by farmers asking for higher field efficiency or by custom harvest groups asking for smarter and more automatic equipment that does not need a skilled labor to run it because of the continued declines in the access to skilled workforce. End users of biomass asking for higher-quality biomass (e.g., lower ash content) can also create this demand. Reviewing five recent transitions in agricultural equipment and interviewing farm equipment manufacturers revealed that the main drivers behind the introduction of new and improved machineries include the desire to:

- Improve the field efficiency of harvest and collection operations.

- Increase biomass transport efficiency and the stability of biomass in storage.

- Increase the demand for renewable energy sources.

- Eliminate the need for skilled operators or any operators at all.

- Reduce wheel traffic and the damage that excessive wheel traffic causes to the growth of the next crop.

- Reduce operator fatigue.

- Reduce equipment costs (e.g., fuel consumption, maintenance, and repair) and increase the service life of the existing agricultural fleet.

- Reduce emissions.

- Improve implement control.

- Realize the autonomous technology in other industries.

- Downsize field equipment.

- Improve the quality of collected biomass (e.g., lower ash content).

\subsection{Identifying Challenges}

Adopting these new technologies comes with challenges and barriers, including:

- Resistance from the existing farm machinery industry and its dealers

- Lack of availability of parts suppliers in some regions of the country

- Lack of strong service/support capabilities in the existing distribution and dealer network 
- High costs of new technologies

- Organizational conflicts within companies between departments promoting existing vs. new technologies, or between manufacturers promoting new technology and dealers that depend on servicing existing technology for revenue.

\subsection{Addressing Barriers}

Farm machinery supply chains need strong signals from biomass producers, biomass logistics companies, and biomass end users to tackle the barriers for the adoption of new technologies. There are several factors to consider to accelerate the transitions in agricultural equipment to support the development of a bioeconomy in the United States.

- Transition adoption: A transition will be self-sustaining if it creates a net gain for all supply chain stakeholders, which is not usually the case. A transition may create organizational conflicts. For example, introducing electric and autonomous farm machinery has created resistance among dealers, because a large portion of their income comes from maintenance and repair services they provide customers. Dealers would have to rethink their economic model, because electric equipment requires less maintenance. Involving dealers in installing electric drive systems would allow them to charge for parts and labor. Further, interviews with Krone and Vermeer indicate that adopting new technologies in farms requires strong support from dealers to provide farmers and custom harvest groups with a wide range of services before and after the sale of the equipment, especially the availability of skilled personnel and parts in case equipment does not function as expected in the field. Another example is organizational conflict between the tractor manufacturing department and the implement (e.g., balers) department with the introduction of self-propelled harvest equipment by full-line companies.

- Market size for the modified/new machinery: Market size of new machinery is important for farm machinery manufacturers. The size of the market should be large enough to offset all the transition costs, such as design of new equipment, manufacturing, field tests, dealer training and support, and distribution network. The market size is mainly determined by the size of the demand for biomass by biorefineries.

- Farm-gate price of biomass: The price paid to crop growers and custom harvest groups should be high enough to cover the costs of harvesting operations using new or existing equipment. This factor is connected to the affordability of biorefineries and how much they are willing to pay for the biomass.

- Size of harvest area: Harvest area is an important factor for custom harvest operators and individual growers who consider purchasing modified/new machinery. The new farm machine needs to be used for a certain number of hours in a harvest season to recover its capital costs. This is a decision that some of the dedicated biomass crop producers consider. As these producers grow, they would like to know how many acres 
they need to harvest to recover the capital cost of the equipment in 5-10 years if they own the equipment.

- Labor supply: This is important for custom harvest operators, individual growers who own the modified/new machinery, and biorefineries. The number of acres that can be completed each day is the most critical measure of machinery capacity, more than machine width or acres completed per hour. The availability of extra operators, the level of required expertise to harvest a crop in a timely and cost-efficient manner, and the possibility of working longer hours during critical periods and variability because of weather conditions can impact the decision about purchasing new equipment. Biorefineries in remote areas may have difficulty attracting and retaining skilled workers, which can lead to operational difficulties, and ultimately lower profitability.

- Quality of biomass: Putting a price or a penalty on the quality of biomass by biorefineries can push custom harvest groups and crop growers to consider the purchase of new equipment that is capable of meeting the quality specifications of biorefineries.

- Education and outreach: Farmers need to see the right signals for adopting appropriate technologies. They will consider, invest in, and implement new technologies if they expect the investment will be profitable; if they have the right education, information, and motivation; and if government policies set clear goals. Agricultural policies can impact the prices for farmers' inputs and outputs, which influences their net incomes and decisions on investment in new technologies (OECD 2001). The psychological component of the technology adoption must be recognized and addressed as part of the educational process, because generating knowledge is not always synonymous with diffusing and adopting knowledge (OECD 2001).

- Clear benefits: The ability of biorefineries to recognize the benefits of new technologies in farm equipment can support a sustainable transition in biomass supply chains. For example, adopting the tomato harvester caused a shift from the variable cost of hand harvest to the high fixed cost of mechanization. Growers were willing to make this investment because of processors' support in tomato pricing (Schmitz and Moss 2015). Farmers will most likely assimilate and implement new technologies when they can realize the benefits within 1-2 years, implementation tools are readily available and accessible in the local marketplace, implementation risks are small, and they can comfortably integrate new technologies into the existing systems.

- Financing: Factors such as low interest rates, ample credit, tax policies (e.g., tax deduction provisions), and farm profits impact the development and sale of new equipment. These factors are behind the rapid rise of farm machinery inventory for an extended period beginning in the mid-2000s.

New equipment technologies are implemented at the farm level; thus, it is imperative to engage farmers regarding technology adoption. The combination of the many different economic, structural, behavioral, and policy factors in a wide range of different situations means there is no simple or unique explanation as to what drives farmers to adopt new technologies. Research and development efforts; better education and training of farmers; the 
shift in the focus of advice; quicker and cheaper means of disseminating and sharing information; the availability of financial resources; and pressures from consumers, nongovernment organizations, the media, and the public in general contribute to facilitating the adoption of new farm technologies (OECD 2001). The introduction and adoption of new technologies can be led by voluntary co-operative industry-led initiatives to guide the development, dissemination, and adoption of technologies or by government intervention ranging from facilitation to mandates, and can include direct funding for research, payments for dissemination and adoption, information, and advice. Moreover, the overall context of agricultural policies and the level of support are key factors in determining which technologies are adopted at the farm level (OECD 2001).

\subsection{Transitioning to New Feedstock Supply Systems}

The conventional feedstock supply system, equipment, and methods analyzed in this report may not meet the quality feedstock requirements for biofuel technologies. The current approach of using low-cost agriculture residues with variable properties has led to severe operating difficulties of several pioneer biorefineries. New generation biorefineries should use the knowledge gained from current agricultural practices to design feedstock supply systems that meet conversion technology requirements and refrain from using low-cost agricultural residues that consistently fail to meet the required quality. The delivery of feedstock with consistent quality to the gate of biorefineries at a competitive price requires a transition strategy to advanced and dedicated biomass supply chains and development of new technologies in logistical and preprocessing equipment. Idaho National Laboratory has developed an advanced feedstock supply system to provide stable, consistent feedstock quality to biorefineries. The advanced feedstock supply system is based on the densification of the biomass feedstock and features distributed depots either near the biomass sources or near the biorefineries and includes two scenarios of agricultural biomass supply chains: baling and chopping. Further research and development will be required to develop equipment and methods that supply low-cost and consistently high-quality biomass feedstock to biorefineries. Until this advanced biomass preprocessing technology is commercially proven at large scale, it is difficult to determine the requirements for transition to a commodity-based feedstock supply system. 


\section{References}

AGCO Corporation. 2015. https://www.agcocorp.com/.

Argo, A.M., E.C.D. Tan, D. Inman, M.H. Langholtz, L.M. Eaton, J.J. Jacobson, C.T. Wright et al. 2013. "Investigation of biochemical biorefinery sizing and environmental sustainability impacts for conventional bale system and advanced uniform biomass logistics designs." Biofuels, Bioproducts and Biorefining 7:282-302. doi: 10.1002/bbb.1391.

Couto, L., I. Nicholas, and L. Wright. 2011. Short Rotation Eucalypt Plantations for Energy in Brazil. IEA Bioenergy Task 43 Report 2, p. 17.

Ebadian, M., S. Sokhansanj, E. Webb. 2017. "Estimating the required logistical resources to support the development of a sustainable corn stover bioeconomy in the USA." Biofuels, Bioproducts and Biorefining. https://doi.org/10.1002/bbb.1736.

Edwards. W. 2015. "Estimating Farm Machinery Costs." lowa State University Extension and Outreach, Ag. Decision Maker, PM 710, File A3-29, Ames, lowa.

Eisenbies, M.H., T.A. Volk, L. Abrahamson, R. Shuren, B. Stanton, J. Posselius et al. 2014. Development and deployment of a short rotation woody crops harvesting system based on a case New Holland forage harvester and SRC woody crop header. State University of Environmental Science and Forestry, DE-EE0001037.

Farm Credit Association. 2016. FCA Economic Report: Update on U.S. Farm Equipment Trends. Farm Credit Association Office of Regulatory Policy Agricultural and Economic Policy Team. March 22, 2016. https://www.fca.gov/templatefca/download/EconomicReports/7\%20UpdateOnFarmEquipmentTrends.pdf

Freedonia Group. 2016. World Agricultural Equipment-Demand and Sales Forecasts, Market Share, Market Size, Market Leaders. Freedonia Group Study \#3395. April 2016. https://www.freedoniagroup.com/World-Agricultural-Equipment.html.

Garvey, S. 2016. "Introducing the pellet harvester." Grainews. March 2016.

Golecha, R., and J. Gan. 2015. "Effects of corn stover year-to-year supply variability and market structure on biomass utilization and cost." Renewable and Sustainable Energy Reviews 57:3444.

Gutesa, S. 2013. "Using GIS and intelligent transportation tools for biomass supply chain modeling and cost assessment" (master's thesis, Agricultural Engineering, lowa State University).

Hess, J.R., K. Kenney, L. Ovard, E. Searcy, and C. Wright. 2009. Commodity-Scale Production of an Infrastructure-Compatible Bulk Solid from Herbaceous Lignocellulosic Biomass. INL/EXT-0917527. Idaho National Lab (INL), U.S. Department of Energy. 
Humbird, D., R. Davis, L. Tao, C. Kinchin, D. Hsu, A. Aden, P. Schoen, et al. 2011. Process Design and Economics for Biochemical Conversion of Lignocellulosic Biomass to Ethanol-Dilute-Acid Pretreatment and Enzymatic Hydrolysis of Corn Stover. Golden, CO: National Renewable Energy Laboratory. NREL/TP-5100-47764. https://www.nrel.gov/docs/fy11osti/47764.pdf.

Idaho National Laboratory (INL). 2014. Feedstock supply system design and analysis: The feedstock logistics design case for multiple conversion pathways. Prepared for the U.S. Department of Energy (DOE), Office of Biomass Program, Under DOE Idaho Operations Office. Contract DE-AC07-05ID14517.

IHS Markit. 2017. The Market Size and Economic Contributions of the Off-Highway Equipment Industry. A report for the Association of Equipment Manufacturers. http://www.aem.org/AEM/media/docs/Advocacy/AEM-Economic-Research-Report.pdf.

International Trade Administration. 2017. 2017 Top Markets Report Agricultural Equipment. U.S. Department of Commerce. February 2017. https://www.trade.gov/topmarkets/pdf/Ag Equipment Top Markets Report.pdf.

Jeschke, M., and A. Heggenstaller. 2012. "Sustainable corn stover harvest for biofuel production." Crop Insights 22:1-6.

Jones, S., P. Meyer, L. Snowden-Swan, A. Padmaperuma, E. Tan, A. Dutta, J. Jacobson, and K. Cafferty. 2013. Process Design and Economics for the Conversion of Lignocellulosic Biomass to Hydrocarbon Fuels - Fast Pyrolysis and Hydrotreating Bio-oil Pathway. Golden, CO: National Renewable Energy Laboratory. NREL/TP-5100-61178. PNNL-23053.

https://www.nrel.gov/docs/fy14osti/61178.pdf.

Kinze Manufacturing, Inc. 2014. https://www.kinze.com/.

Koenig, S., 2016. Update on U.S. Farm Equipment Trends. Economic Report, Office of Regulatory Policy, Agricultural and Economic Policy Team.

Miller, R.E., and P.D. Blair. 2009. Input-Output Analysis: Foundations and Extensions.

Cambridge, UK: Cambridge University Press.

Morris Industries. 2014. https://www.morris-industries.com/products/.

Muth, D.J., M.H. Langholtz, E.C.D. Tan, J. Jacobson, A. Schwab, M.M. Wu, A. Argo, et al. 2014. "Investigation of thermochemical biorefinery sizing and environmental sustainability impacts for conventional supply system and distributed pre-processing supply system designs." Biofuels, Bioproducts and Biorefining 8:545-67. doi: 10.1002/bbb.1483.

Organisation for Economic Co-operation and Development (OECD). 2001. "Adoption of technologies for sustainable farming systems" (Wageningen Workshop proceedings, Netherland's Ministry of Agriculture, Nature Management and Fisheries, July 4-7, 2000).

Schmitz, A., and C.B. Moss. 2015. “Mechanized Agriculture: Machine Adoption, Farm Size, and Labor Displacement." AgBioForum 18(3): 278-296. 
Sedjo, R.A. 1999. "The potential of high-yield plantation forestry for meeting timber needs." New Forests 17:339-360.

Shah, A. 2013. "Techno-economic analysis and life cycle assessment of the corn stover biomass feedstock supply chain system for a Midwest-based first-generation cellulosic biorefinery." (graduate thesis and dissertation, Agricultural and Biosystems Engineering, lowa State University).

Sharma, B., C. Brandt, and E. Webb. 2017. "Spatial multi-feedstock biomass supply chain modeling framework for the U.S" (study conducted by the Environmental Sciences Division, Oak Ridge National Laboratory).

Stinger Inc. 2016. http://www.stingerltd.com/index.php\#.

Thompson, D. 2017. “Feedstock Supply Chain Analysis WBS 1.1.1.2 FY17 Annual Milestone Report." September 30, 2017.

Tumuluru, J. 2017. "Biomass Engineering: Size reduction, drying and densification of high moisture biomass." U.S. Department of Energy (DOE) Bioenergy Technologies Office 2017 Project Peer Review. March 7, 2017.

Turhollow, A., E. Wilkerson, and S. Sokhansanj. 2009. Cost methodology for biomass feedstocks: herbaceous crops and agricultural residues. Oak Ridge, TN: Oak Ridge National Laboratory. ORNL/TM-2008/105.

U.S. Census Bureau. 2016. Manufacturing and International Trade Report: 2014. U.S. Department of Commerce, January 29, 2016. https://www.census.gov/foreign-trade/PressRelease/MITR/2014/index.html.

U.S. Census Bureau. 2018. Manufacturing and International Trade Report: 2016. U.S. Department of Commerce, February 28, 2018. https://www.census.gov/foreign-trade/PressRelease/MITR/2016/index.html.

U.S. Department of Agriculture (USDA). May 2014. 2012 Census of Agriculture: Summary and State Data. Vol. 1, Geographic Area Series, Part 51, AC-12-A-51. Available at https://www.nass.usda.gov/Publications/AgCensus/2012/.

U.S. Department of Agriculture (USDA). 2016. "Farming and Farm Income." Economic Research Service. https://www.ers.usda.gov/data-products/ag-and-food-statistics-charting-theessentials/farming-and-farm-income/. Accessed February 8, 2018.

U.S. Department of Energy (DOE). 2016. "Billion-Ton report: advancing domestic resources for a thriving bioeconomy" (study sponsored by DOE Office of Energy Efficiency and Renewable Energy, Office of the Biomass Program).

U.S. Department of Labor. 2018. Bureau of Labor Statistics: Current Employment Statistics. Table B-1a. "Employees on nonfarm payrolls by industry sector and selected industry detail, 
seasonally adjusted." http://www.bls.gov/web/empsit/ceseeb1a.htm. Accessed September 26, 2018.

Vermeer Corporation. 2017. https://www.vermeer.com/NA/en/N.

Volk, T.A., Heavey, J.P., \& Eisenbies, M.H. 2016. "Advances in shrub-willow crops for bioenergy, renewable products, and environmental benefits." Food and Energy Security 5(2): 97-106.

Wallich, P. 2013. "Everything you always wanted to know about big ag." IEEE Spectrum.

http://spectrum.ieee.org/energy/environment/everything-you-always-wanted-to-know-aboutbig-ag. Accessed September 8, 2017.

Wendt, L. 2017. "Development of a Wet Logistics System for Bulk Corn Stover." U.S.

Department of Energy (DOE) Bioenergy Technologies Office 2017 Project Peer Review. March 7, 2017. 